US Army Corps of Engineers

Waterways Experiment Station

\section{US-CE-C Property of the}

United States Government

\title{
Preliminary Analytical Model for Flexible Pavement
}

\author{
by Larry M. Bryant, Applied Research Associates, Inc.
}

Approved for public release; distribution is unlimited

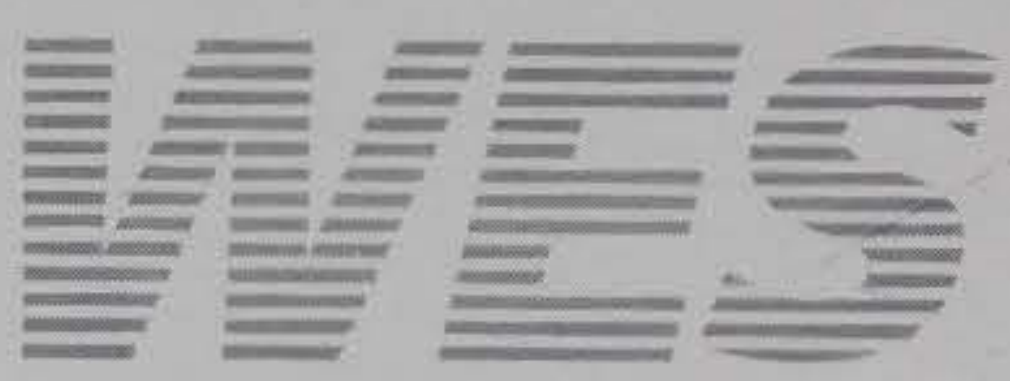

\section{Research Library}

US Army Engineer Waterways

Experiment Station

Vicksburg. Mississippi

Prepared for Headquarters, U.S. Army Corps of Engineers 


\section{Preliminary Analytical Model for Flexible Pavement}

by Larry M. Bryant

Applied Research Associates, Inc.

112 Monument Place

Vicksburg, MS 39180

Final report

Approved for public release; distribution is unlimited

Prepared for U.S. Army Corps of Engineers

Washington, DC 20314-1000

Monitored by U.S. Army Engineer Waterways Experiment Station 3909 Halls Ferry Road, Vicksburg, MS 39180-6199 


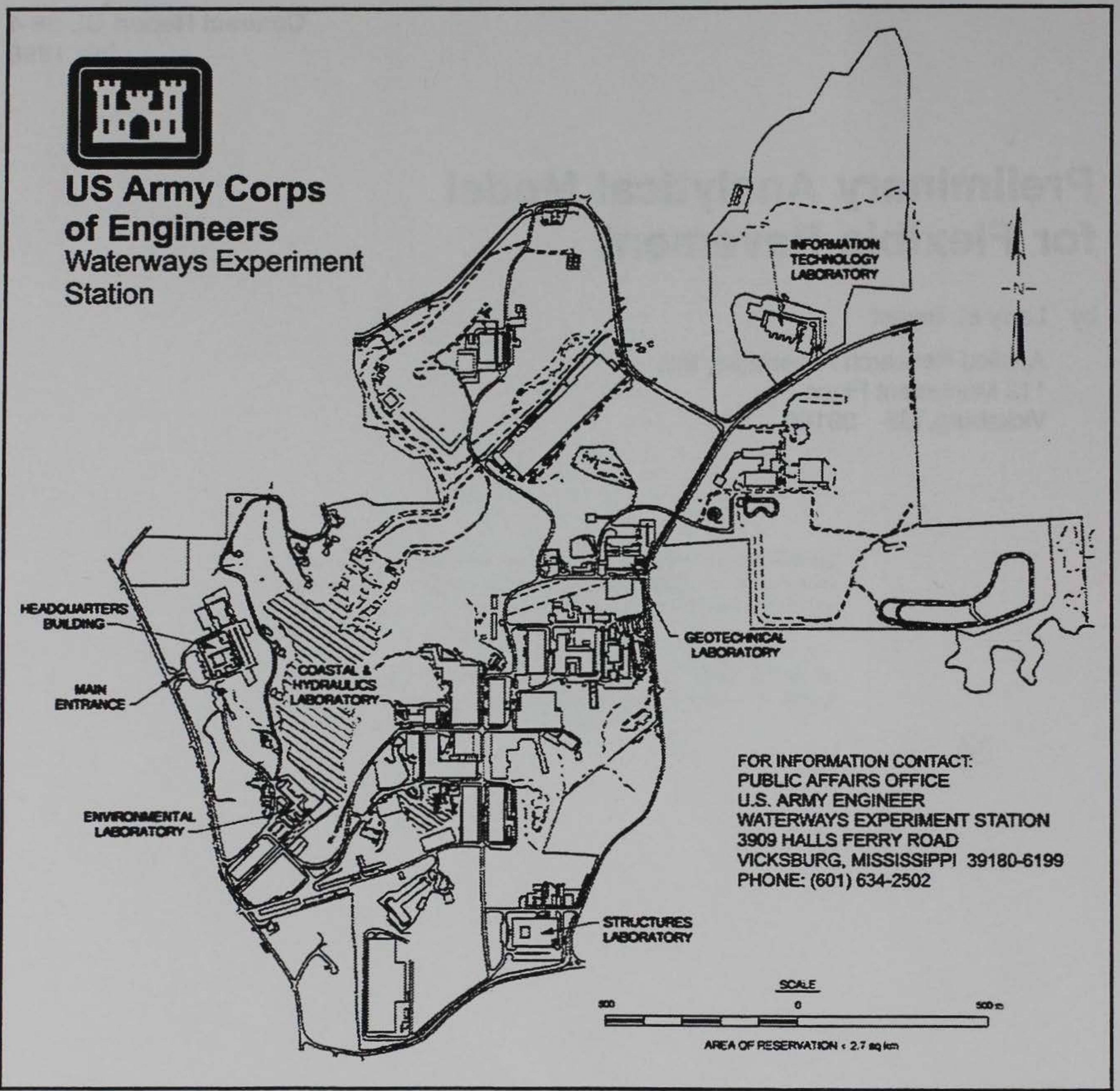

Waterways Experiment Station Cataloging-in-Publication Data

Bryant, Larry $\mathrm{M}$.

Preliminary analytical model for flexible pavement / by Larry M. Bryant ; prepared for

U.S. Army Corps of Engineers; monitored by U.S. Army Engineer Waterways

Experiment Station.

63 p. : ill. ; $28 \mathrm{~cm}$. - (Contract report ; GL-98-4)

Includes bibliographical references.

1. Pavements, Flexible -- Testing. 2. Pavements -- Design. 3. Finite element method.

I. United States. Army. Corps of Engineers. II. U.S. Army Engineer Waterways

Experiment Station. III. Geotechnical Laboratory (U.S. Army Engineer Waterways

Experiment Station) IV. Title. V. Series: Contract report (U.S. Army Engineer

Waterways Experiment Station); GL-98-4.

TA7 W34c no.GL-98-4 


\section{TABLE OF CONTENTS}

Section

Page

LIST OF FIGURES ii

LIST OF TABLES iii

PREFACE iv

CONVERSION FACTORS

Chapter 1 INTRODUCTION.

Chapter 2 BASELINE MODELS

2.1 LAYERS AND MATERIALS

2.2 WHEEL LOADS AND LAYER THICKNESSES

2.3 FIGURES OF MERIT

Chapter 3 COMPARATIVE STUDY OF ANALYTICAL MODELS

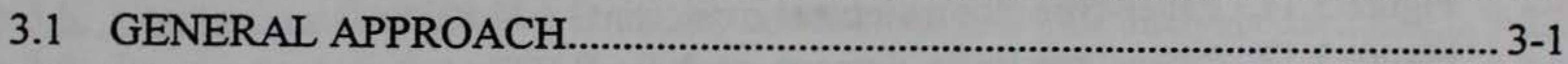

3.2 BOUSSINESQ SOLUTION (CLOSED FORM) …............................................ 3-1

3.3 FLEXIBLE PLATE SOLUTION ................................................................... 3-3

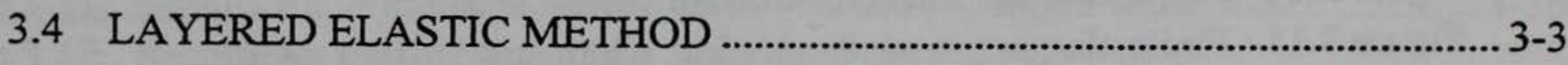

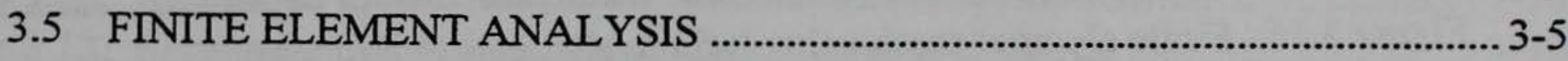

3.5.1 Two-Dimensional (Axisymmetric) Model .............................................. 3-6

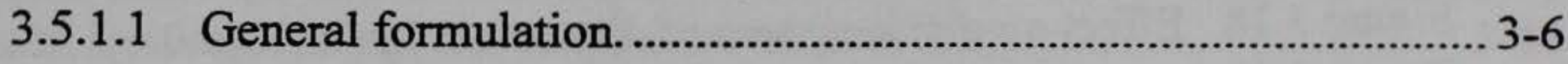

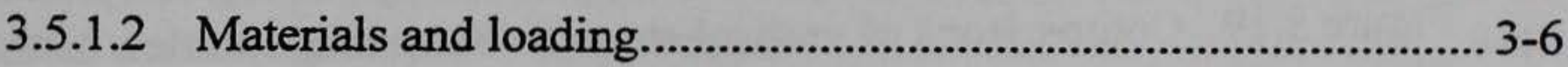

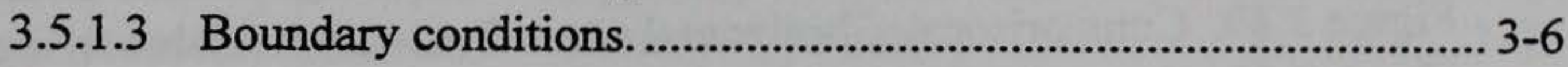

3.5.1.4 Finite element mesh. .................................................................. 3-7

3.5.1.5 Two-dimensional finite element analysis results....................... 3-10

3.5.1.6 Two-dimensional parameter study............................................. 3-13

3.5.1.7 Summary of two-dimensional results comparison...................... 3-24

3.5.2 Three-Dimensional Model .............................................................. 3-26

3.5.2.1 General formulation. ........................................................... 3-26

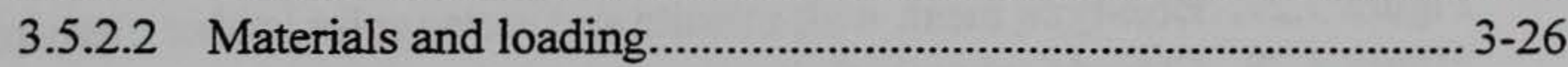

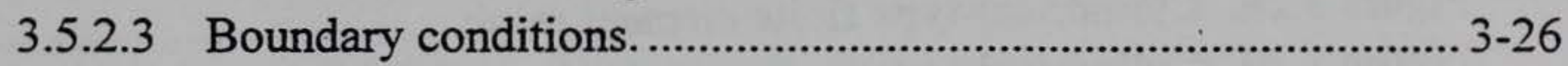

3.5.2.4 Finite element mesh......................................................... 3-27

3.5.2.5 Three-dimensional finite element analysis results.................... 3-28

3.5.2.6 Summary of three-dimensional results comparison................... 3-49

Chapter 4 CONCLUSIONS AND RECOMMENDATIONS ............................................. 4-1

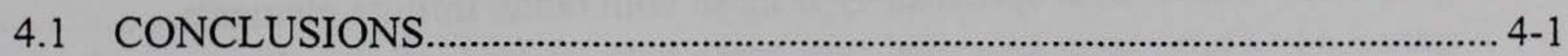

4.2 RECOMMENDATIONS ........................................................................... 4-1

Chapter 5 REFERENCES...................................................................................... 5 -1 


\section{LIST OF FIGURES}

Figure

$\underline{\text { Page }}$

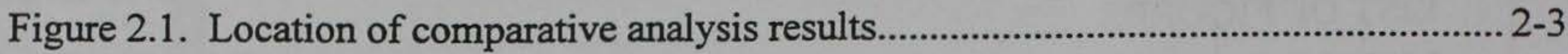

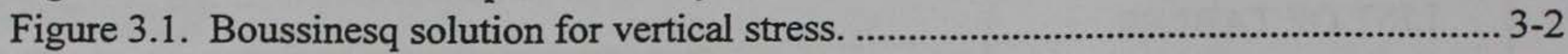

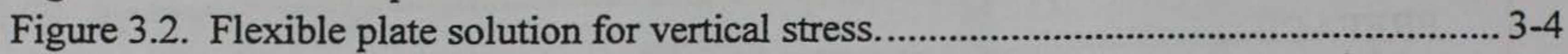

Figure 3.3. Layered elastic solution for vertical stress. .......................................................... 3-4

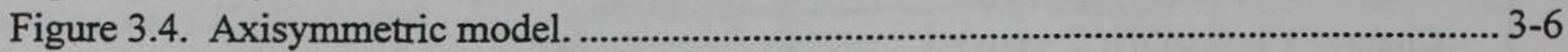

Figure 3.5. Baseline finite element mesh for C-141 analysis.......................................... 3-8

Figure 3.6. Baseline finite element mesh for B-727 analysis. .......................................... 3-9

Figure 3.7. Baseline finite element mesh for F-15 analysis................................................ 3-9

Figure 3.8. Uniform bias finite element mesh for C-141 analysis................................... 3-14

Figure 3.9. Uniform bias finite element mesh for B-727 analysis................................... 3-15

Figure 3.10. Uniform bias finite element mesh for F-15 analysis. .................................. 3-15

Figure 3.11. Paver-type finite element mesh for C-141 analysis........................................ 3-16

Figure 3.12. Paver-type finite element mesh for B-727 analysis..................................... 3-16

Figure 3.13. Paver-type finite element mesh for F-15 analysis. ...................................... 3-17

Figure 3.14. Finite element mesh for 20-foot depth. ..................................................... 3-19

Figure 3.15. Finite element mesh for 36-foot width and 50-foot depth............................ 3-20

Figure 3.16. Finite element mesh using infinite elements at boundaries............................ 3-21

Figure 3.17. Effect on results of distance to lower boundary.......................................... 3-23

Figure 3.18. Effect on displacement of distance to lower boundary.................................. 3-23

Figure 3.19. Comparisons of vertical stress from various solution methods....................... 3-25

Figure 3.20. Comparisons of horizontal stress from various solution methods................... 3-25

Figure 3.21. General 3-D finite element mesh types. .................................................. 3-27

Figure 3.22. Locations for result comparisons............................................................. 3-28

Figure 3.23. Box-type finite element mesh with fixed boundaries................................... 3-29

Figure 3.24. Box-type mesh with infinite elements....................................................... 3-30

Figure 3.25. Comparisons of predicted deflection basin. ............................................ 3-32

Figure 3.26. Box-type models with different meshes in loaded area................................. 3-33

Figure 3.27. Box-type mesh with infinite and rectangular loaded elements........................3-33

Figure 3.28. Cylindrical-type finite element mesh. ........................................................ 3-35

Figure 3.29. Cylindrical-type mesh with horizontal infinite elements. ............................ 3-37

Figure 3.30. Cylindrical-type mesh with vertical and horizontal infinite elements............. 3-40

Figure 3.31. Single-layer spherical-type finite element mesh. ...................................... 3-42

Figure 3.32. Predicted nodal stress versus depth (spherical model). ................................. 3-44

Figure 3.33. Three-layer spherical-type mesh with radial infinite elements....................... 3-45

Figure 3.34. Three-layer spherical-type mesh with layered infinite elements..................... 3-46

Figure 3.35. Refined three-layer spherical-type mesh with layered infinite elements........ 3-48 


\section{LIST OF TABLES}

Table

Page

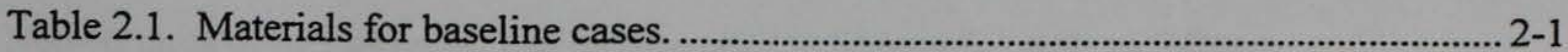

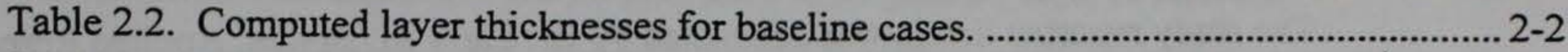

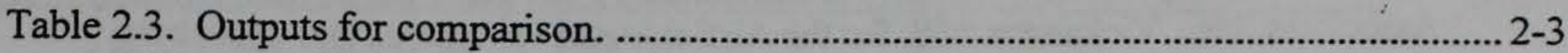

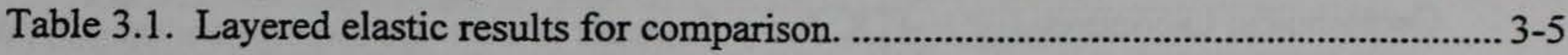

Table 3.2. Ratios of selected baseline FEM and LEM results. ........................................ 3-10

Table 3.3. Normalized comparison of selected baseline results. ...................................... 3-12

Table 3.4. Comparison of FEM and modified LEM results for B-727............................ 3-13

Table 3.5. Comparison of different mesh types for C-141 analysis................................. 3-17

Table 3.6. Comparison of different mesh types for B-727 analysis. ................................. 3-18

Table 3.7. Comparison of different mesh types for $\mathrm{F}-15$ analysis.................................... 3-18

Table 3.8. Comparison for different boundary conditions for B-727 analysis. ................... 3-22

Table 3.9. Results for box-type models with fixed and infinite boundaries....................... 3-31

Table 3.10. Results for models with circular area and rectangular loaded elements...........3-34

Table 3.11. Results for cylindrical model, fixed boundaries, single wheel load. ................ 3-36

Table 3.12. Results for cylindrical model, horizontal infinite elements............................ 3-38

Table 3.13. Results for cylindrical model, vertical infinite elements. ............................... 3-39

Table 3.14. Results for cylindrical model, horizontal and vertical infinite elements. ........ 3-41

Table 3.15. Results for simple, single layer spherical-shaped model................................ 3-43

Table 3.16. Results for three-layer spherical-type model. ................................................ 3-47

Table 3.17. Results for refined three-layer spherical-type model...................................... 3-48 


\section{Preface}

The study reported herein was conducted by Dr. Larry M. Bryant, Applied Research Associates, Inc., Vicksburg, MS, for the Airfields and Pavements Division (APD), Geotechnical Laboratory (GL), U.S. Army Engineer Waterways Experiment Station (WES), under Contract No. DNA001-93-C-0147. Dr. Michael I. Hammons and Mr. Donald M. Smith, Materials Analysis Branch (MAB), APD, GL, technically monitored the work. Mr. Timothy W. Vollor was Chief, MAB, and Dr. David W. Pittman was Chief, APD. Director of GL was Dr. William F. Marcuson III.

At the time of the preparation of this report, Director of WES was Dr. Robert W. Whalin. Commander was COL Robin R. Cababa, EN.

The contents of this report are not to be used for advertising, publication, or promotional purposes. Citation of trade names does not constitute an official endorsement or approval of the use of such commercial products. 
Non-SI units of measurement can be converted to SI (metric) units as follows:

\begin{tabular}{|l|l|l|}
\hline Multiply & By & To Obtain \\
\hline inches & 25.4 & millimeters \\
\hline feet & 0.3048 & meters \\
\hline pound & 4.44822 & Newton \\
\hline pounds per square inch & 6.8948 & kiloPascal \\
\hline square inches & 645.16 & square millimeters \\
\hline
\end{tabular}




\section{Chapter 1 INTRODUCTION}

This report documents the first step in development of a preliminary analytical model for flexible pavement analysis for the Airfields and Pavements Division (APD) of the Geotechnical Laboratory at the US Army Engineer Waterways Experiment Station. This first step may be generally described as development of a linear elastic finite element model that reasonably compares with the empirical and/or layered elastic solutions in current use. This report does not attempt to document a literature survey related to pavement analysis nor does it discuss the background of previous pavement analysis methods or finite element methods beyond that necessary for understanding of the problem at hand. Further, this study attempts to determine the optimal usage of the specific tools at hand, i.e., PATRAN (1993) and ABAQUS (1992), in development of the improved analytical model. It does not attempt to generalize to other finite element modeling tools or the broad finite element method. This report includes and builds upon previous work done by the author in this area (Bryant, 1996).

The rationale and impetus for development of a detailed analytical model rests in the limitations of current pavement design and evaluation procedures. Current design procedures are very much empirical and are based on a limited number of tests conducted decades ago. Current and future wheel loadings and configurations and potential pavement systems differ considerably from the empirical basis in many cases and thus may not be easily handled by these procedures. Further, the most common current analytical tools based on the Layered Elastic Method are limited by the assumptions of this method which include (1) linear elastic material, (2) circular, static, constant pressure wheel loads, and (3) fully bonded interfaces between pavement layers. A more detailed analytical model is required to overcome these limitations.

The goal of this study is to provide a baseline, or starting point, for development of a detailed analytical model for flexible pavements. As such, the present development identifies the current methods of analysis, constructs reasonable baseline cases for analysis, and compares key results of these baseline cases as predicted by the current methods and the finite element method. The finite element models are constructed to mimic the basis and assumptions of the current methods of analysis to provide the most reasonable comparison of the results possible, i.e., to compare apples to apples.

In this report we describe the approach, baseline models, two- and three-dimensional finite element models, and compare the key results of the current and finite element analyses. Further, the effect of several variables or options in the finite element analysis models are investigated via a limited parameter study using the two-dimensional (axisymmetric) finite element model. This parameter study provides some insight as to future development of rational finite element models for general application. Finally, this report draws conclusions as to what this study has accomplished and presents recommendations as to what is appropriate for the next steps in the development of the detailed analytical model. 


\section{Chapter 2 BASELINE MODELS}

Three baseline cases, each involving a different type aircraft, were selected for comparing the results of the different analytical methods. The general parameters relating to number of pavement layers; surface course, base course, and subgrade materials; as well as loadings, were taken to be representative of at least some of the wide (some would say infinite) range of values in the real world. These general parameters were used to determine the actual pavement layer thicknesses for the analyses. In addition, several key response parameters were identified as figures of merit for comparing the results of the different analyses. The various parameters of the baseline cases are described in the following paragraphs.

\subsection{LAYERS AND MATERIALS}

Each of the three baseline cases considers a three-layer system consisting of an asphaltic concrete $(\mathrm{AC})$ surface course and an unbound base course $(\mathrm{BC})$ overlying the subgrade. For purposes of the analyses, the layers are considered fully bonded, i.e., there is 100 percent friction at the layer interfaces. The surface layer was taken with an elastic modulus, E, and Poisson's ratio, $v$, of $250,000 \mathrm{psi}$ and 0.3 , respectively, to represent a typical asphaltic concrete. The second layer utilized a modulus and ratio of 90,000 psi and 0.33 , respectively, to represent a typical unbound base course. Finally, the modulus and ratio for the subgrade was taken as $6,000 \mathrm{psi}$ and 0.45 . Typical mechanical properties and specific values used in the analyses for these three layers are summarized in Table 2.1 .

Table 2.1. Materials for baseline cases.

\begin{tabular}{|l|l|c|c|c|c|}
\hline & Layer & $E_{\min }(\mathrm{psi})$ & $\mathrm{E}_{\max }(\mathrm{psi})$ & $\mathrm{E}_{\text {typ }}(\mathrm{psi})^{\S}$ & $v^{\S}$ \\
\hline 1 & Asphaltic concrete & $10^{5}$ & $10^{6}$ & 250,000 & 0.3 \\
\hline 2 & Base & 40,000 & 150,000 & 90,000 & 0.33 \\
\hline 3 & subgrade & - & - & 6,000 & 0.45 \\
\hline \multicolumn{5}{|}{ typical properties used for baseline cases } \\
\hline
\end{tabular}

\subsection{WHEEL LOADS AND LAYER THICKNESSES}

Each baseline case considered a single wheel load from a different aircraft. The three aircraft were selected to represent a wide range of contact areas, standard loads, and design tire pressures. Specifically, the three aircraft considered in these cases were the C-141 transport, the Boeing B-727, and the F-15 fighter. The C-141 is very heavy, having twin tandem gear with moderate wheel spacing. The B-727 is somewhat lighter with more closely spaced twin gear. The F-15, though relatively light, has single wheel gear with very high tire pressure. 
The aircraft specifications were determined from the Pavement Computer Aided Structural Engineering (PCASE) computer program (NEWFILE, 1994). The C-141 transport, with a standard load of $345,000 \mathrm{lb}$., two main gear with four tires per gear, and a tire contact area of 208 sq. in., results in a design tire pressure of 186.6 psi. The B-727, with a standard load of $210,000 \mathrm{lb}$., two main gear with two tires per gear, and a tire contact area of 237 sq. in., has a design tire pressure of 199.4 psi. The much lighter F-15, with a standard load of $68,000 \mathrm{lb}$., has only one tire with a relatively small contact area of $87 \mathrm{sq}$. in. for each of the two main gear, resulting in a high tire pressure of $340 \mathrm{psi}$. Thus, the three aircraft considered encompass a wide range of wheel loads and tire pressures.

The required thicknesses of the surface course and base course were determined from the Aircraft Specification Data (computer program FAD, 1994) based on 50,000 passes, nonfrost design, CBR 100 base material and CBR 4 subgrade material for Traffic Area A. The computed layer thicknesses for each aircraft for the given conditions are summarized in Table 2.2. The $F A D$ calculations indicated a required surface layer thickness of 4 inches and a base course thickness of 49 inches for the heavy, but low tire pressure, C-141 aircraft. The surface and base course thicknesses required for the somewhat lighter B-727 were 3 inches and 43 inches, respectively. The F-15, with a much lower load but high tire pressure required a 4inch surface layer with only 24 -inch base course.

Table 2.2. Computed layer thicknesses for baseline cases.

(50,000 passes, no frost, CBR 100 base, CBR 4 subgrade, Traffic Area A)

\begin{tabular}{|l|l|l|l|l|l|}
\hline Aircraft & $\begin{array}{l}\text { Design Load } \\
\text { (lb.) }\end{array}$ & $\begin{array}{l}\text { tire pressure } \\
\text { (psi) }\end{array}$ & $\begin{array}{l}\text { Surface } \\
\text { (in) }\end{array}$ & $\begin{array}{l}\text { Base } \\
\text { (in) }\end{array}$ & $\begin{array}{l}\text { Total } \\
\text { (in) }\end{array}$ \\
\hline C-141 & 345,000 & 186.6 & 4 & 49 & 53 \\
\hline B-727 & 210,000 & 199.4 & 3 & 43 & 46 \\
\hline F-15C/D & 68,000 & 340.0 & 4 & 24 & 28 \\
\hline
\end{tabular}

\subsection{FIGURES OF MERIT}

Six computed results of the analyses (response parameters) of the baseline cases were selected to provide figures of merit for comparison of the methods. These selected results are summarized in Table 2.3 as primary (most important) and secondary (less critical). The primary comparative results include the vertical deflection at the surface under the wheel load, the tensile horizontal strain at the bottom of the surface layer (AC), and the vertical strain at the top of the subgrade. These three parameters are the most commonly used parameters for evaluation of pavement design. The three secondary results (principal stresses) are less commonly used in design but are of interest here due to their characterization of the stresses existing in each layer. These outputs and their locations are depicted in Figure 2.1. These six parameters are compared (as available) for each of the analysis methods. 
Table 2.3. Outputs for comparison.

\begin{tabular}{|l|l|}
\hline \multicolumn{1}{|c|}{ Primary } & \multicolumn{1}{c|}{ Secondary } \\
\hline vertical deflection under load & principal stresses at center of AC \\
\hline tensile horizontal strain at bottom of AC & principal stresses at center of base course \\
\hline vertical strain @ top of subgrade & principal stresses at top of subgrade \\
\hline
\end{tabular}

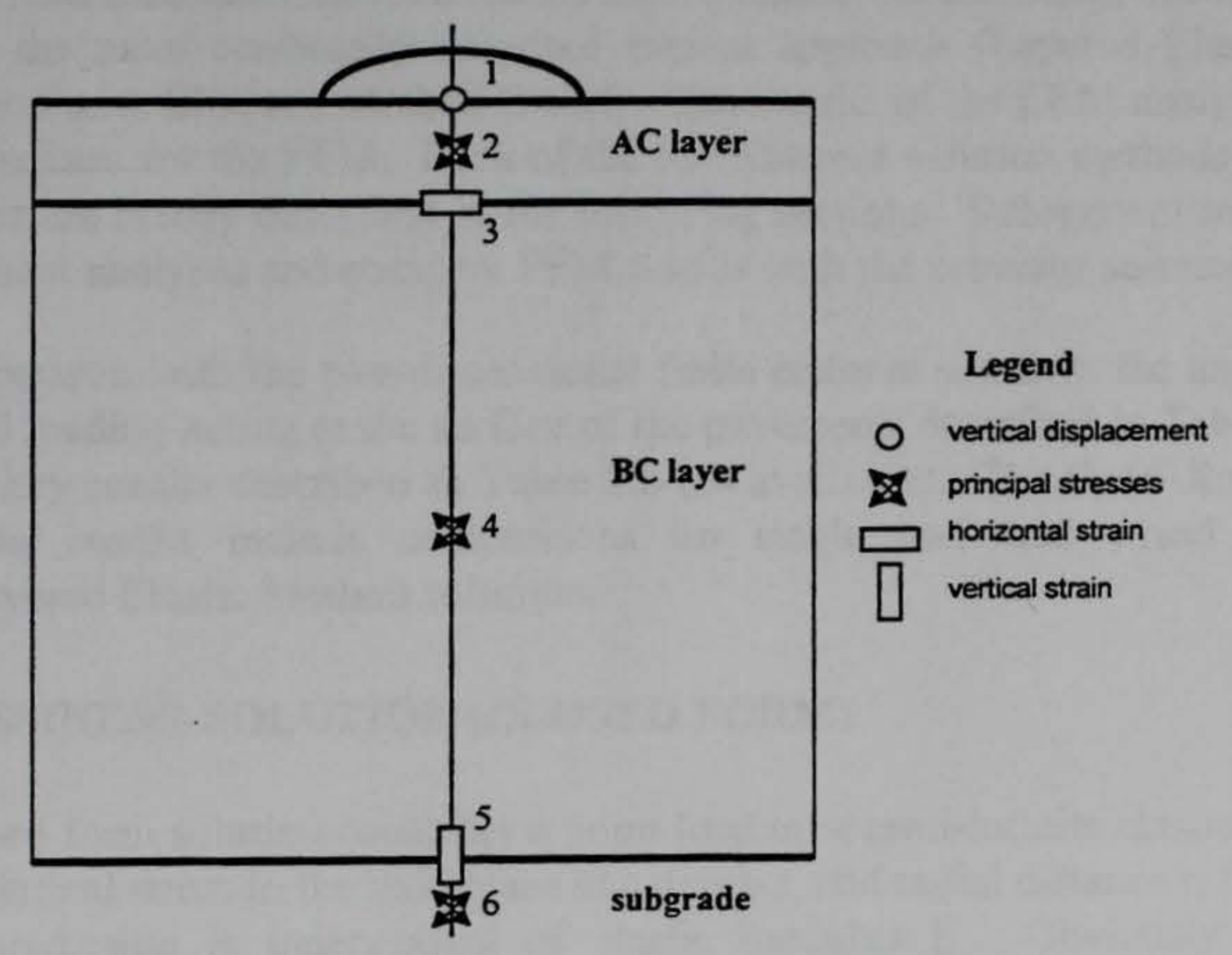

Figure 2.1. Location of comparative analysis results. 


\section{Chapter 3 COMPARATIVE STUDY OF ANALYTICAL MODELS}

\subsection{GENERAL APPROACH}

This study considered four methods of analysis for the baseline cases described previously. These methods include a closed form solution (Boussinesq), elastic flexible plate on subgrade, the most commonly accepted current approach (Layered Elastic Method or LEM), and the Finite Element Method (FEM). The results of the LEM analyses provide the basis of comparison for the FEM. Each of the three former solution methods and the results of the analyses are briefly described in the following sections. Subsequent sections describe the finite element analyses and compare FEM results with the previous solutions.

For comparison with the two-dimensional finite element solution, the analyses consider a single wheel loading acting at the surface of the pavements described in Tables 2.1 and 2.2, reporting the key results described in Table 2.3 (as available). The three-dimensional finite element model results include comparisons for single and dual wheel loadings with equivalent Layered Elastic Method solutions.

\subsection{BOUSSINESQ SOLUTION (CLOSED FORM)}

This closed-form solution considers a point load on a semi-infinite elastic half-space and predicts the vertical stress in the half-space at a depth $\mathrm{z}$, and radial distance $\mathrm{r}$, from the load $\mathrm{P}$. This stress prediction is independent of elastic modulus E. Obviously there are two assumptions in this prediction that violate even the simplified assumptions inherent in the Layered Elastic Method solutions, specifically, (1) the load is concentrated at a point instead of over a circular area, and (2) only a single homogeneous elastic layer is considered instead of the multiple elastic layers used in the LEM analyses.

The general equation for the Boussinesq solution is (Yoder and Witczak, 1975)

$$
\sigma_{z}=k \frac{P}{z^{2}}
$$

where:

$$
k=\frac{3}{2 \pi}\left[\frac{1}{\left(1+\left(\frac{r}{z}\right)^{2}\right)^{\frac{5}{2}}}\right]
$$




$$
\begin{aligned}
& r=\text { radial distance from point load } \\
& z=\text { depth } \\
& P=\text { total load at surface }
\end{aligned}
$$

For $\mathrm{r}=0$ (beneath point load)

$$
\begin{aligned}
& k=\frac{3}{2 \pi} \\
& \sigma_{z}=\frac{3 P}{2 \pi z^{2}}=0.4775 \frac{P}{z^{2}}
\end{aligned}
$$

thus the vertical stress is an inverse quadratic function of depth $z$, proportional to load $P$. The vertical stress under the load $(r=0)$ is plotted versus depth in Figure 3.1 for the three subject aircraft loadings.

\section{Boussinesq Solution}

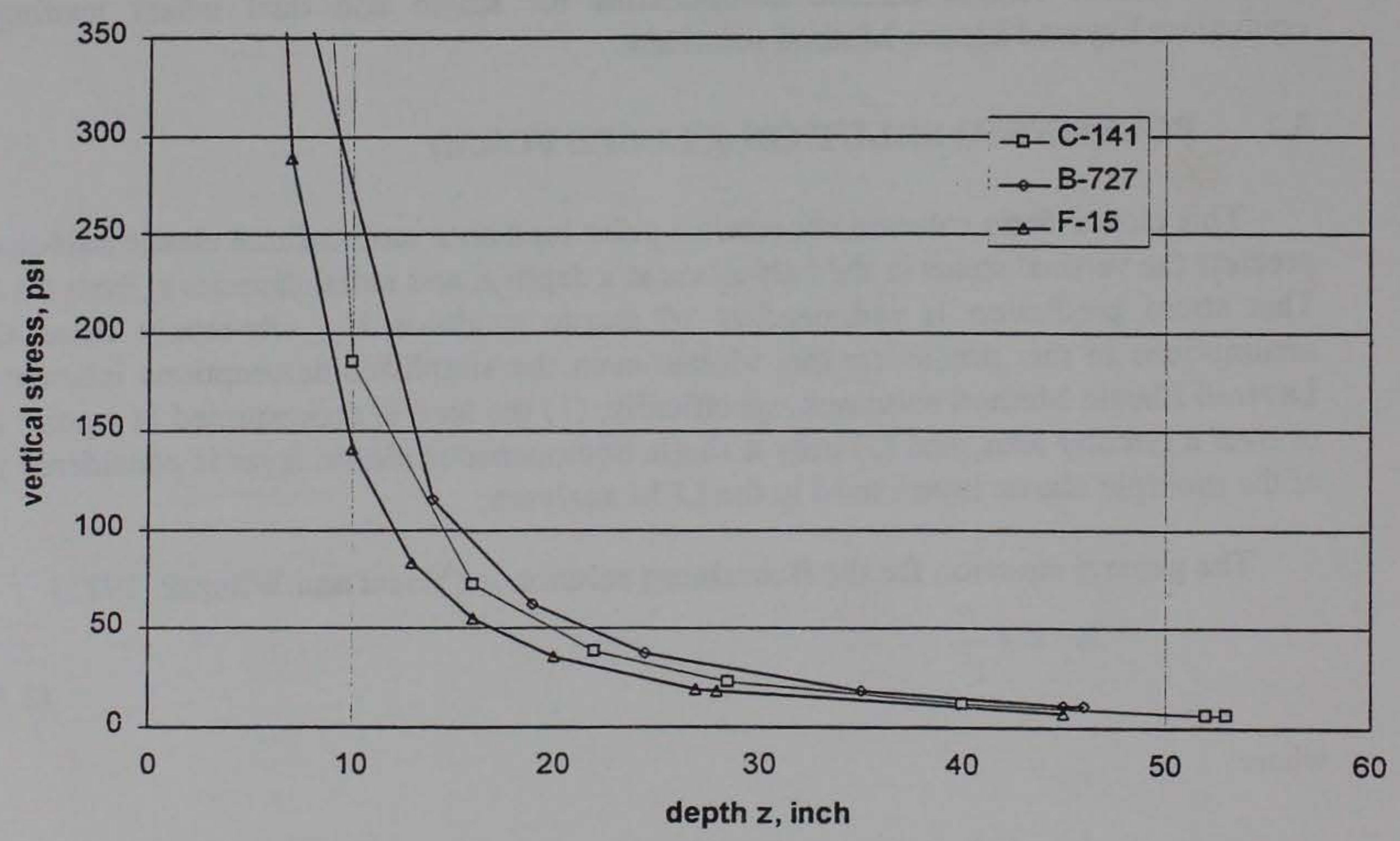

Figure 3.1. Boussinesq solution for vertical stress.

Note that the Boussinesq solution predicts extremely high stresses near the surface, due to the assumption of a point load. In fact, Equation 3.2 shows that the stress approaches infinity as depth, z, approaches zero (at the surface). Obviously, this is a serious limitation to application of the method or use of the predictions for tire pressures that vary from $187 \mathrm{psi}$ 
for the C-141 to 340 psi for the F-15. Further, this closed form solution is not dependent on the presence of different layers or the absolute or relative stiffnesses of the layers.

\subsection{FLEXIBLE PLATE SOLUTION}

A solution for a single, circular flexible plate loaded over an elastic half-space is presented by Huang (1993). The relatively straightforward equations are easily solved in a spreadsheet for vertical and radial stresses and strains. Vertical deflection under the load can be computed if constants are presumed for Young's modulus and Poisson's ratio (single elastic layer). The equations for vertical ( $\mathrm{z}$ ) and radial ( $\mathrm{r}$ ) stress are:

$$
\begin{aligned}
& \sigma_{z}=q\left[1-\frac{z^{3}}{\left(a^{2}+z^{2}\right)^{1.5}}\right] \\
& \sigma_{r}=\frac{q}{2}\left[1+2 v-\frac{2(1+v) z}{\left(a^{2}+z^{2}\right)^{0.5}}+\frac{z^{3}}{\left(a^{2}+z^{2}\right)^{1.5}}\right]
\end{aligned}
$$

where:

$$
\begin{aligned}
& a=\text { radius of loaded circular area } \\
& q=\text { vertical pressure at surface } \\
& v=\text { Poisson's ratio }
\end{aligned}
$$

and other terms are as previously defined.

The vertical stress predictions for the three aircraft cases are presented in Figure 3.2. Note that the stress predictions are much more reasonable than those of the Boussinesq solution, which presumed a single point load.

\subsection{LAYERED ELASTIC METHOD}

The three baseline cases for a single wheel load were analyzed using BISAR to determine the output parameters of interest in Table 2.3 for comparison with subsequent twoand three-dimensional finite element analyses using ABAQUS. Each case was analyzed using the parameters in Table 2.1 for the materials in each layer and the design pavement and base course thicknesses in Table 2.2. These analyses presumed fully bonded interfaces between the layers, and a circular loaded area equal to the total single wheel load divided by the tire pressure. Outputs were requested at the locations directly beneath the wheel $(x=y=0)$ for the depths corresponding to the locations in Table 2.3. The vertical stresses determined from these analyses, shown in Figure 3.3, are generally similar to those from the previous flexible plate solution. 


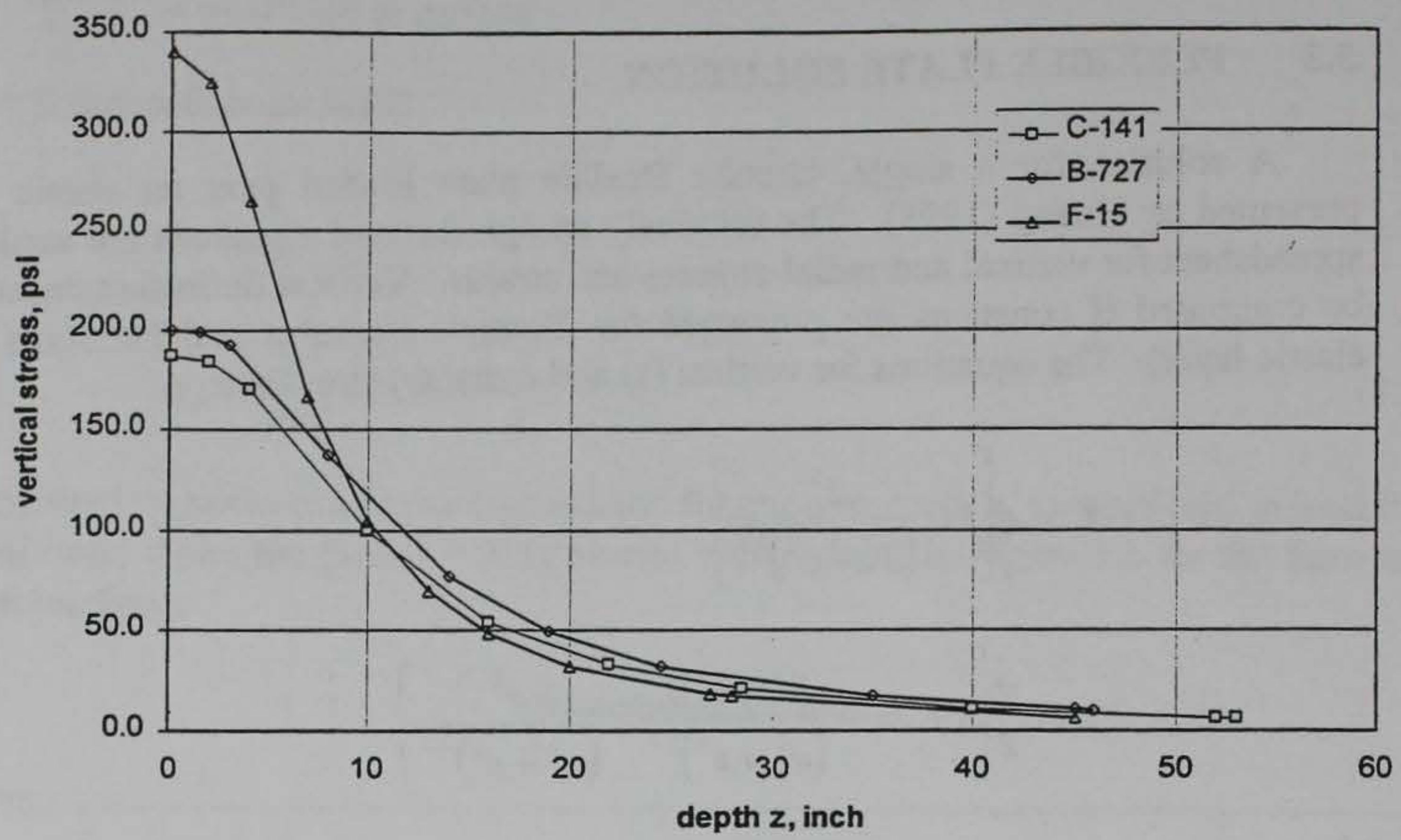

Figure 3.2. Flexible plate solution for vertical stress.

\section{Layered Elastic Solution}

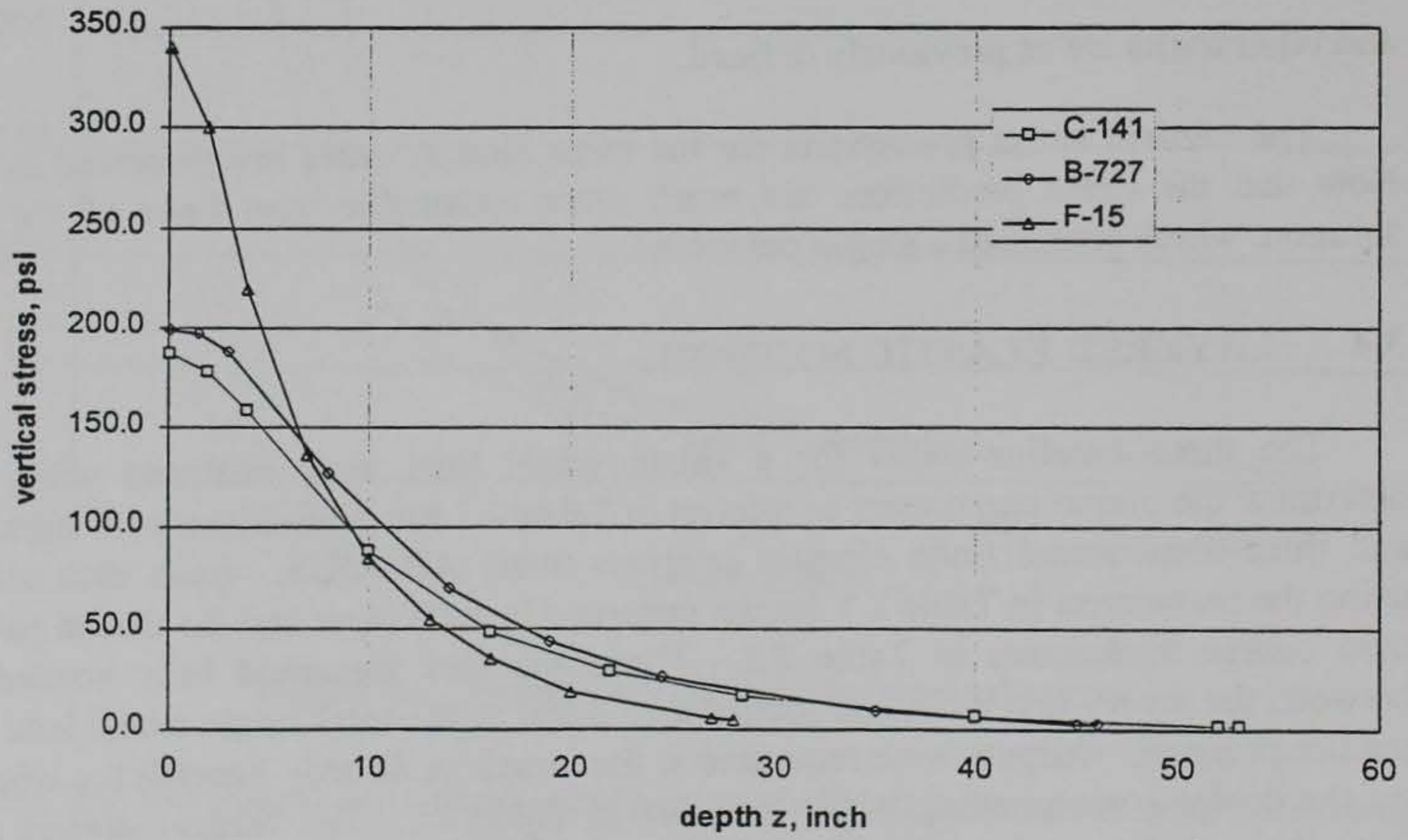

Figure 3.3. Layered elastic solution for vertical stress. 
The comparison set of results described in Table 2.3 and Figure 2.1 for the single wheel loading are summarized in Table 3.1 below for the three cases.

Table 3.1. Layered elastic results for comparison.

\begin{tabular}{|l|c|c|c|c|l|}
\hline Selected Results & & $\underline{\mathrm{C}-141}$ & $\underline{\mathrm{B}-727}$ & $\underline{\mathrm{F}-15 \mathrm{C} / \mathrm{D}}$ & \\
\hline Description & point & & & & unit \\
\hline vertical displacement at top & 1 & 0.0479 & 0.0628 & 0.0582 & in \\
\hline horiz. strain at bottom of AC & 3 & 263 & 148 & 557 & micro-strain \\
\hline vertical strain at subgrade & 5 & -241 & -386 & -627 & micro-strain \\
\hline max. prin. stress - AC center & 2 & -109 & -150 & -144 & psi \\
\hline min. prin. stress - AC center & 2 & -178 & -197 & -300 & psi \\
\hline max. prin. stress - BC center & 4 & 26.2 & 3.75 & 8.25 & psi \\
\hline min. prin. stress - BC center & 4 & -16.4 & -25.9 & -34.6 & psi \\
\hline max. prin. stress - subgrade & 5 & -0.178 & -0.299 & -0.434 & psi \\
\hline min. prin. stress - subgrade & 5 & -1.6 & -2.59 & -4.16 & psi \\
\hline
\end{tabular}

Note that the minimum principal stresses in the asphaltic concrete, which correspond to the vertical stresses, are appropriate to (slightly less than) the vertical tire pressures for the subject aircraft. Thus, the predicted stresses at any depth are less than those from the Boussinesq solution, as were those from the flexible plate solution. These results form the basis for comparison with the subsequent two-dimensional finite element analyses.

\subsection{FINITE ELEMENT ANALYSIS}

Finite element analyses for the three baseline cases were developed using procedures and methods typical to most general finite element analysis programs. The goal of the initial set of finite element analyses was to model the procedures and assumptions inherent in the Layered Elastic Method and thus to validate the ability of the FEM to match the results from the LEM. From this validation, the considerable power and versatility of the FEM can be exploited by expansion to consider more realistic modeling of the materials and loadings.

The finite element models for the three baseline cases are based on the following assumptions consistent with the LEM analyses:

1. The material is linear elastic.

2. Interfaces between the layers are fully bonded (no slip).

3. Loading is a constant pressure over a circular area and is static.

The finite element analysis was carried out using the PATRAN software for pre- and post-processing and the ABAQUS finite element software for the analysis. The PATRAN software, running on the SGI and Sun workstations in the APD, provides a reasonably simple and rapid method for developing the input for ABAQUS and for inspecting and visualizing the output results. Specifically, the output deflections, strains, and stresses desired for comparison, described in Table 2.3, were extracted using the cursor tool option in the INSIGHT application in PATRAN. These selected results were tabulated for comparison with the baseline results of the Layered Elastic Analyses described previously. 


\subsubsection{Two-Dimensional (Axisymmetric) Model}

\subsubsection{General formulation.}

The axial symmetry of the single-wheel loading and model (pavement, base course, and subgrade) permits a simplified analytical model, specifically using axisymmetric twodimensional solid elements with no loss in accuracy. By taking the axis of symmetry vertically through the loaded area, the finite element model need model only one sector of a "cylindrical" volume of the pavement layers and subgrade, as indicated in Figure 3.4.

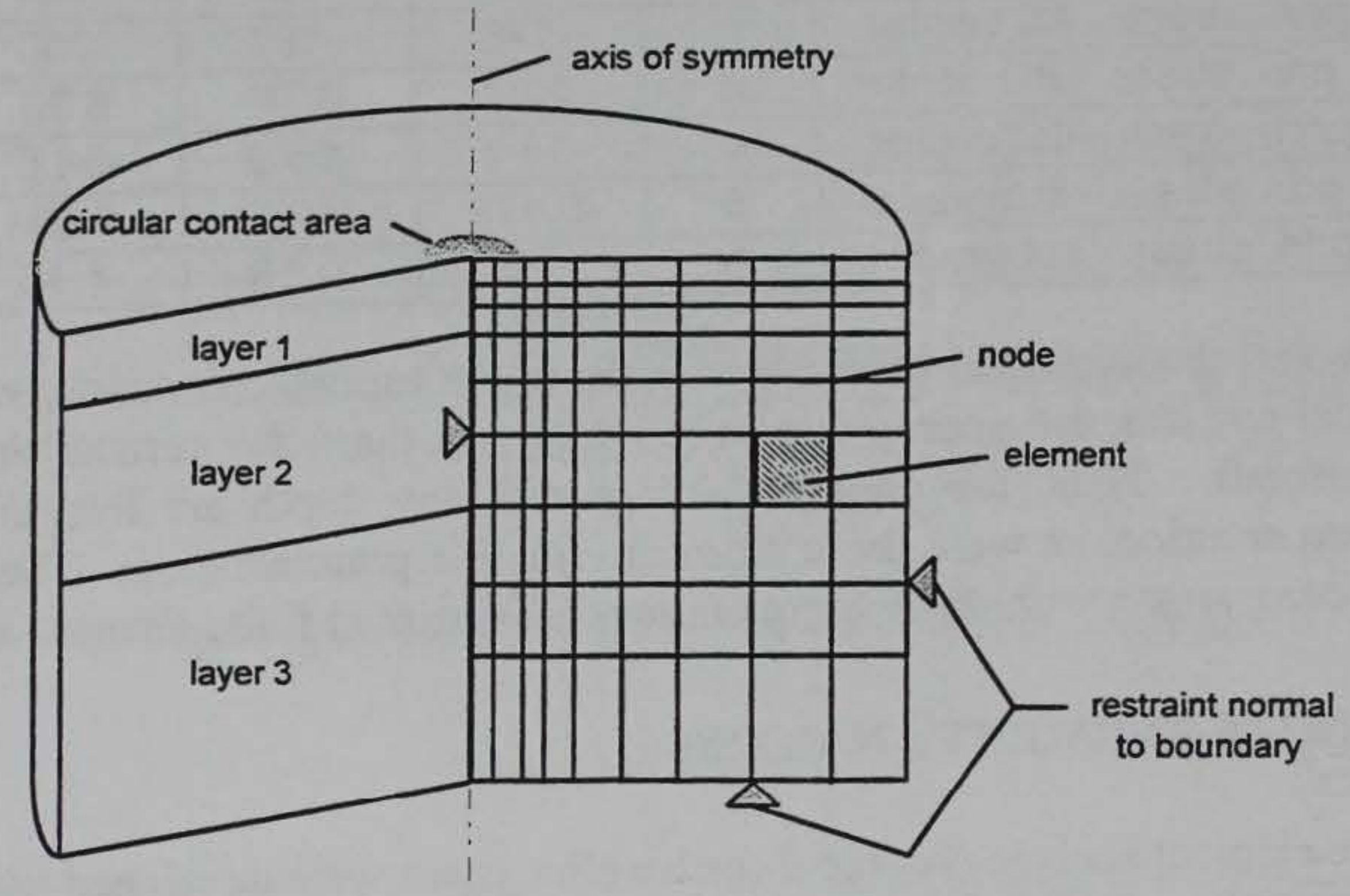

Figure 3.4. Axisymmetric model.

\subsubsection{Materials and loading.}

This model uses the material constants defined in Table 2.1 and the thicknesses of AC and BC defined in Table 2.2. Note that Young's modulus and Poisson's ratio are the only required material properties for a linear elastic material model. The loadings are taken as single wheel tire pressures for the subject aircraft, acting over a circular area derived from the ratio of the single wheel load to the tire pressure.

\subsubsection{Boundary conditions.}

The finite element analysis, as the name implies, generally models only a finite portion of the pavement and soil continuum. Thus, the extent of the model in the horizontal (in this case radial) and vertical directions must be specified a priori. The distance to these side and bottom boundaries has a direct effect on the "accuracy" of the results and the computational effort required for the solution. Specifically, the wider and deeper the finite element model is constructed, the more the solution results will approach those of an unbounded continuum. 
This increase in solution fidelity comes at the cost of additional computational effort (computer time). Typical geomechanical analyses try to achieve reasonable balance between accuracy and computational effort.

For the purposes of the initial validation analyses, the location of the side and bottom boundaries of the model were selected based on the geometry of the assumed loading (radius, r) and the depth to subgrade (AC + BC thicknesses). Specifically, for each case considered, the radial distance to the side boundary was taken as the larger of 10 times the load radius or 2 times the depth to subgrade. Similarly, the "bottom" of the finite element model was taken at twice the depth to subgrade, i.e., a thickness of subgrade equal to that of both pavement layers was considered in the model. These boundary locations, though rather arbitrary, are not inconsistent with typical finite element analyses and extend the model in each direction well away from regions of high stress. At these boundaries, the displacement normal to the boundary was assumed zero (fixed). In other words, the horizontal displacements along the side boundaries and the vertical displacements along the bottom boundary were fixed. By symmetry, the horizontal displacements along the axial line of symmetry are identically zero. Displacements parallel to the boundaries were left free to permit motions in that direction.

\subsubsection{Finite element mesh.}

The other key decision required for finite element analysis of a continuum is the selection of the mesh fineness, i.e., how many elements are to be used to subdivide the model. In general, a more refined mesh (more smaller elements) yields more accurate results at the expense of higher computational effort than a coarser mesh. Similarly, the use of higher order elements generally increases accuracy but requires more effort than using lower order elements. For the baseline validation models, a generally fine mesh of lower order elements (4 node 2-D solids) was utilized. The mesh was subdivided into six regions, or surfaces, corresponding to the geometry of the load and the layer thicknesses ( 3 layers, loaded and unloaded surface). The baseline meshes are shown for the C-141, B-727, and F15 analyses in Figures 3.5, 3.6, and 3.7, respectively. In each case, the mesh consists of very small elements, each with an aspect ratio close to unity (square). 


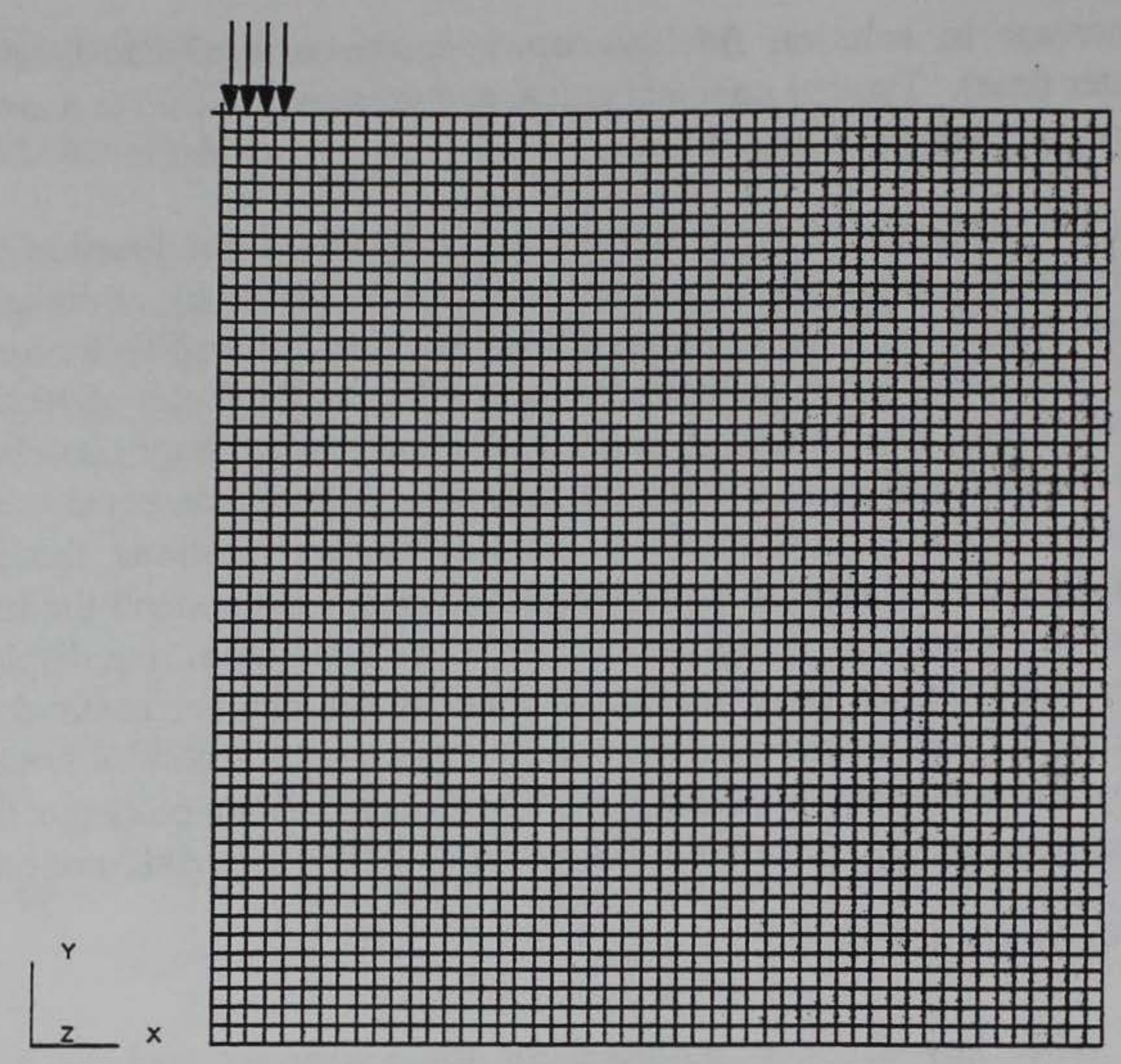

Figure 3.5. Baseline finite element mesh for C-141 analysis.

The orientation of these meshes is similar to that shown previously in Figure 3.4, i.e., the axis of symmetry is the left boundary of the mesh and the upper edge is the free surface. The right and lower boundaries are restrained normal to the boundary. In each mesh, the extent of the wheel load is indicated on the pavement surface extending from the axis of symmetry to the equivalent radius of the contact area. 


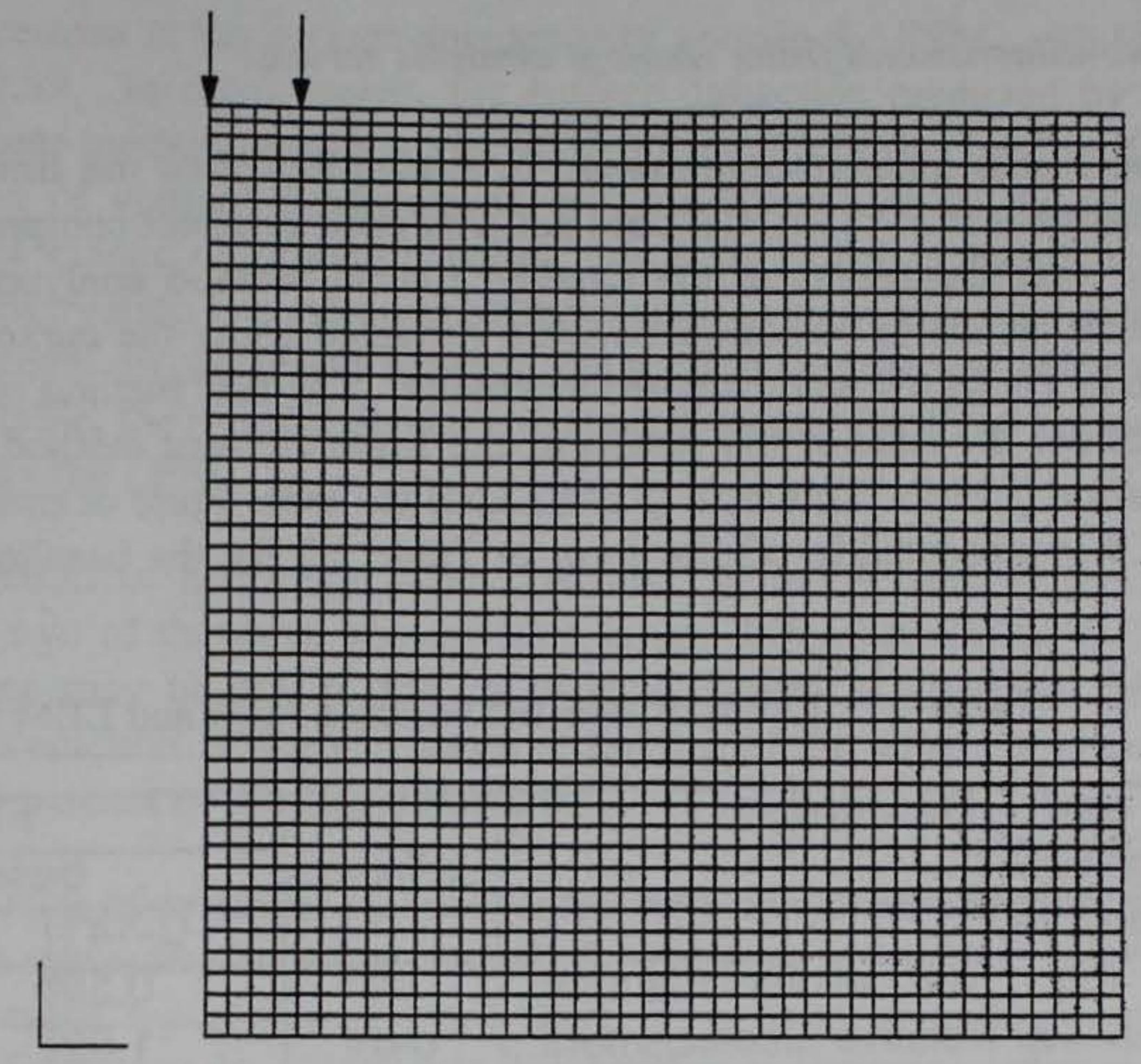

Figure 3.6. Baseline finite element mesh for B-727 analysis.

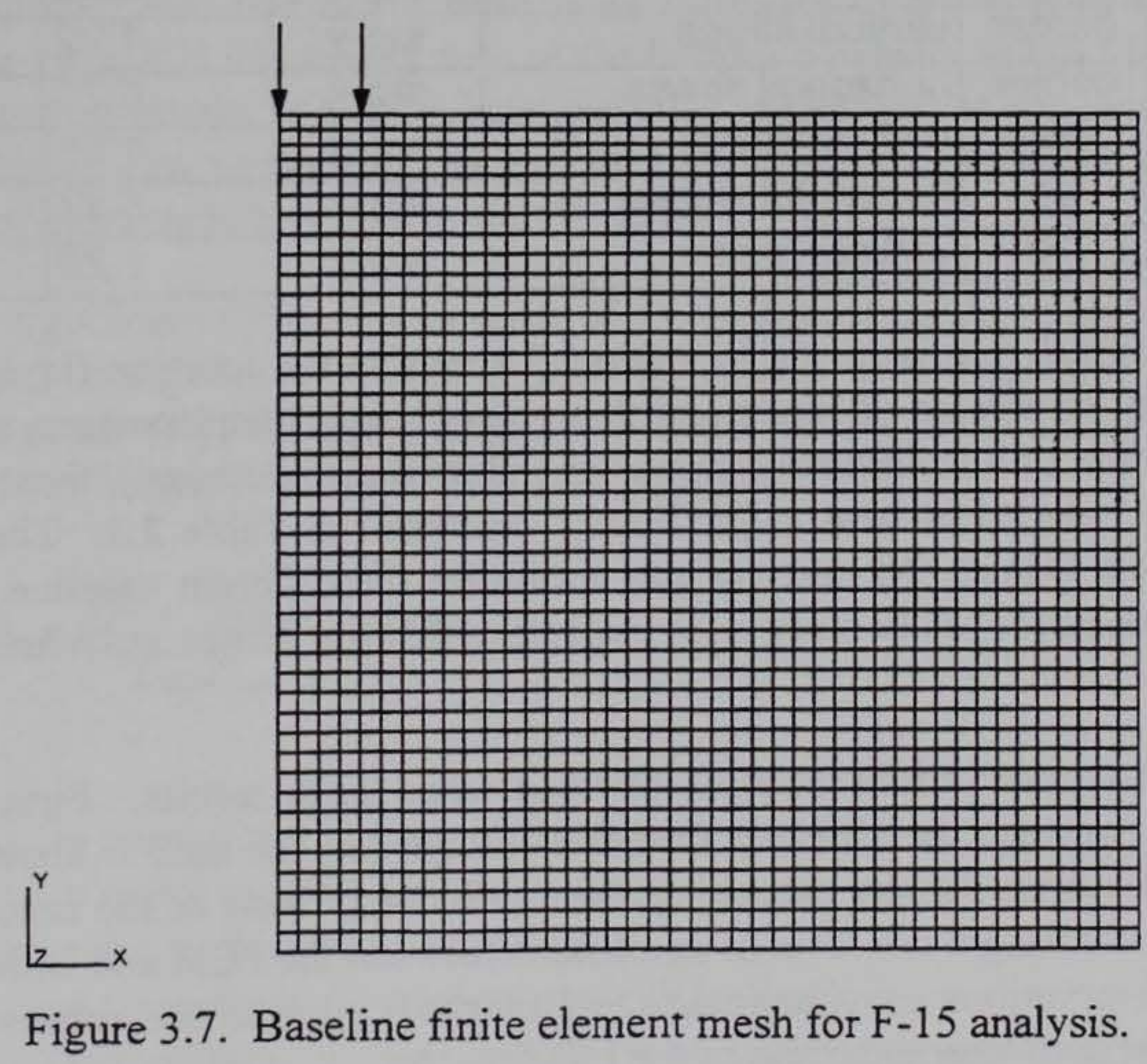




\subsubsection{Two-dimensional finite element analysis results.}

Although it is quite straightforward to extract and view the finite element results for a particular analysis in PATRAN, it does not lend itself to direct comparison of results between analyses or with the results of the Layered Elastic Method analyses. Thus, the particular finite element results to be compared were extracted using the cursor tool in the INSIGHT application in PATRAN and tabulated externally. The first method of comparison employed was to consider the ratio of the results of the finite element method (FEM) to the Layered Elastic Method (LEM). This ratio (FEM/LEM) for each figure of merit described previously in Table 2.3 is presented in tabular form in Table 3.2 for the baseline analyses of the three aircraft.

Table 3.2. Ratios of selected baseline FEM and LEM results.

\begin{tabular}{|c|c|l|c|r|r|r|}
\hline Layer & top/ & Description & FEM & \multicolumn{3}{|c|}{ FEM/LEM } \\
\hline & center/ & & definition & \multicolumn{3}{|c|}{ baseline cases } \\
\hline & bottom & & & $C-141$ & $\mathrm{~B}-727$ & $\mathrm{~F}-15$ \\
\hline 1 & top & vertical displacement & dy & 0.59 & 0.56 & 0.52 \\
\hline $1-3$ & relative & relative displacement & d-dy & 1.02 & 1.02 & 1.01 \\
\hline 1 & bottom & horizontal strain & ex & 1.13 & 1.39 & 1.10 \\
\hline 3 & top & vertical strain & ey & 0.85 & 0.84 & 0.85 \\
\hline 1 & center & horizontal stress & sig-x & 0.96 & 0.95 & 0.91 \\
1 & center & vertical stress & sig-y & 1.02 & 1.02 & 1.00 \\
\hline 2 & center & horizontal stress & sig-x & 0.75 & 0.75 & 0.68 \\
\hline 2 & center & vertical stress & sig-y & 1.01 & 1.01 & 1.02 \\
\hline 3 & top & horizontal stress & sig-x & 5.17 & 4.83 & 5.14 \\
\hline 3 & top & vertical stress & sig-y & 1.28 & 1.26 & 1.25 \\
\hline
\end{tabular}

The initial four columns in Table 3.2 describe the location (layer number and whether top, center, or bottom of layer) and the type of result (displacement, strain, or stress). With the exception of an additional parameter (relative displacement), these output parameters are ranked in order of interest as previously described in Table 2.3. The three columns to the right are the FEM/LEM ratios of the results for the different baseline cases. Obviously, the closer these ratios are to unity is an indication that the FEM results are approaching the LEM results.

Several observations become obvious from these results. First, results are generally consistent between the different aircraft loadings, i.e., the ratio is about the same for each of the three analyses for any particular output. Second, many of the ratios are reasonably close to unity, indicating a fair level of agreement between the FEM and LEM analyses. These two general observations provide some level of confidence in the results of the finite element analyses, at least in comparison to the LEM results.

Looking at particular FEM/LEM comparisons provides insight as to the accuracy with which this particular finite element model predicts that result. For example, the prediction of 
vertical displacement at the surface appears very poor in the FEM, with FEM/LEM ratios of only 0.52 to 0.59 . In other words, the surface deflection predicted by the finite element analysis (for these models) is only about 50 to 60 percent of that predicted by the LEM. The FEM prediction of vertical displacement very much depends on the location of the lower boundary, since elastic deformation below this level is not included in the finite element model. This observation is confirmed by the second comparison in the table which compares the relative vertical displacement between the surface and the top of the subgrade (layer 3). As seen in the table, the relative displacement predicted by the FEM is essentially identical to that predicted by the LEM.

The prediction of horizontal strain (tension) at the bottom of the AC layer is quite reasonable for two of the three cases with a larger difference for the B-727 analysis. This larger difference may be due to the 25 percent thinner AC layer in the B- 727 pavement system. The prediction of vertical strain at the top of the subgrade is extremely consistent and is about 85 percent of the LEM prediction.

The prediction of principal stresses (identically horizontal and vertical) is fairly good to excellent in the upper two layers, especially for the vertical stresses. While the prediction of vertical stress at the top of the subgrade (layer 3 ) is reasonable, the horizontal stress at this location is predicted poorly. Note that this horizontal stress is predicted as tension in both analysis methods (e.g., see Table 3.1), a result that does not reflect reality in the base and subgrade layers. Since the prediction of horizontal stress becomes consistently poorer with depth, it is suspected that this result reflects an influence of the bottom boundary on the horizontal stress (which is identically zero at the bottom boundary in the FEM). We expect that the difference in results is also at least partially attributable to the location of the side boundary. It should also be pointed out that the predicted stress levels in the subgrade are about 2 orders of magnitude less than in the AC layer.

Due to the significant difference in order of magnitude of results at different locations, a more meaningful comparative measure was developed and employed for subsequent comparisons. Specifically, the difference between the results of the finite element method (FEM) and Layered Elastic Method (LEM) was normalized as :

$$
\lambda=\frac{\chi_{F E M}-\chi_{L E M}}{\chi_{L E M \max }} \times 100 \%
$$

where:

$\lambda \quad=$ normalized percent difference

$\chi \quad=$ result variable being compared

$\chi_{\mathrm{FEM}}=$ finite element method result

$\chi_{\text {LEM }}=$ layered elastic method result (baseline)

$\chi_{\mathrm{LEM}_{\max }}=$ maximum or characteristic magnitude of the result variable 
This normalized comparator essentially applies a scale factor to the comparison that accounts for the significant magnitude of the variable under consideration. For example, the more simplified ratio (FEM/LEM) used in Table 3.2 to compare the results sometimes appears to indicate large discrepancies between the solutions where the magnitude of the result is relatively small. In the normalized comparator, a small difference in a relatively small value is compared with reference to a relevant magnitude of some significance. The results presented in Table 3.2 are shown in Table 3.3 using this normalized comparator.

Table 3.3. Normalized comparison of selected baseline results.

\begin{tabular}{|c|c|l|c|r|r|r|}
\hline Layer & \multirow{2}{*}{$\begin{array}{c}\text { top/ } \\
\text { centerl }\end{array}$} & Description & FEM & \multicolumn{3}{|c|}{$\lambda$} \\
& definition & \multicolumn{3}{|c|}{ baseline cases } \\
\cline { 4 - 6 } & bottom & & & C-141 & B-727 & $F-15$ \\
\hline 1 & top & vertical displacement & dy & -40.9 & -44.4 & -48.3 \\
$1-3$ & & relative displacement & d-dy & 0.7 & 0.6 & 0.2 \\
\hline 1 & bottom & horizontal strain & ex & 13.3 & 38.5 & 9.7 \\
3 & top & vertical strain & ey & -15.4 & -15.5 & -15.3 \\
\hline 1 & center & horizontal stress & sig-x & 2.1 & 4.0 & 3.8 \\
1 & & vertical stress & sig-y & -1.6 & -2.0 & -0.4 \\
\hline 2 & center & horizontal stress & sig-x & -0.3 & -0.5 & -0.8 \\
2 & & vertical stress & sig-y & -0.1 & -0.2 & -0.2 \\
\hline 3 & top & horizontal stress & sig-x & -0.4 & -0.6 & -0.5 \\
3 & & vertical stress & sig-y & -0.2 & -0.3 & -0.3 \\
\hline
\end{tabular}

These results confirm that the predicted vertical displacement at the surface is 40 to $50 \%$ lower than the LEM prediction but the relative displacement in the top two layers is less than $1 \%$ different. The horizontal and vertical strains are somewhat over-predicted and underpredicted, respectively, and the relative stress predictions are quite good.

In a somewhat reverse comparison of results between the Layered Elastic Method and the Finite Element Method, a modified BISAR analysis was conducted that more closely modeled the bottom boundary condition of the baseline finite element model for the B-727 wheel load and pavement system. In this case, an extremely stiff layer ( $E=10^{8} \mathrm{psi}$ ) was added at a depth of 92 inches (bottom of finite element model). The results from this BISAR analysis are compared to the baseline B-727 finite element results in Table 3.4, showing both the ratio (LEM/FEM) and the relative normalized difference, $\lambda$. This comparison clearly shows the effect of the stiff lower layer (boundary) in the BISAR results. When this constraint is placed in the LEM model, the results compare very favorably with those from the finite element model. In particular, the predictions of vertical displacement agree within a few percent for these models which are more comparable as to vertical constraint. Note that the LEM model still assumes an elastic continuum in the horizontal direction, whereas the FEM model is restrained at a distance of 88 inches. 
Table 3.4. Comparison of FEM and modified LEM results for B-727.

\begin{tabular}{|c|c|c|c|c|c|c|c|}
\hline \multirow[t]{2}{*}{ Layer } & \multirow{2}{*}{$\begin{array}{l}\text { top/ } \\
\text { center/ } \\
\text { bottom }\end{array}$} & \multirow[t]{2}{*}{ Description } & \multirow[b]{2}{*}{$\begin{array}{c}\text { FEM } \\
\text { definition }\end{array}$} & \multicolumn{4}{|c|}{ B-727 } \\
\hline & & & & $\begin{array}{l}\text { FEM } \\
\text { Value }\end{array}$ & $\begin{array}{r}\text { BISAR } \\
\text { modified }\end{array}$ & $\begin{array}{l}\text { LEM/ } / \\
\text { FEM }\end{array}$ & $\lambda$ \\
\hline 1 & top & vertical displacement & dy & 0.0349 & 0.0371 & 7.06 & 6.3 \\
\hline $1-3$ & relative & relative displacement & $d-d y$ & 0.0246 & 0.0244 & 0.99 & -0.8 \\
\hline 1 & bottom & horizontal strain & ex & 205 & 173 & 0.84 & -15.6 \\
\hline 3 & top & vertical strain & ey & -326 & -400 & 1.23 & 22.7 \\
\hline 1 & center & horizontal stress & sig- $x$ & -142 & -141 & 0.99 & 0.5 \\
\hline 1 & center & vertical stress & sig-y & -201 & -197 & 0.98 & 2.0 \\
\hline 2 & center & horizontal stress & sig-x & 2.8 & 3.76 & 1.34 & 0.5 \\
\hline 2 & center & vertical stress & sig-y & -26.2 & -26.5 & 1.01 & -0.2 \\
\hline$\overline{3}$ & top & horizontal stress & sig- $x$ & -1.45 & -1.42 & 0.98 & 0.0 \\
\hline 3 & top & vertical stress & sig-y & -3.26 & -3.68 & 1.13 & -0.2 \\
\hline
\end{tabular}

In general, the finite element models predicted most of the results of interest with reasonable agreement with the LEM. The vertical displacement at the surface is quite underpredicted when compared with a semi-infinite elastic continuum, but this is due to the location of the lower boundary (where the displacement is constrained). This effect was confirmed by review of the relative displacement in the upper two layers and by the LEM analysis with a very stiff (nearly fixed) layer. The other result with the largest relative discrepancy in prediction is the horizontal stress at the top of the subgrade. This prediction is probably affected by the location of both the bottom boundary and the side boundary in the finite element model. By St. Venant's theorem we would expect the effect of these boundaries to be more noticeable as they are approached. These suppositions and the effect of the boundaries are investigated in the parameter studies described in the following section of this report.

\subsubsection{Two-dimensional parameter study.}

Prior to, and during the course of the two-dimensional finite element analyses, we recognized several parameters relevant to the finite element modeling technique that would be good candidates for at least a brief review of their effect on the results. First, the fineness and type of mesh utilized for a given model dimension likely has some effect on the "accuracy" of the predicted results. Second, the modeling of the bottom and side boundaries (location and boundary condition) also has some effect on the predicted results. An additional parameter not considered in the baseline LEM analyses but available to the finite element model is the difference in compressive and tensile response of the different materials in the structure. A brief parameter study and excursions from the baseline case were considered and are described in the following paragraphs.

Mesh type and density. Finite element meshes are typically more refined (smaller elements) in the regions of higher stress gradients and coarser away from these locations. Two additional mesh types and density using this principle were investigated for each baseline case to evaluate this effect on the predicted results. These two variations on mesh 
discretization are generally referred to herein as uniform bias and paver-type, using the notation of the PATRAN pre-processor used to generate the meshes. These mesh types are best understood by viewing the generated meshes for the three baseline cases.

The uniform bias mesh discretizations for the three cases are illustrated in Figures 3.8, 3.9 , and 3.10, respectively. In these cases the mesh is finer in the region of load application where the stress gradients are higher, and becomes progressively coarser as the distance from this region increases. In fact, the distance between nodes in the vertical and horizontal directions increase generally proportionally with distance from the surface and axis of symmetry (thus the description as uniform bias). All of the elements are still rectangular but the aspect ratio varies considerably from the preferred unity away from the region of most interest. This mesh utilizes far fewer elements than the baseline cases described previously.

The paver-type meshes, shown in Figures 3.11, 3.12, and 3.13, have some similarities to the uniform bias types in that the mesh becomes coarser with distance from the loaded region. In fact, the regions along the surface in the AC layer and adjacent to the axis of symmetry under the loaded area are the same as the uniform bias mesh. The mesh in the remaining region is somewhat coarser than the uniform bias mesh with a decreasing number of nodes (and elements) at a given level or horizontal distance from the axis of symmetry. This type of mesh, sometimes resembling a spider web, results in quadrilateral elements that are no longer rectangular but that still have reasonable aspect ratios and skew ratios. The paver-type mesh has somewhat fewer nodes and elements than the uniform bias mesh.

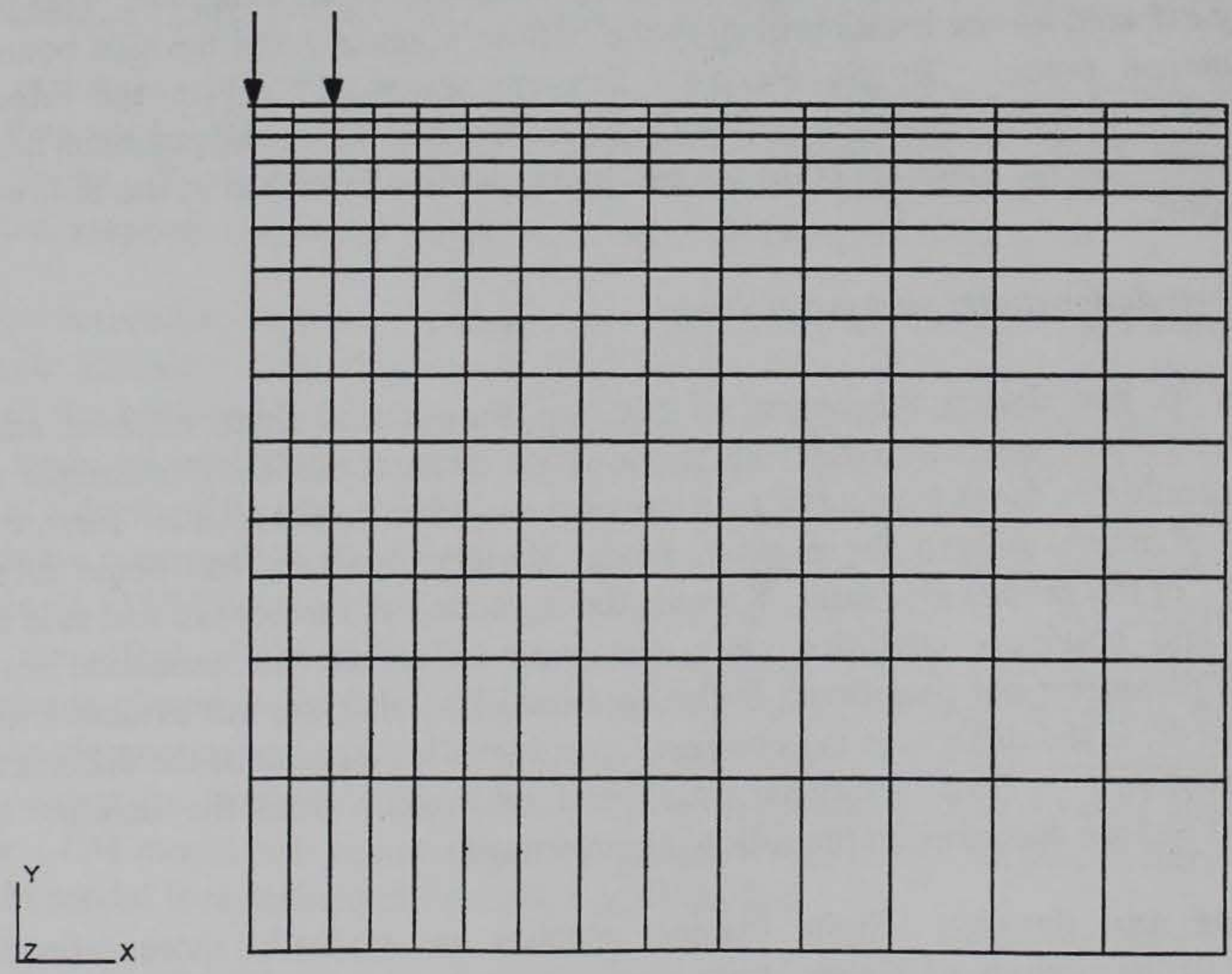

Figure 3.8. Uniform bias finite element mesh for C-141 analysis. 


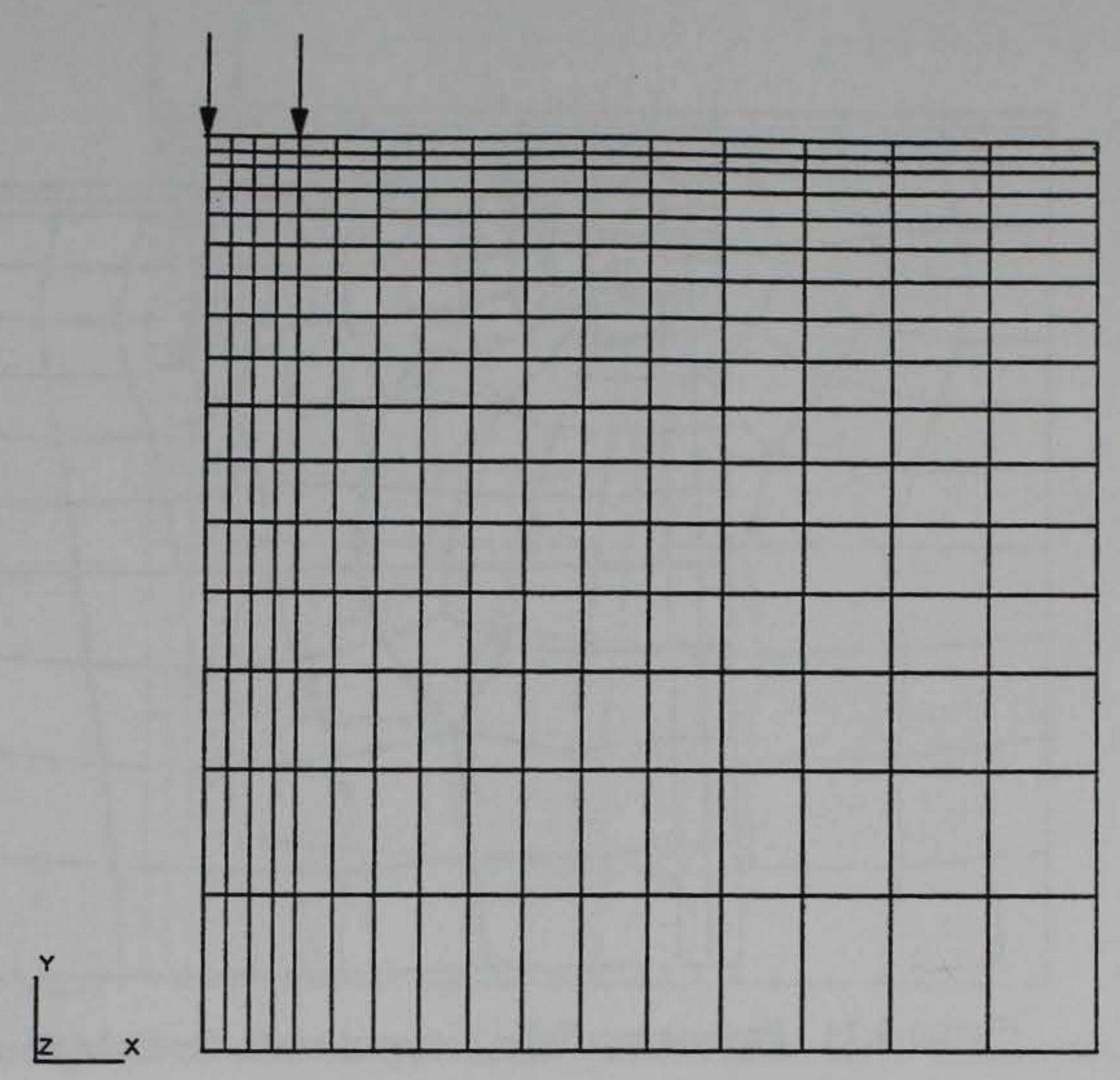

Figure 3.9. Uniform bias finite element mesh for B-727 analysis.

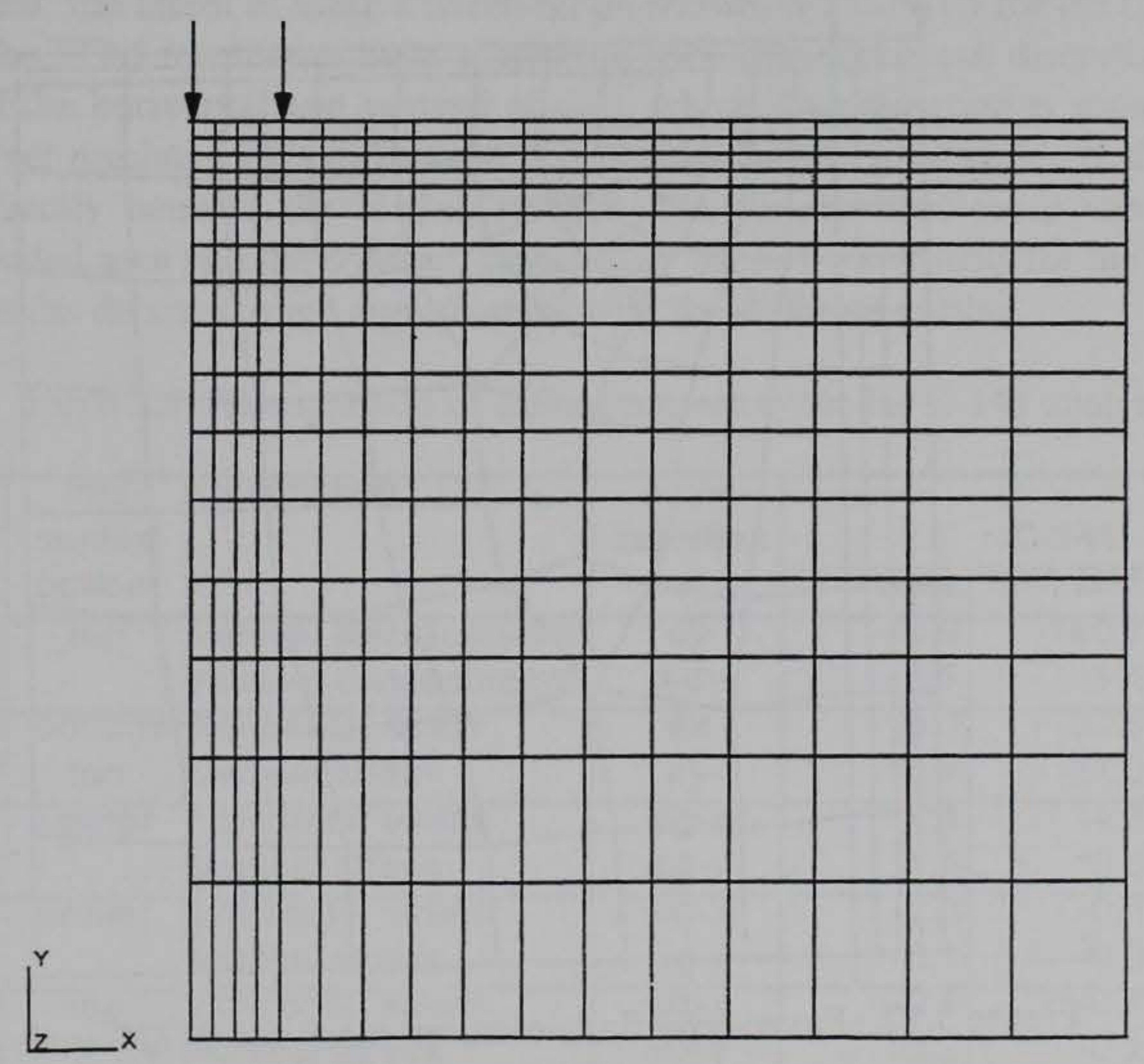

Figure 3.10. Uniform bias finite element mesh for F-15 analysis. 


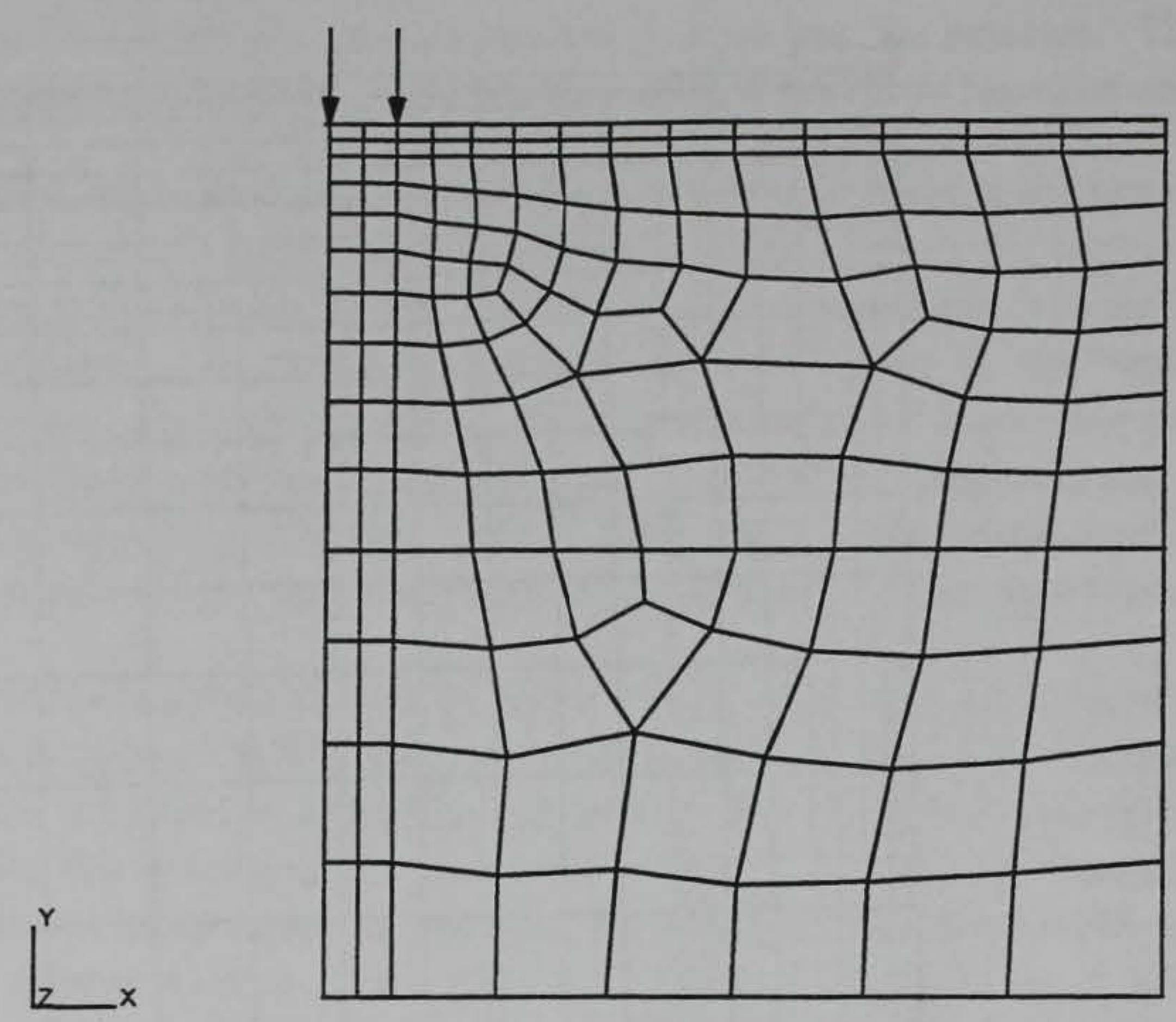

Figure 3.11. Paver-type finite element mesh for C-141 analysis.

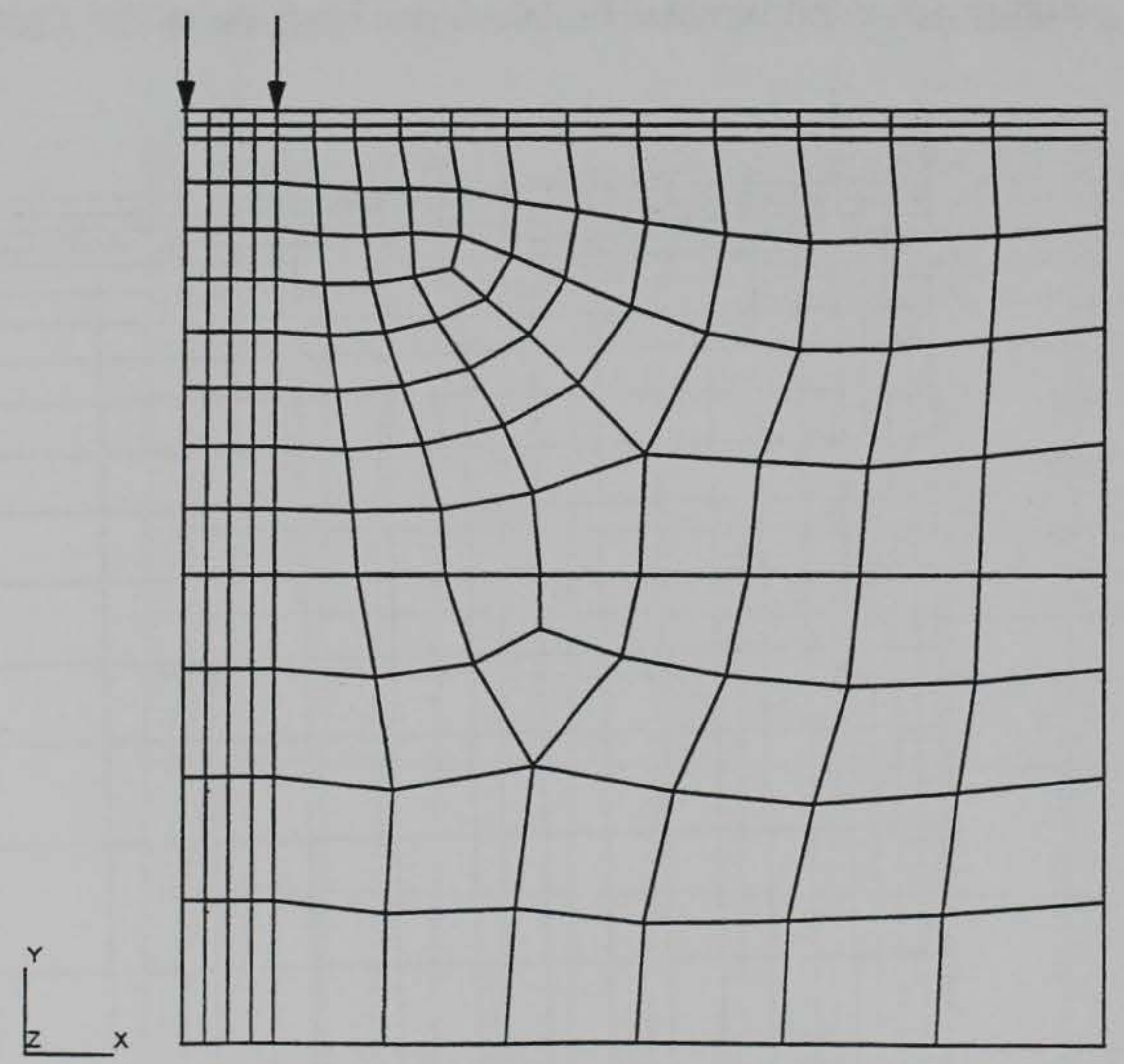

Figure 3.12. Paver-type finite element mesh for B-727 analysis. 


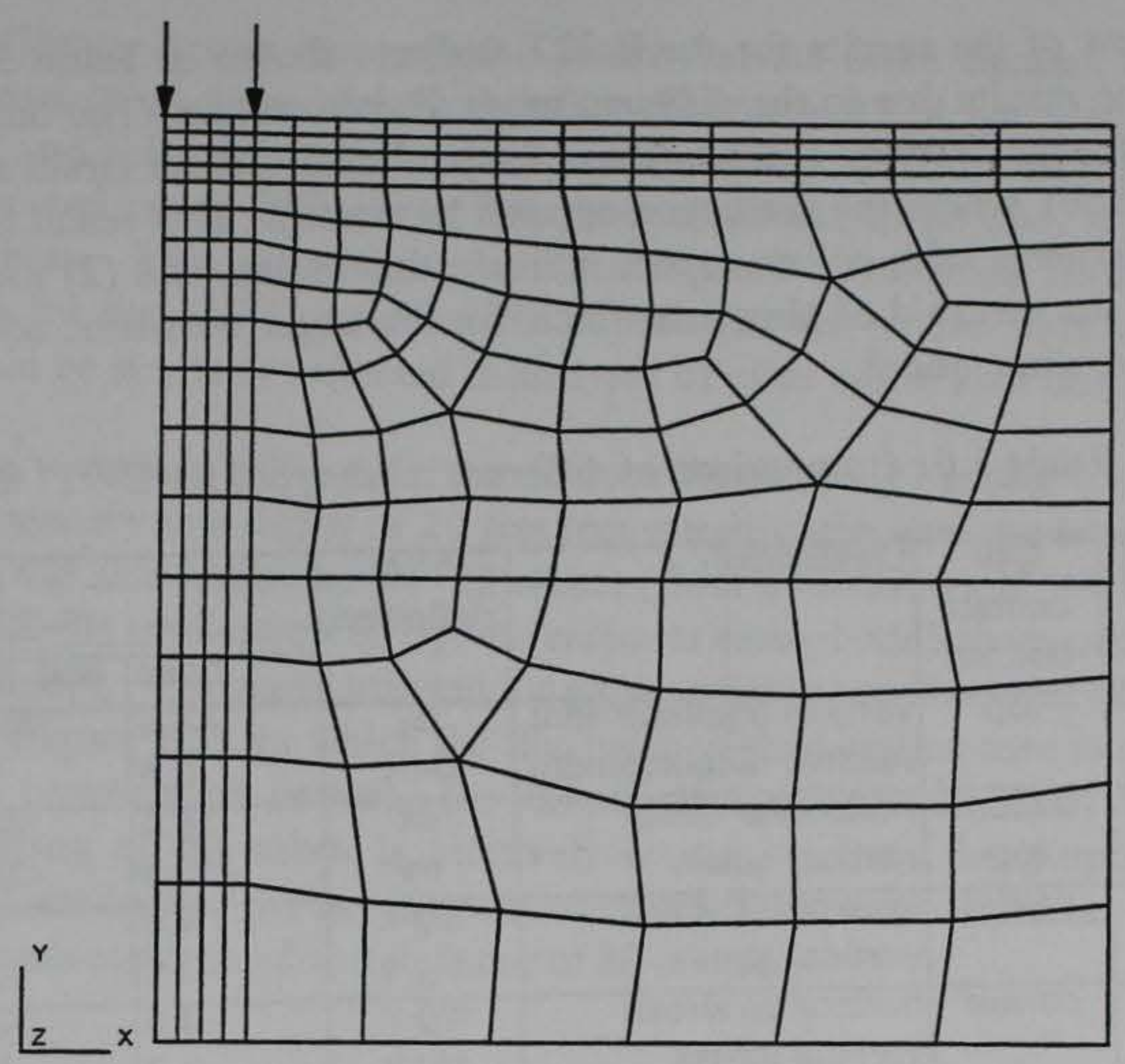

Figure 3.13. Paver-type finite element mesh for F-15 analysis.

In general, the effect of mesh discretization shown in Table 3.5 for the C-141 analyses is small, i.e., the FEM results are little changed by the different mesh discretizations, with the exception of the horizontal and vertical strains, where the prediction is somewhat worse for the two coarser meshes. This difference is probably directly attributable to the coarsening of the mesh directly beneath the loaded surface, i.e., the baseline mesh used four elements across the loaded area and the coarser meshes only used two elements for the C-141 analyses. The other results do not change significantly with the different meshes.

Table 3.5. Comparison of different mesh types for C-141 analysis.

\begin{tabular}{|c|c|c|c|c|c|c|}
\hline \multirow[t]{2}{*}{ Layer } & \multirow{2}{*}{$\begin{array}{c}\text { topl } \\
\text { center/ } \\
\text { bottom }\end{array}$} & \multirow[t]{2}{*}{ Description } & \multirow[t]{2}{*}{$\begin{array}{c}\text { FEM } \\
\text { definition }\end{array}$} & \multicolumn{3}{|c|}{$\frac{\lambda}{C-141}$} \\
\hline & & & & base & unif. bias & paver \\
\hline 1 & top & vertical displacement & dy & -40.9 & -40.7 & -40.9 \\
\hline $1-3$ & & relative displacement & d-dy & 0.7 & 1.1 & 0.9 \\
\hline 1 & bottom & horizontal strain & ex & 13.3 & 39.5 & 39.2 \\
\hline 3 & top & vertical strain & ey & -15.4 & -27.0 & -32.4 \\
\hline 1 & center & horizontal stress & sig- $x$ & 2.1 & -4.3 & -4.3 \\
\hline 1 & & vertical stress & sig-y & -1.6 & 0.0 & 0.0 \\
\hline 2 & center & horizontal stress & sig- $x$ & -0.3 & -0.3 & -0.3 \\
\hline 2 & & vertical stress & sig-y & -0.1 & -0.9 & -0.8 \\
\hline 3 & top & horizontal stress & $\operatorname{sig}-x$ & -0.4 & -0.4 & -0.4 \\
\hline 3 & & vertical stress & sig-y & -0.2 & -0.2 & -0.1 \\
\hline
\end{tabular}


A review of the results for the B-727 analyses shown in Table 3.6 also indicate little change in the results due to the different mesh discretizations. The only result that shows a significant change between mesh types is the predicted vertical strain at the top of the third layer (subgrade), where the prediction appears to worsen. This result is probably due to (1) the larger elements with poorer aspect ratios in this region, and (2) the fact that results are presented at the centroid of elements which, for the larger elements, occurs at a lower depth than in the baseline model.

Table 3.6. Comparison of different mesh types for B-727 analysis.

\begin{tabular}{|c|c|c|c|c|c|c|}
\hline \multirow[t]{2}{*}{ Layer } & \multirow{2}{*}{$\begin{array}{c}\text { topl } \\
\text { centerl } \\
\text { bottom }\end{array}$} & \multirow[t]{2}{*}{ Description } & \multirow[t]{2}{*}{$\begin{array}{c}\text { FEM } \\
\text { definition }\end{array}$} & \multicolumn{3}{|c|}{$\begin{array}{c}\lambda \\
B-727\end{array}$} \\
\hline & & & & base & unif. bias & paver \\
\hline 1 & top & vertical displacement & dy & -44.4 & -44.9 & -44.9 \\
\hline $1-3$ & & relative displacement & d-dy & 0.6 & 0.3 & 0.3 \\
\hline 1 & bottom & horizontal strain & ex & 38.5 & 40.5 & 42.6 \\
\hline 3 & top & vertical strain & ey & -15.5 & -28.5 & -30.6 \\
\hline$T$ & center & horizontal stress & sig- $x$ & 4.0 & 4.0 & 4.0 \\
\hline 1 & & vertical stress & sig-y & -2.0 & -2.0 & -2.0 \\
\hline$\overline{2}$ & center & horizontal stress & sig- $x$ & -0.5 & -0.6 & -0.6 \\
\hline 2 & & vertical stress & sig-y & -0.2 & -2.8 & -3.4 \\
\hline 3 & top & horizontal stress & sig- $x$ & -0.6 & -0.6 & -0.6 \\
\hline 3 & & vertical stress & sig-y & -0.3 & -0.2 & -0.2 \\
\hline
\end{tabular}

The results shown in Table 3.7 for the F-15 analyses generally agree with the observations from the previous comparison.

Table 3.7. Comparison of different mesh types for F-15 analysis.

\begin{tabular}{|c|c|c|c|c|c|c|}
\hline \multirow[t]{2}{*}{ Layer } & \multirow{2}{*}{$\begin{array}{c}\text { topl } \\
\text { center/ } \\
\text { bottom }\end{array}$} & \multirow[t]{2}{*}{ Description } & \multirow[t]{2}{*}{$\begin{array}{c}\text { FEM } \\
\text { definition }\end{array}$} & \multicolumn{3}{|c|}{$\stackrel{\lambda}{A-15}$} \\
\hline & & & & base & unif. bias & paver \\
\hline $\begin{array}{c}1 \\
1-3\end{array}$ & top & $\begin{array}{l}\text { vertical displacement } \\
\text { relative displacement }\end{array}$ & $\begin{array}{l}\text { dy } \\
\text { d-dy }\end{array}$ & $\begin{array}{r}-48.3 \\
0.2\end{array}$ & $\begin{array}{r}-48.6 \\
-1.9\end{array}$ & $\begin{array}{r}-48.6 \\
0.0\end{array}$ \\
\hline $\begin{array}{l}1 \\
3\end{array}$ & $\begin{array}{l}\text { bottom } \\
\text { top }\end{array}$ & $\begin{array}{l}\text { horizontal strain } \\
\text { vertical strain }\end{array}$ & $\begin{array}{l}\text { ex } \\
\text { ey }\end{array}$ & $\begin{array}{r}9.7 \\
-15.3\end{array}$ & $\begin{array}{r}8.4 \\
-38.8\end{array}$ & $\begin{array}{r}3.2 \\
-27.6\end{array}$ \\
\hline $\begin{array}{l}1 \\
1\end{array}$ & center & $\begin{array}{l}\text { horizontal stress } \\
\text { vertical stress }\end{array}$ & $\begin{array}{l}\text { sig- } x \\
\text { sig-y }\end{array}$ & $\begin{array}{r}3.8 \\
-0.4\end{array}$ & $\begin{array}{r}3.8 \\
-0.3\end{array}$ & $\begin{array}{r}4.1 \\
-0.6\end{array}$ \\
\hline $\begin{array}{l}2 \\
2\end{array}$ & center & $\begin{array}{l}\text { horizontal stress } \\
\text { vertical stress }\end{array}$ & $\begin{array}{l}\text { sig- } x \\
\text { sig-y }\end{array}$ & $\begin{array}{l}-0.8 \\
-0.2\end{array}$ & $\begin{array}{l}-0.9 \\
-1.0\end{array}$ & $\begin{array}{l}-0.8 \\
-1.0\end{array}$ \\
\hline $\begin{array}{l}3 \\
3\end{array}$ & top & $\begin{array}{l}\text { horizontal stress } \\
\text { vertical stress }\end{array}$ & $\begin{array}{l}\text { sig-x } \\
\text { sig-y }\end{array}$ & $\begin{array}{l}-0.5 \\
-0.3\end{array}$ & $\begin{array}{r}3.1 \\
-0.9\end{array}$ & $\begin{array}{l}-0.5 \\
-0.2\end{array}$ \\
\hline
\end{tabular}

Overall, the coarser meshes predicted most of the results of interest about the same as the more refined baseline meshes. The differences between meshes was generally smaller than the differences between the FEM and LEM, and generally were only significant in the subgrade layer. Thus, biased or paver-type meshes should be relatively useful for analysis if properly applied in regions of most interest. 
Boundary effects. It was recognized $a$ priori that the finite element modeling technique imposes constraints on the model through fixed bottom and side boundaries to the continuum of pavement and soil. In fact, the comparison of results of the baseline FEM and LEM analyses indicated some differences that were suspected to be due, at least partly, to the boundary effects. This supposition was investigated by selected revised analyses of the baseline case for the B-727 model. We expect that the results obtained from the B-727 analyses would be similarly reflected in analyses of other wheel load cases.

The three variations of boundary conditions for the B-727 model considered (1) moving the bottom boundary to a depth of 20 feet (compared to the base model depth of 92 inches), (2) extending the side boundary to 432 inches (from 88 inches) and the bottom boundary to 600 inches, and (3) application of infinite elements along both bottom and side boundaries of the baseline model. The mesh utilized for moving the bottom boundary to a depth of 20 feet is depicted in Figure 3.14, in which the fine mesh of the baseline case is quickly transformed to a relatively coarse mesh between the 92 -inch depth and the 240 -inch depth. Even though the lower portion of the mesh is relatively crude, it serves the purpose of considerably lowering the boundary of the model without changing other parameters. The side boundary in this model was maintained at a distance of 88 inches.

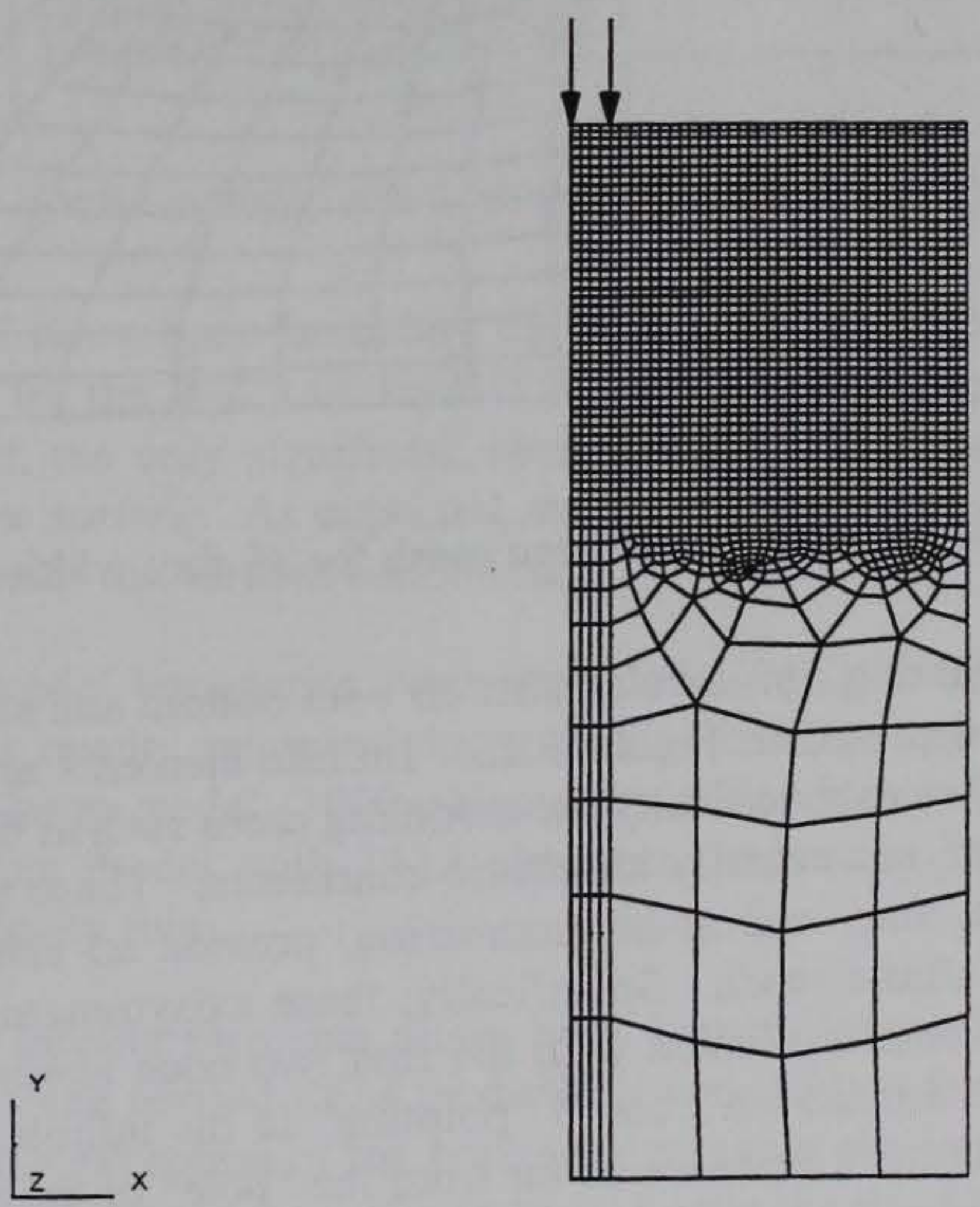

Figure 3.14. Finite element mesh for 20 -foot depth.

A detailed finite element model was generated with the side boundary at a horizontal distance of 432 inches ( $36 \mathrm{ft}$.) and the bottom boundary at a depth of 600 inches ( $50 \mathrm{ft}$.). This model, shown in Figure 3.15, consisted of 1195 nodes and 1132 elements. An even more 
detailed model with a rectangular grid having over 3000 elements was also analyzed, but is not shown here. This model is considered to be larger in extent and mesh size than would normally be applied in typical geomechanical analyses and serves as an upper bound on mesh size and refinement.

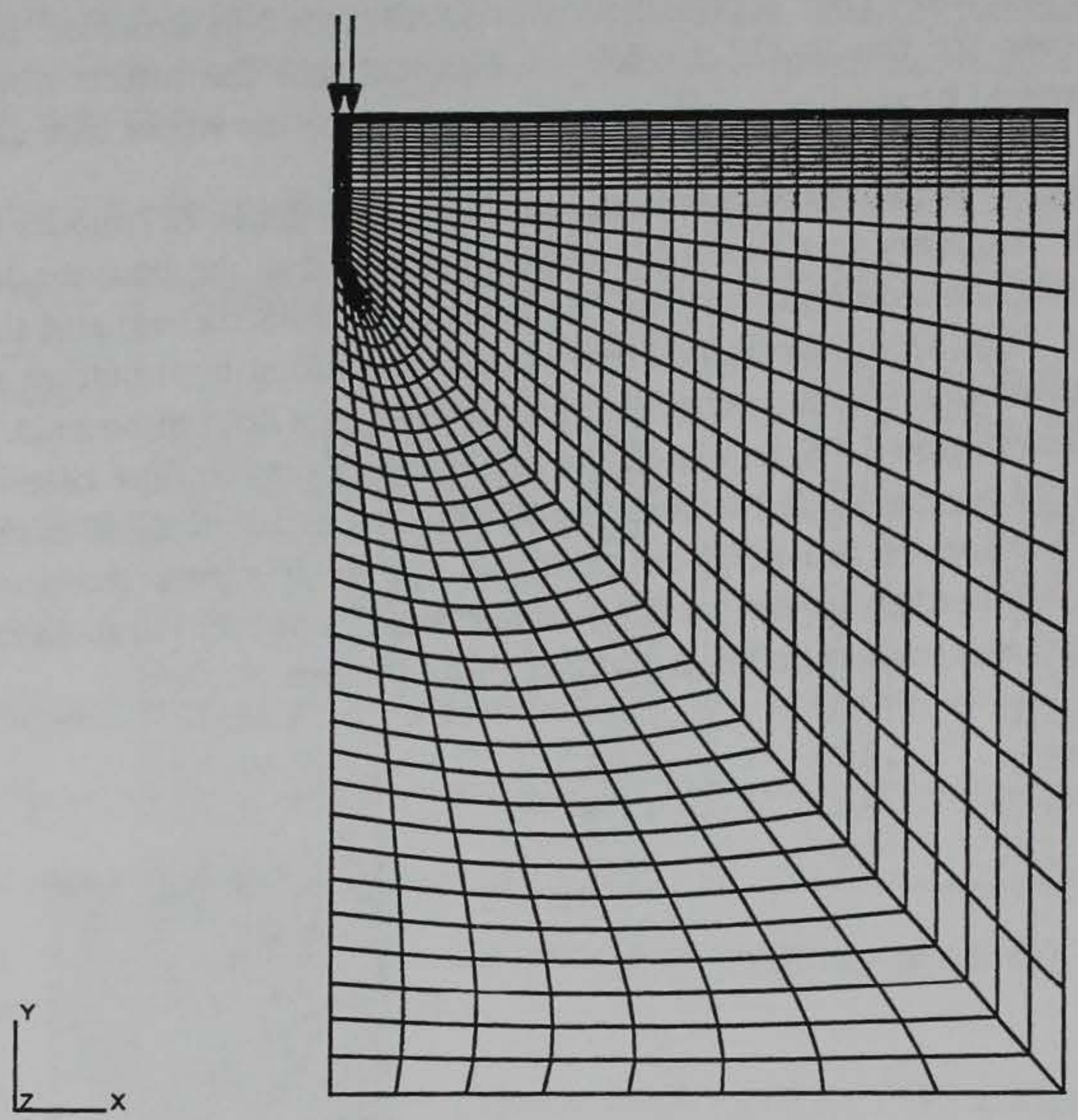

Figure 3.15. Finite element mesh for 36-foot width and 50-foot depth.

The mesh utilizing infinite elements on both bottom and side boundaries of the baseline B-727 model is depicted in Figure 3.16. Infinite elements are available in the ABAQUS finite element software specifically for modeling cases such as this where the actual structure, or portions thereof, are actually an elastic continuum. These elements, which have special rules for location, size, and nodal numbering, provide an elastic boundary that models a continuum with infinite reach. Specifically, these axisymmetric infinite elements are fournoded, with the element oriented with the first two node numbers along the boundary with the finite elements and nodes 2 and 3 "pointing" in the infinite direction. The "far end" of the infinite element must be twice as far from the "pole" of the model as the finite boundary nodes (the "pole" in this model is the center of the loaded radius at the surface). The infinite elements are added to the side and bottom boundaries of the baseline model as shown in Figure 3.16. The aspect ratio of these elements is controlled by the special rules for infinite elements. 


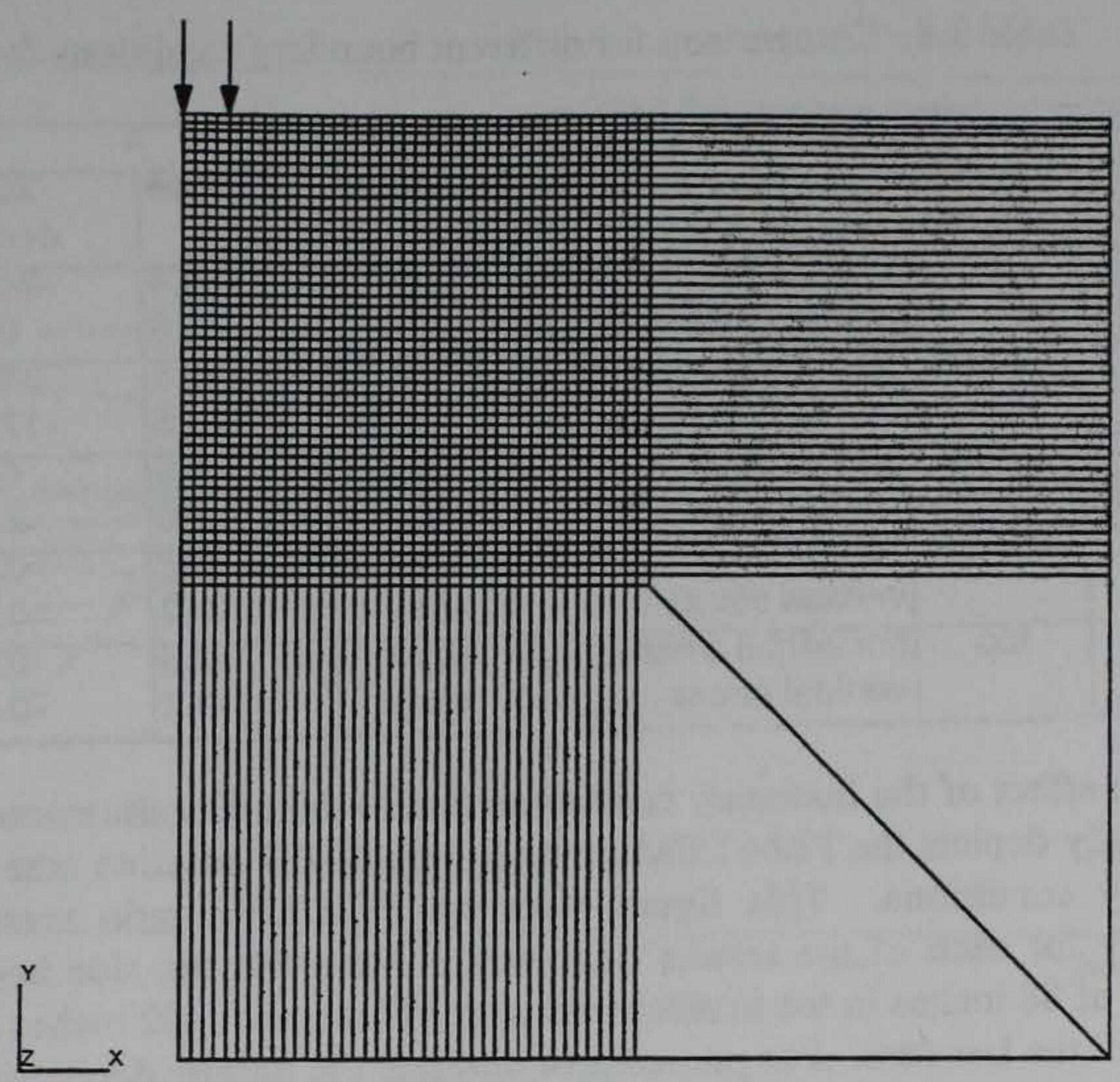

Figure 3.16. Finite element mesh using infinite elements at boundaries.

The key results of these three boundary condition variations are compared with those from the baseline case for the B-727 in Table 3.8. For the case where the bottom boundary was lowered to 20 feet, the only significant change was in the improved prediction of the vertical deflection at the surface. As expected, this deflection increased in the deeper model due to inclusion of more of the vertical continuum.

When the finite model boundaries were extended to 432 inches horizontally and 600 inches vertically, most results improved to generally excellent agreement with the LEM analysis. The refined large model ( $3000+$ elements) showed only a slight improvement in fidelity compared to the model with 1132 elements, indicating that the mesh shown in Figure 3.15 was sufficiently fine.

The model using infinite elements along both boundaries generally agreed very well with the LEM results. The revised FEM predictions were only a few percent different from the LEM results with the exception of the horizontal stress at the top of the third (subgrade) layer. However, this prediction was greatly improved over the fixed boundary model and the actual magnitudes of this value are quite small. 
Table 3.8. Comparison for different boundary conditions for B-727 analysis.

\begin{tabular}{|c|c|c|c|c|c|c|c|}
\hline \multirow[t]{2}{*}{ Layer } & \multirow{2}{*}{$\begin{array}{l}\text { top/ } \\
\text { center/ } \\
\text { bottom }\end{array}$} & \multirow[t]{2}{*}{ Description } & \multirow{2}{*}{$\begin{array}{c}\text { FEM } \\
\text { definition }\end{array}$} & \multicolumn{2}{|c|}{$\lambda$} & \multicolumn{2}{|c|}{$B-127$} \\
\hline & & & & base & $\begin{array}{r}20 \mathrm{ft} \\
\text { depth }\end{array}$ & $\begin{array}{l}\text { t wide } \\
\text { t deep }\end{array}$ & $\begin{array}{r}\text { infinite } \\
\text { elements }\end{array}$ \\
\hline$T$ & top & vertical displacement & dy & -44.4 & -24.2 & -12.1 & -5.8 \\
\hline $1-3$ & & relative displacement & d-dy & 0.6 & 0.6 & 0.7 & 0.4 \\
\hline$T$ & bottom & horizontal strain & ex & 38.5 & 38.5 & 10.8 & 4.7 \\
\hline 3 & top & vertical strain & ey & -15.5 & -17.1 & -14.0 & -12.2 \\
\hline 1 & center & horizontal stress & sig- $x$ & 4.0 & 4.0 & -2.0 & -2.5 \\
\hline 1 & & vertical stress & sig-y & -2.0 & -2.5 & -2.5 & -1.5 \\
\hline 2 & center & horizontal stress & sig- $x$ & -0.5 & -0.4 & 0.0 & 0.1 \\
\hline 2 & & vertical stress & sig-y & -0.2 & -0.2 & -0.5 & -0.1 \\
\hline 3 & top & horizontal stress & sig-x & -0.6 & -0.6 & 0.0 & -0.2 \\
\hline 3 & & vertical stress & sig-y & -0.3 & -0.3 & 0.2 & 0.0 \\
\hline
\end{tabular}

The effect of the boundary conditions is also generally illustrated in Figure 3.17, which graphically depicts the FEM/LEM ratios for the B-727 baseline case and three variations of boundary conditions. This figure plots the FEM/LEM ratio versus depth to the lower boundary for each of the results of interest. Note that the side boundary location is at a distance of 88 inches in the first two cases, at a distance of 432 inches in the third case, and at infinity in the last case. For purposes of plotting, the infinite depth was arbitrarily assigned a depth of 2000 inches to permit some reasonable scale. (Thus the slope of each line between $y=600$ and $y=2000$ is arbitrary instead of undefined). This plot indicates the relative trend and magnitude of convergence of the selected results as the distance to the lower boundary is increased (assumed infinite in LEM). It is seen in the plot that the FEM/LEM ratio generally approaches unity (perfect agreement) as the boundary distance increases.

A detailed look at the computed vertical displacements for different boundary conditions is illustrated in Figure 3.18. Vertical displacement under the center of the load is plotted versus depth for the different boundary conditions and compared to the LEM (BISAR) results. As seen in this plot, the predictions improve to extremely good as the distance to the boundary increases.

The key conclusion drawn from the data in Table 3.8 and the graph in Figure 3.17 is that the results improve, often dramatically, as the real or apparent distance to the lower boundary is increased. Note that the distance to the side boundary is also changed in the second variation with infinite elements on both boundaries. The use of infinite elements for the boundaries provides excellent agreement with the LEM results. Thus, the use of these elements should be strongly considered in future finite element models of this nature. 


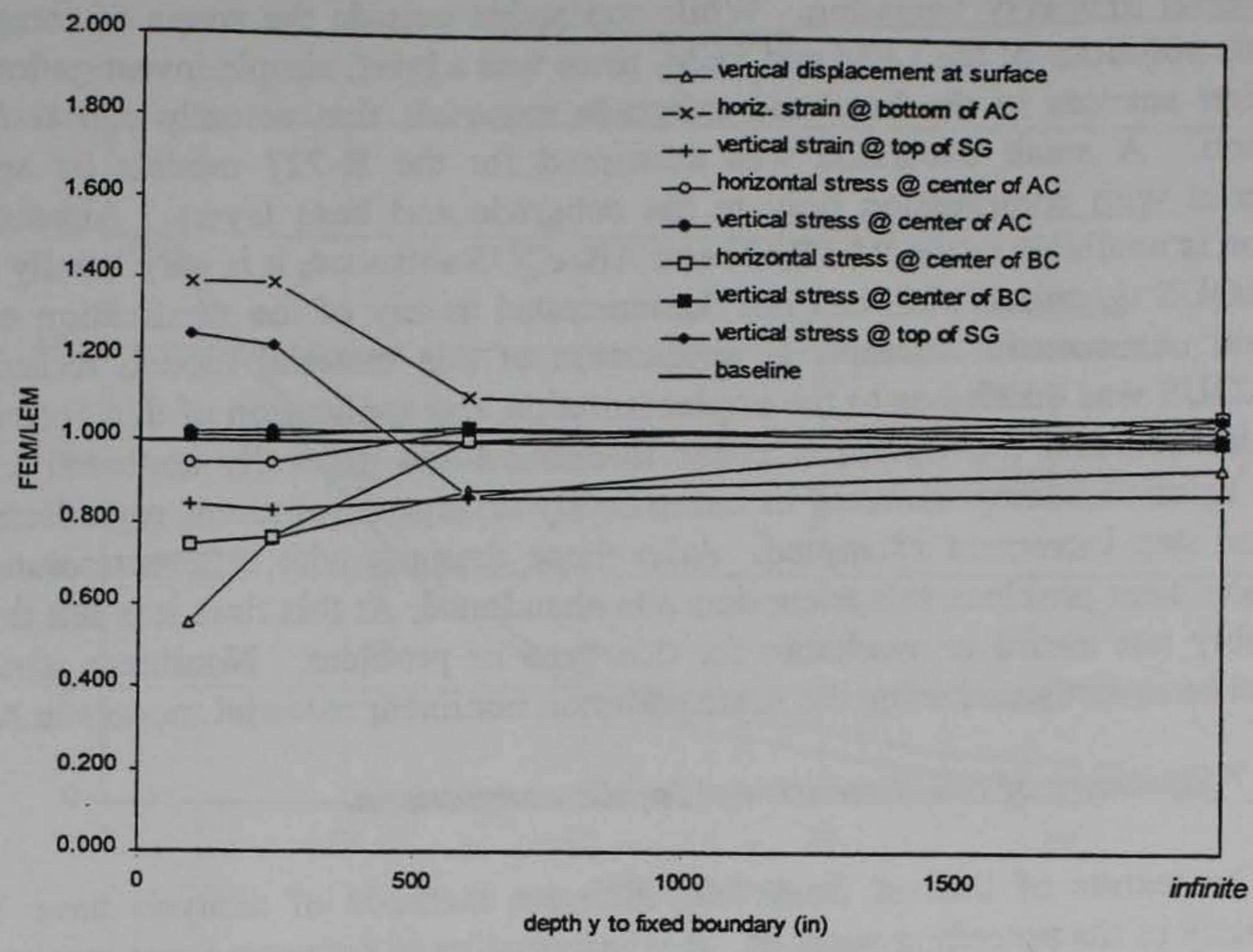

Figure 3.17. Effect on results of distance to lower boundary.

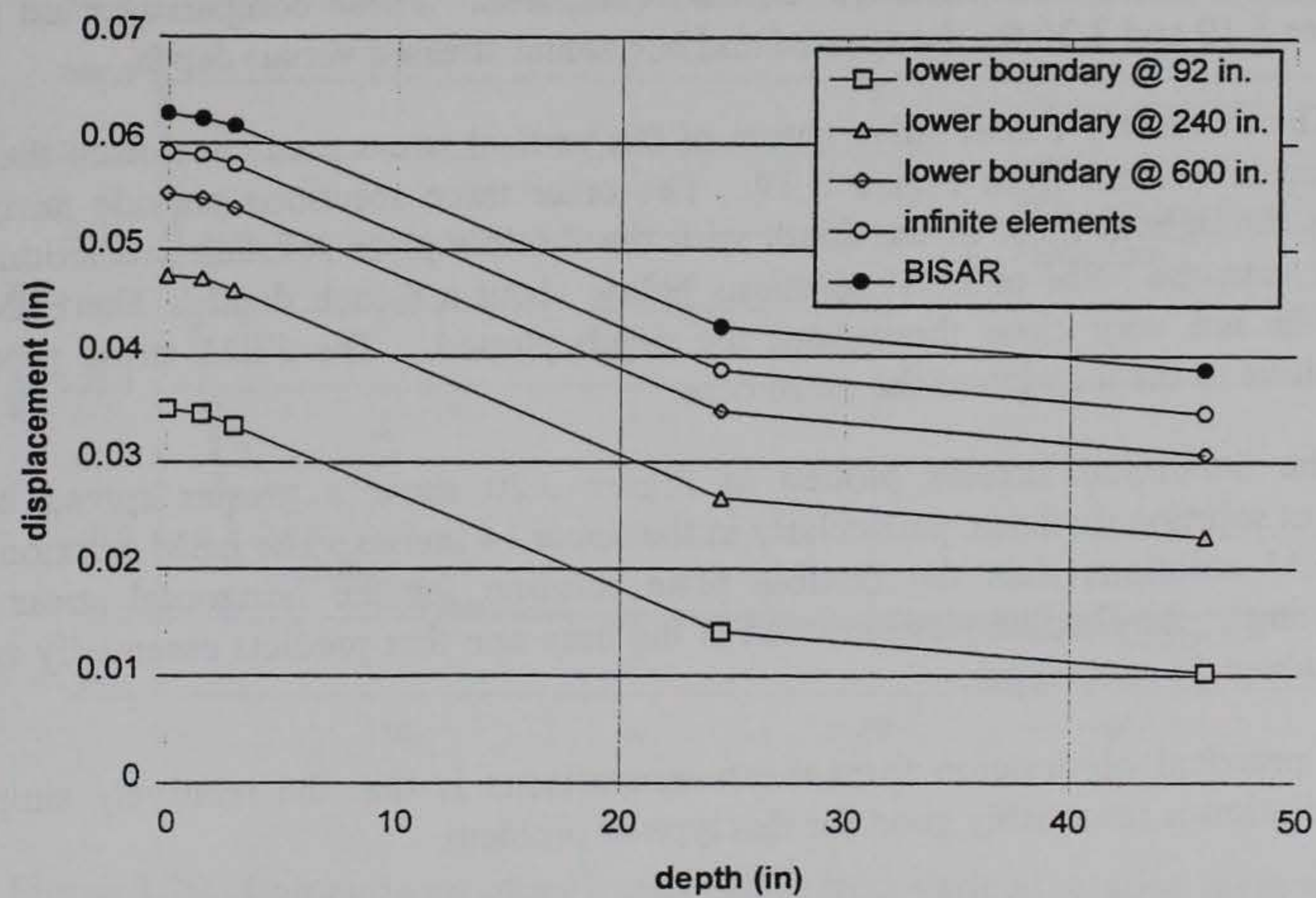

Figure 3.18. Effect on displacement of distance to lower boundary. 
Material property variation. While somewhat outside the scope of comparing the linear elastic solutions of the LEM and FEM, there was a brief, simple investigation of the effect of tension stresses in the base and subgrade materials that actually can resist little, if any, tension. A small excursion was attempted for the B-727 models by specifying elastic material with compression only in the subgrade and base layers. Although this material option is available in the PATRAN and ABAQUS software, it is only briefly discussed in the ABAQUS documentation and not demonstrated in any of the verification examples. After several unsuccessful attempts at application of this material model, technical support for ABAQUS was queried as to the implementation and application of this option. In general, it was learned that this option is rather ill-defined and generally appeared to be little used. Each solution attempt resulted in immediately divergent solutions, regardless of the scheme or load step increment attempted. After these attempts with different solution schemes for this nonlinear problem, this excursion was abandoned. At this time it is felt that this option is probably not useful or workable for this type of problem. Nonlinear material properties should be investigated using the more common nonlinear material models in ABAQUS.

\subsubsection{Summary of two-dimensional results comparison.}

The results of interest from four different methods of analysis have been presented separately in the preceding sections. It is informative to compare these results, not only from an academic perspective, but also to illuminate the potential for the simpler methods of analysis for this type of problem. For purposes of comparison, the vertical and horizontal (radial) stresses computed from the different methods are plotted versus depth. The comparisons illustrated here are for the B-727 analyses, so that the effects of the finite element boundary conditions can be also compared. These comparisons are presented in Figures 3.19 and 3.20 for the vertical and horizontal stresses versus depth.

The extremely conservative nature of the vertical stress prediction from the Boussinesq solution is evident from Figure 3.19. The other three solutions provide fairly consistent results throughout most of the depth with the flexible plate solution predictions somewhat higher than the FEM or LEM solutions below about a 6-inch depth. The FEM and LEM solutions are very close throughout the depth plotted. The FEM stress predictions are insensitive to the location of the mesh base.

The horizontal stresses plotted in Figure 3.20 show a greater spread between the different solution methods, particularly in the upper 14 inches. The LEM solution is closer to the FEM solutions than the flexible plate solution for the horizontal stress prediction. Interestingly, the flexible plate solution is the only one that predicts essentially zero stresses below about 20 -inch depth.

A practical observation from these comparisons is that the relatively simple flexible plate solution is reasonably good for this type of problem. 


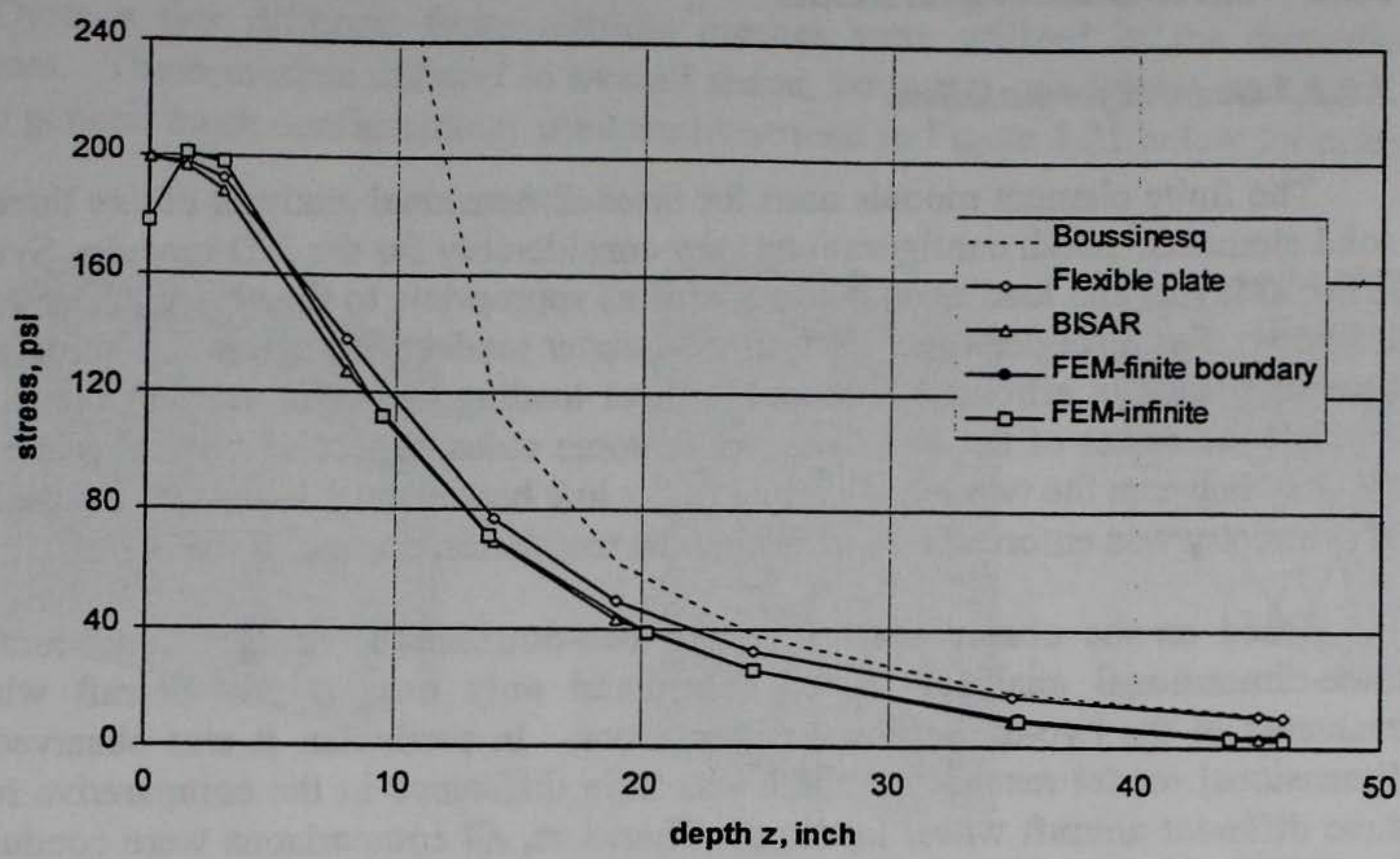

Figure 3.19. Comparisons of vertical stress from various solution methods.

B-727 Horizontal Stress

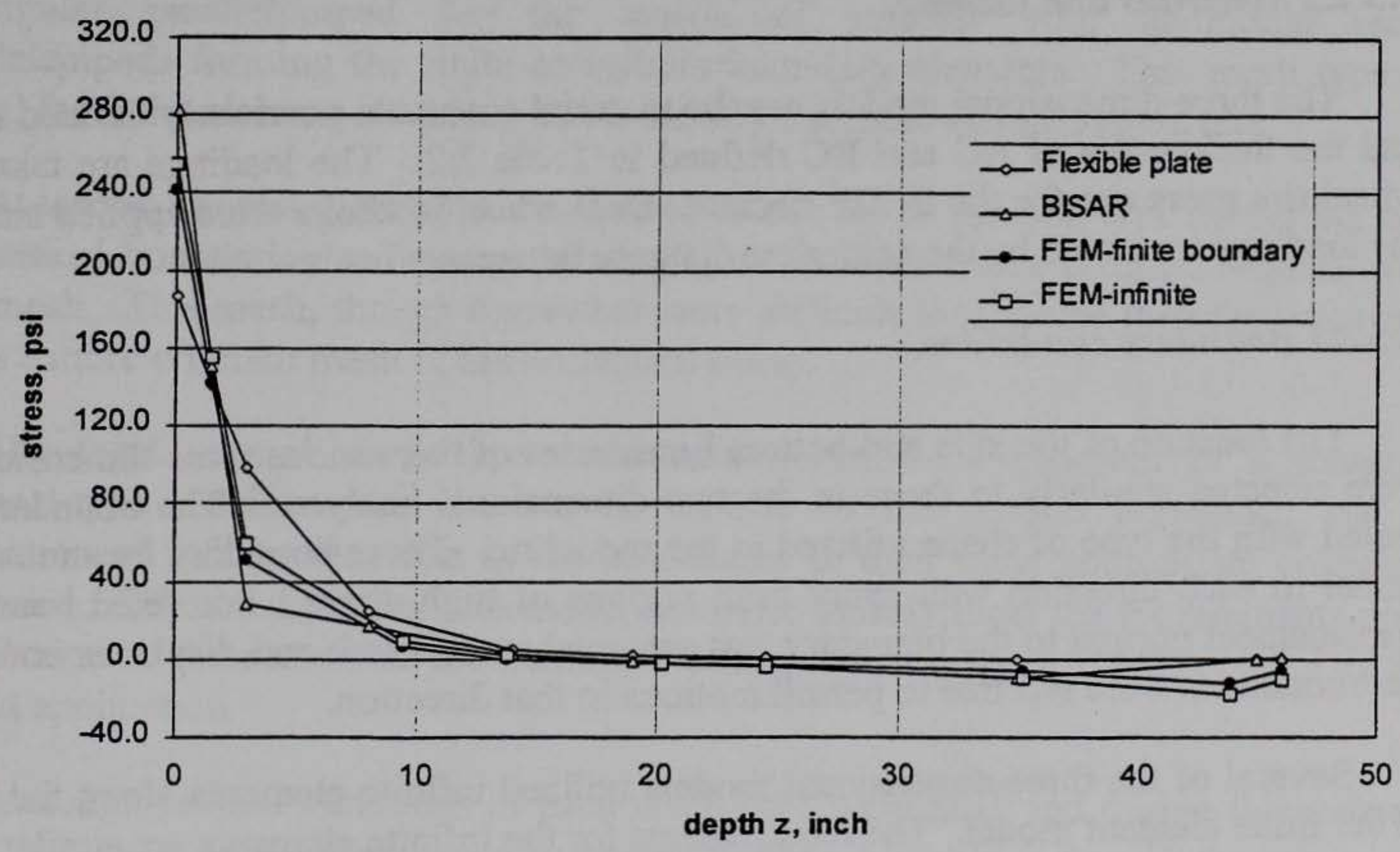

Figure 3.20. Comparisons of horizontal stress from various solution methods. 


\subsubsection{General formulation.}

The finite element models used for three-dimensional analysis utilize three-dimensional solid elements. Mesh configurations vary considerably for the 3-D models. Symmetry of the material layers and loading was considered as appropriate to the single wheel and dual-wheel loadings. For a single wheel load, a one-quarter model with symmetry about the two major vertical planes is efficient. For dual wheel loading, a single vertical plane of symmetry through the center of the two loads, or in some cases, a second vertical plane of symmetry midway between the two loads normal to the line between the loads was utilized. Each plane of symmetry was enforced by restraining the translation normal to the plane.

Based on the observations from the two-dimensional analyses and comparisons, the three-dimensional analyses herein considered only one of the aircraft wheel loadings evaluated in the two-dimensional comparisons. In particular, it was observed in the twodimensional model results that there was little difference in the comparative results for the three different aircraft wheel loadings. Therefore, all comparisons were conducted only for the B-727 wheel loading in the three-dimensional analyses. Although both single and dual wheel loadings were analyzed, results are reported herein only for the cases with single wheel loadings since the dual wheel loading cases showed the same trends and effects as the single wheel cases.

\subsubsection{Materials and loading.}

The three-dimensional models use the material constants previously defined in Table 2.1 and the thicknesses of $\mathrm{AC}$ and $\mathrm{BC}$ defined in Table 2.2. The loadings are taken as single wheel tire pressures for the B-727 aircraft. Dual wheel loadings were applied similarly with the loadings separated by the centerline distance between wheels.

\subsubsection{Boundary conditions.}

The location of the side and bottom boundaries of the various three-dimensional models were selected similarly to those in the two-dimensional analyses. The boundary locations varied with the type of shape utilized in the modeling. These boundary locations extend the model in each direction well away from regions of high stress. For fixed boundaries, the displacement normal to the boundary was assumed zero (fixed) and displacements parallel to the boundaries were left free to permit motions in that direction.

Several of the three-dimensional models utilized infinite elements along the boundaries of the finite element model. The requirements for the infinite elements are similar to those in the axisymmetric analyses, i.e., the infinite elements are directed "away" from the pole and have the far end twice the distance from the pole as the near end. These requirements are difficult to meet exactly for general conditions, e.g., where there is not a well-defined single "pole". In these cases, the requirements were simulated as closely as possible. 


\subsubsection{Finite element mesh.}

Quite a few different finite element meshes were utilized in the three-dimensional analyses. These meshes differed in overall shape, boundary conditions, and mesh fineness. Three general mesh configurations used are illustrated in Figure 3.21 below for reference.

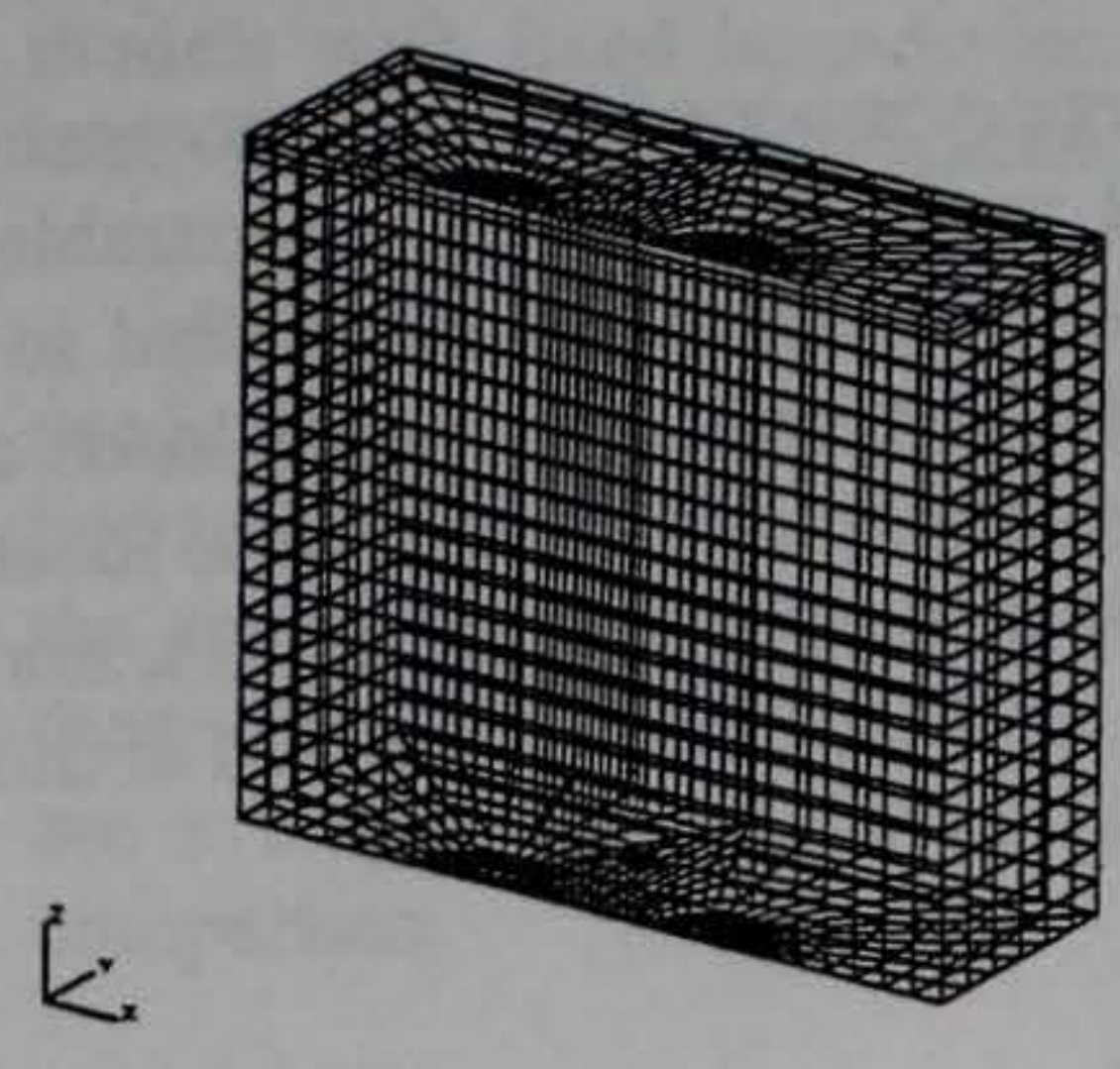

(a) Box-type mesh
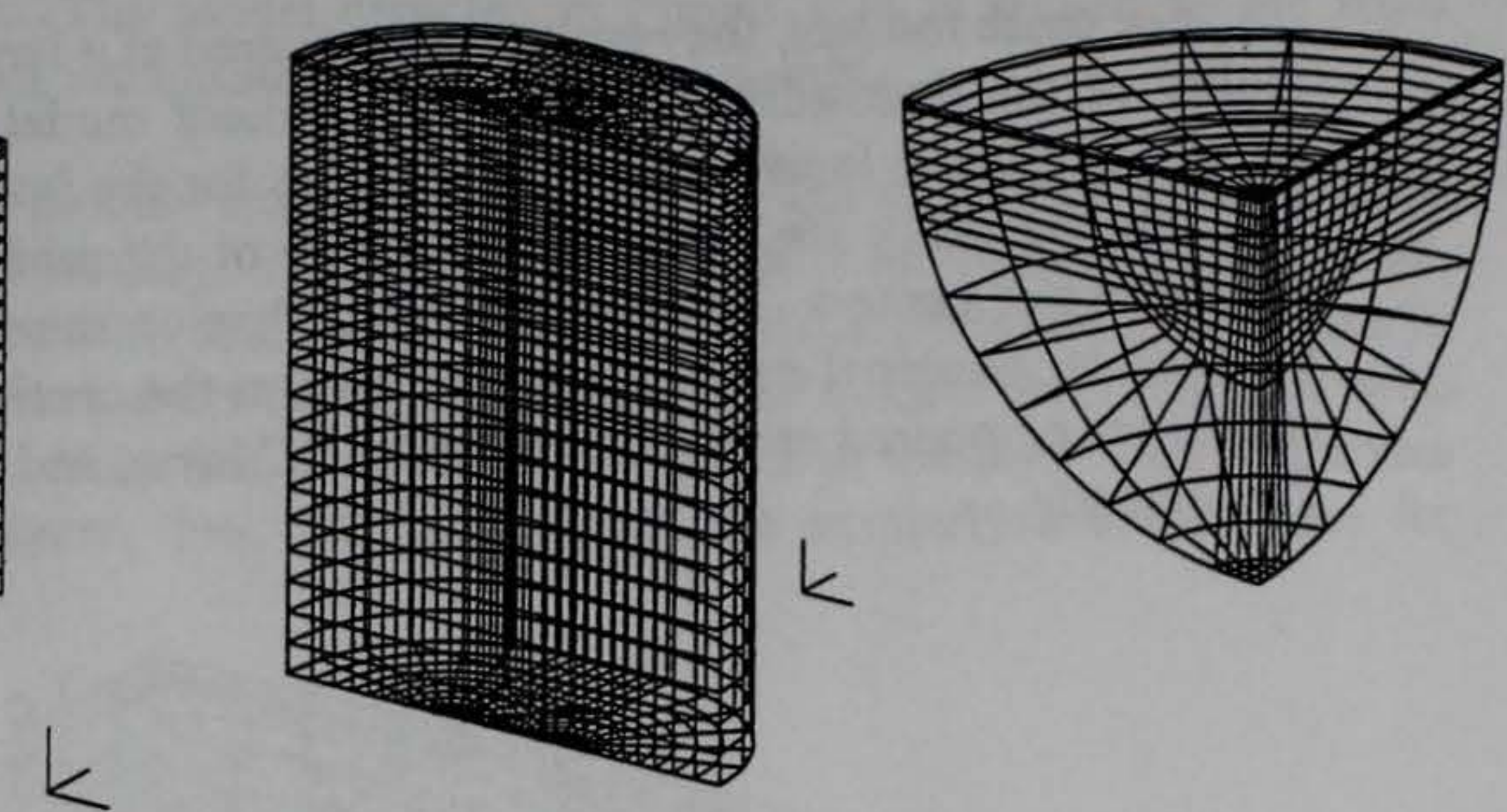

(c) Spherical-type mesh

Figure 3.21. General 3-D finite element mesh types.

The first type of mesh may be described as a box-type model and consists of a rectangular parallelepiped for the region of interest with additional rectangular parallelepipeds forming the finite or infinite boundary elements. This mesh type is fairly typical for finite element modeling and is usually the most simple to generate.

A second general mesh type considered is similar to the box-type model but conforms the vertical boundaries to the circular shape of the loaded area creating a quasi-cylindrical type mesh. This mesh, though somewhat more difficult to generate than the box-type mesh, yields a more efficient mesh in the horizontal plane.

The third general mesh type considered resembles a quadrant of a sphere. This spherical-type mesh carries the curved surface to the second dimension and permits application of infinite elements at the boundaries in their most appropriate orientation and dimension. That is, the infinite elements can more closely meet the requirements previously described as to their location, orientation, and length with respect to the "pole", i.e., the point of load application.

Although several variations of each mesh type were analyzed during the course of this study, results are presented in the following section for only a few of the more important and/or useful variations. These variations are described as appropriate to the understanding of the results in each case. The results are presented in a logical progression, though not necessarily in the order that they were originally developed. 


\subsubsection{Three-dimensional finite element analysis results.}

The extraction of the finite element results and methods of comparison with the Layered Elastic Method results were conducted similarly to that previously described for the twodimensional results. Further, for some cases, results from the third dimension were compared with the LEM results to verify the fidelity of the results in this dimension.

For these models, the results are compared at a large number of locations to examine the ability of the three-dimensional finite element model to predict results comparable to the LEM. The basic locations for comparison for the box-type model are illustrated in Figure 3.22 and generally are along the centerline of the model and under the wheel loads at layer interfaces and centers. In general, vertical displacements are compared at several locations at the surface, principal stresses are compared at the center of the $\mathrm{AC}$ and $\mathrm{BC}$ layers, horizontal strains are compared at the bottom of the $\mathrm{AC}$ layer, and vertical strains compared at the top of the subgrade.

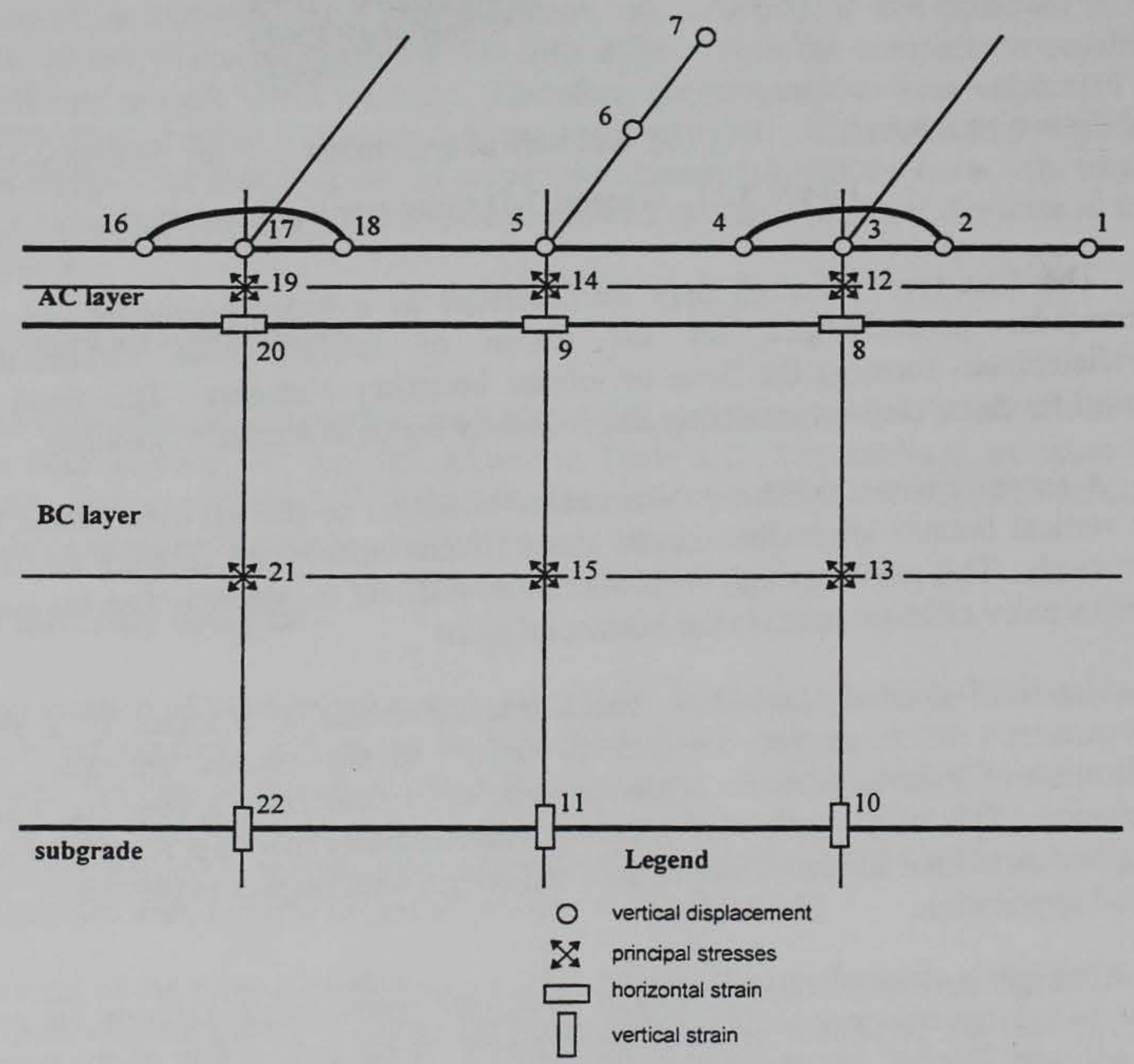

Figure 3.22. Locations for result comparisons. 
The box-type model was analyzed in several configurations, both with fixed boundaries and with infinite elements. The first model, shown in Figure 3.23, utilized only finite elements with the boundaries fixed in a direction normal to the surface. The two semicircular areas at the upper surface are the wheel loaded areas. The model utilizes one plane of symmetry through the two wheel loads. This model serves as the baseline finite element model for this configuration and produced results generally consistent with the axisymmetric models with fixed boundaries. The model depicted in Figure 3.24 is similar to the fixed model except that the boundaries are modeled with infinite elements.

Selected results from both models are shown in Table 3.9 and compared with the LEM predictions for the single wheel loading. This table lists the results for vertical displacement, horizontal and vertical strains, and horizontal and vertical stresses at a number of locations in the model. The computed values from the two finite element models are compared with those from the LEM (BISAR). Note that the FEM strain results at the layer interface nodes are average values between layers, thus, the LEM results are similarly averaged here for comparison.

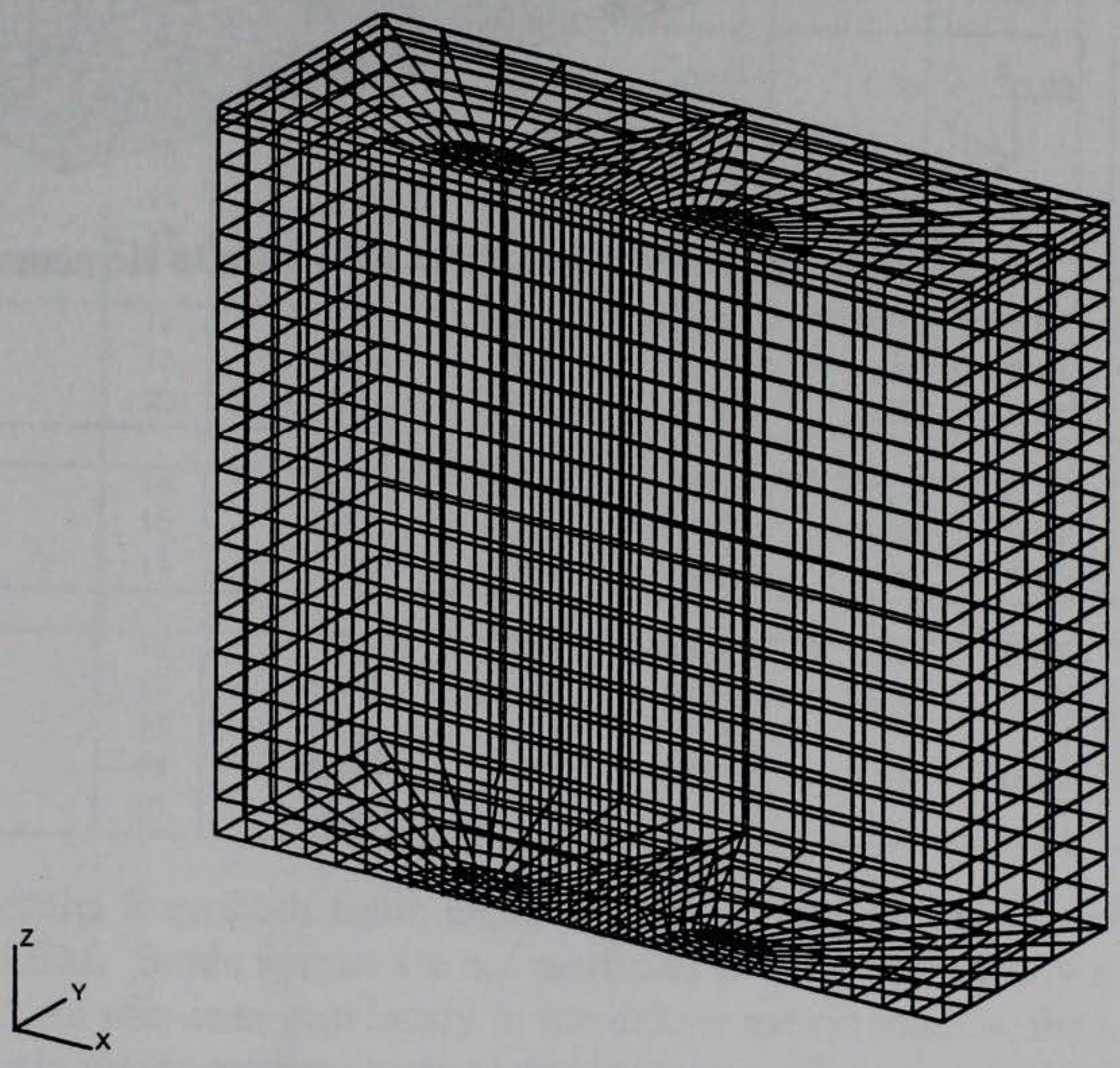

Figure 3.23. Box-type finite element mesh with fixed boundaries. 


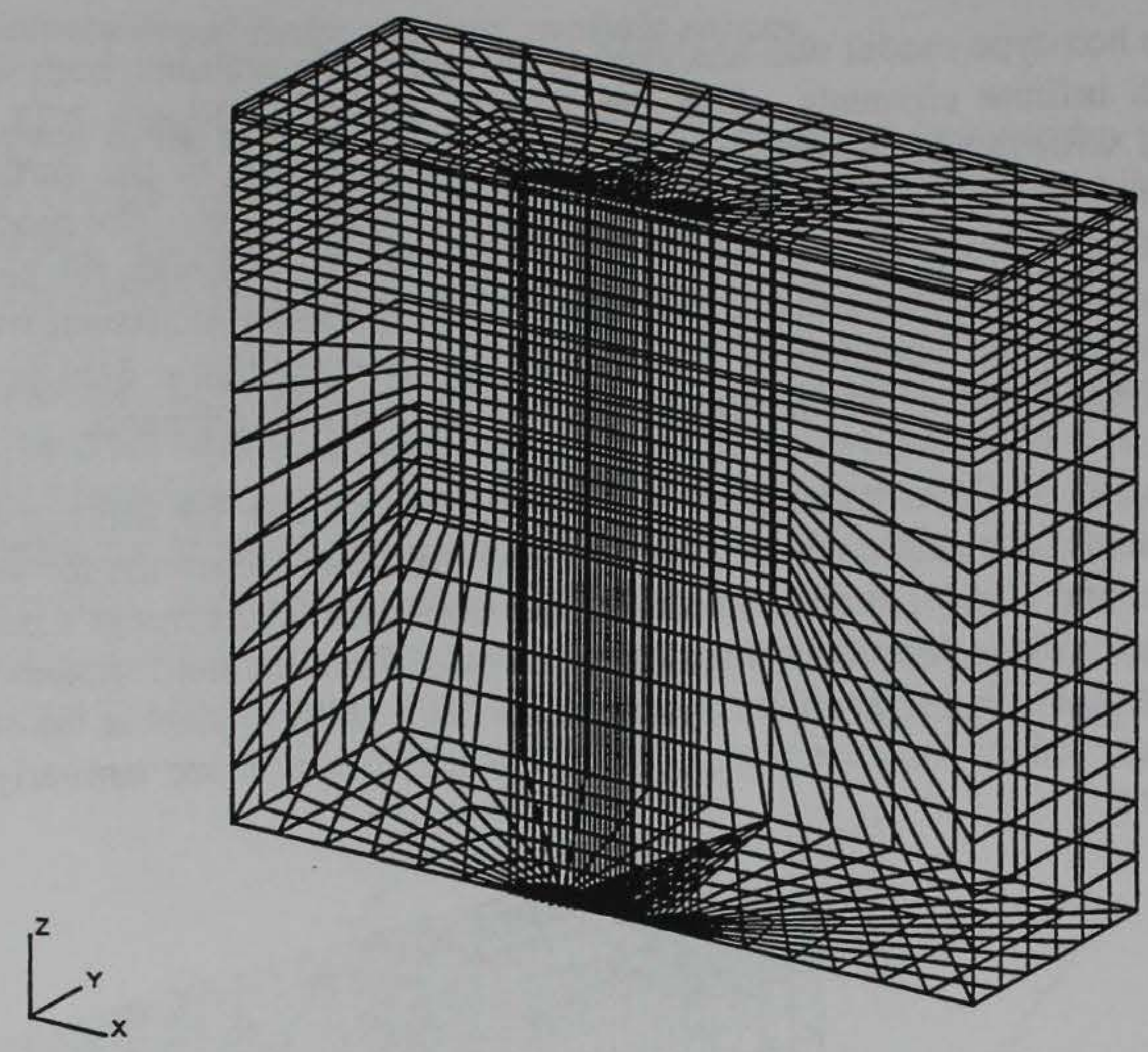

Figure 3.24. Box-type mesh with infinite elements. 
Table 3.9. Results for box-type models with fixed and infinite boundaries.

\begin{tabular}{|c|c|c|c|c|c|c|c|c|}
\hline & & & & & & & \\
\hline & & \multicolumn{7}{|c|}{ single wheelload } \\
\hline & & \multirow{2}{*}{$\begin{array}{r}\text { LEM } \\
\text { BISAR }\end{array}$} & \multicolumn{2}{|c|}{ ABAQUS } & \multicolumn{2}{|c|}{ FEMLEEM } & \multicolumn{2}{|c|}{ Normalized } \\
\hline result vaniable & point & & fixed & infinite, & fixed & infinite & fixed & infinite \\
\hline vertical displacement & 1 & 0.0404 & 0.0247 & 0.0390 & 0.61 & 0.97 & $-25.0 \%$ & $-2.2 \%$ \\
\hline vertical displacement & 2 & 0.0520 & 0.0342 & 0.0503 & 0.66 & 0.97 & $-28.3 \%$ & $-2.7 \%$ \\
\hline vertical displacement & 3 & 0.0628 & 0.0432 & 0.0610 & 0.69 & 0.97 & $-31.2 \%$ & $-2.9 \%$ \\
\hline vertical displacement & 4 & 0.0520 & 0.0313 & 0.0505 & 0.60 & 0.97 & $-33.0 \%$ & $-2.4 \%$ \\
\hline vertical displacement & 5 & 0.0405 & 0.0188 & 0.0393 & 0.46 & 0.97 & $-34.6 \%$ & $-1.9 \%$ \\
\hline vertical displacement & 6 & 0.0370 & 0.0162 & 0.0358 & 0.44 & 0.97 & $-33.1 \%$ & $-1.9 \%$ \\
\hline vertical displacement & 7 & 0.0329 & 0.0148 & 0.0317 & 0.45 & 0.96 & $-28.8 \%$ & $-1.9 \%$ \\
\hline & & & & & & & & \\
\hline horizontal strain & 8 & 148 & & & & & & \\
\hline horizontal strain & 8 & 148 & 118 & 143 & 0.80 & 0.97 & $-20.3 \%$ & $-3.4 \%$ \\
\hline horizontal strain & 8 & 148 & & & & & & \\
\hline horizontal strain & 9 & -146 & & & & & & \\
\hline horizontal strain & 9 & -146.5 & -97 & -145 & 0.66 & 0.99 & $33.4 \%$ & $1.0 \%$ \\
\hline horizontal strain & 9 & -147 & & & & & & \\
\hline & & & & & & & & \\
\hline vertical strain & 10 & -184 & & & & & & \\
\hline vertical strain & 10 & -286 & -310 & -264 & 1.08 & 0.92 & $8.4 \%$ & $-7.7 \%$ \\
\hline vertical strain & 10 & -388 & & & & & & \\
\hline vertical strain & 11 & -144 & & & & & & \\
\hline vertical strain & 11 & -226 & -230 & -209 & 1.02 & 0.92 & $1.8 \%$ & $-7.5 \%$ \\
\hline vertical strain & 11 & -308 & & & & & & \\
\hline & & & & & & & & \\
\hline vertical stress, z & 12 & -197 & -196.3 & -196.3 & 1.00 & 1.00 & $0.4 \%$ & $0.4 \%$ \\
\hline vertical stress, z & 13 & -25.9 & -28.3 & -25.4 & 1.09 & 0.98 & $-1.2 \%$ & $0.3 \%$ \\
\hline vertical stress, $z$ & 10 & -2.6 & -8.39 & -3.15 & 3.23 & 1.21 & $-2.9 \%$ & $-0.3 \%$ \\
\hline & & & & & & & & \\
\hline vertical stress, z & 14 & -0.16 & -0.004 & 0.029 & 0.03 & -0.18 & $0.1 \%$ & $0.1 \%$ \\
\hline vertical stress, $z$ & 15 & -10.3 & -12.86 & -10.15 & 1.25 & 0.99 & $-1.3 \%$ & $0.1 \%$ \\
\hline vertical stress, $z$ & 11 & -2.19 & -7.36 & -2.53 & 3.36 & 1.16 & $-2.6 \%$ & $-0.2 \%$ \\
\hline & & & & $100 \mathrm{a}$ & & 000 & & $07 \%$ \\
\hline horiz. stress, $x$ & $\begin{array}{l}12 \\
13\end{array}$ & $\begin{array}{l}-150 \\
3.75\end{array}$ & $\begin{array}{r}-135 \\
0.916\end{array}$ & $\begin{array}{r}-148.6 \\
3.53\end{array}$ & $\begin{array}{l}0.90 \\
0.24\end{array}$ & $\begin{array}{l}0.99 \\
0.94\end{array}$ & $\begin{array}{r}7.5 \% \\
-1.4 \%\end{array}$ & $\begin{array}{r}0.7 \% \\
-0.1 \%\end{array}$ \\
\hline $\begin{array}{l}\text { horiz. stress, } x \\
\text { horiz. stress, } x\end{array}$ & $\begin{array}{l}13 \\
10\end{array}$ & $\begin{array}{l}3.15 \\
21.2\end{array}$ & 0.910 & & 0.24 & 0.94 & $-1.4 \%$ & $-0.1 \%$ \\
\hline $\begin{array}{l}\text { horiz. stress, } x \\
\text { horiz. stress, } x\end{array}$ & 10 & 10.45 & 1.85 & 8.92 & 0.18 & 0.85 & $-4.3 \%$ & $-0.8 \%$ \\
\hline $\begin{array}{l}\text { horiz. stress, } x \\
\text { horiz. stress, } x\end{array}$ & 10 & -0.3 & & & & & & \\
\hline horiz. stress, $x$ & & & & & & & & \\
\hline
\end{tabular}

The stress results from both finite element models compare very favorably with those predicted by the LEM. Strain results are not predicted as well, particularly in the model with fixed boundaries. As was seen previously in the axisymmetric models, the model with fixed boundaries seriously under-predicts vertical displacement. The model with infinite elements at the boundaries predicts all quantities very well. For example, the predictions for vertical displacement at the surface are compared in Figure 3.25. This comparison indicates that the use of infinite elements produces exceptional agreement. 


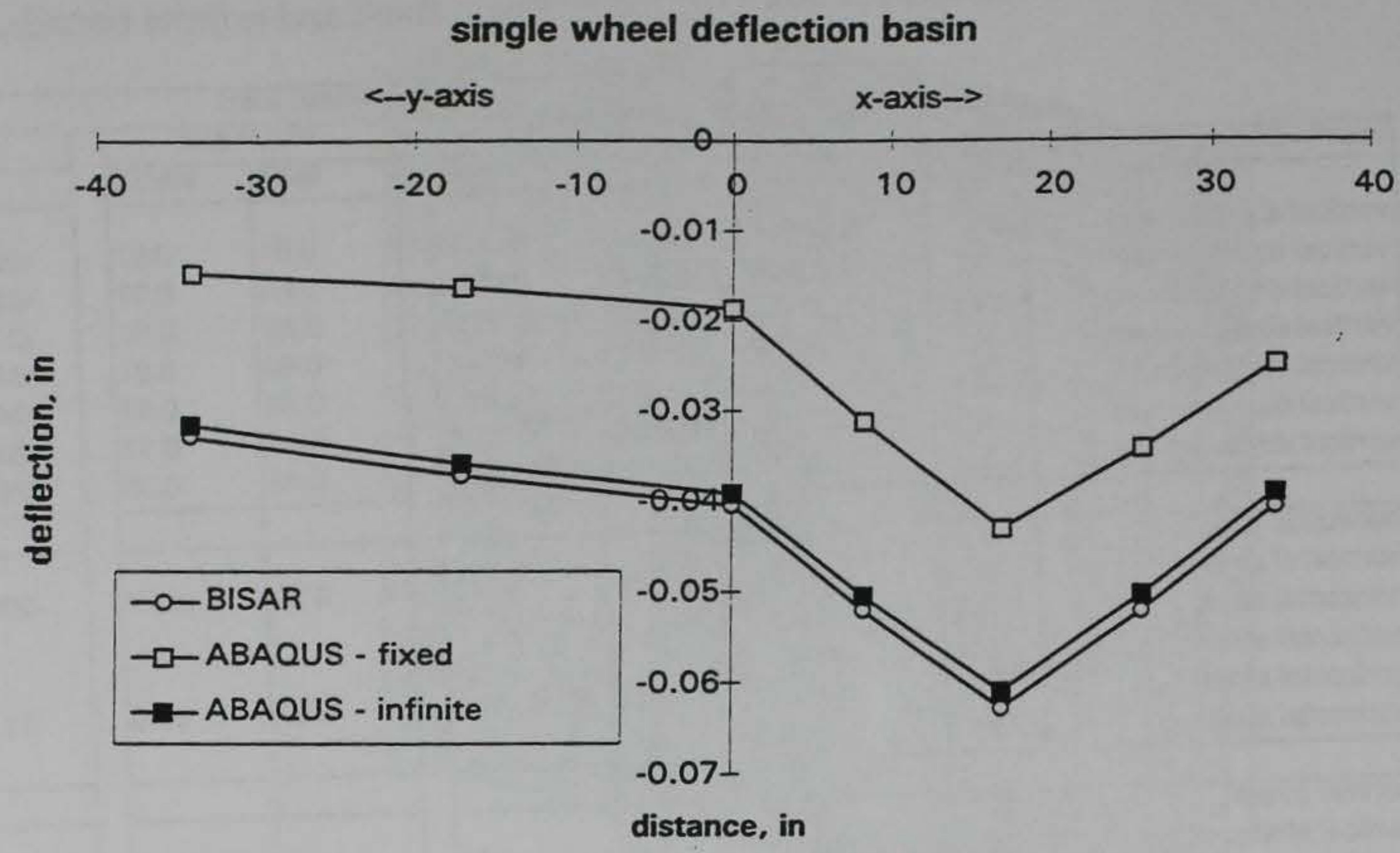

Figure 3.25. Comparisons of predicted deflection basin.

Note that the plot of deflection basin in Figure 3.25 is actually in two horizontal directions. The displacements are plotted at points 1 through 7 , from right to left on the plot. Thus, the "positive" distance values are along the $x$-axis (points 1-5), and the "negative" distance values are along the $y$-axis (points 5-7). This plot clearly indicates the improvement in prediction of vertical displacement provided by the use of infinite elements to model the boundaries.

The box-type mesh was also utilized to consider a slight variation in the mesh in the area of the pressure loading. Whereas the loaded area in the previous models conformed to the assumed circular shape as shown in Figure 3.26(a), the new variation of the mesh in the loaded area is rectilinear as shown in Figure 3.26(b). The shaded area of the mesh was loaded to produce the same total load. The results of this analysis are compared in Table 3.10 to those of the previous model to determine the effect of this slight load pattern variation. As seen in this comparison, the effects of the mesh variation are very small. Revision of the mesh to this degree does not significantly affect the predicted results, i.e., for this case, the simpler rectilinear mesh is adequate for the analysis. It should be noted that the revised mesh is actually quite fine and the boundaries of the loaded area do not diverge greatly from the circular area. Larger variations in the mesh arrangement or load footprint might induce larger differences in the results. 


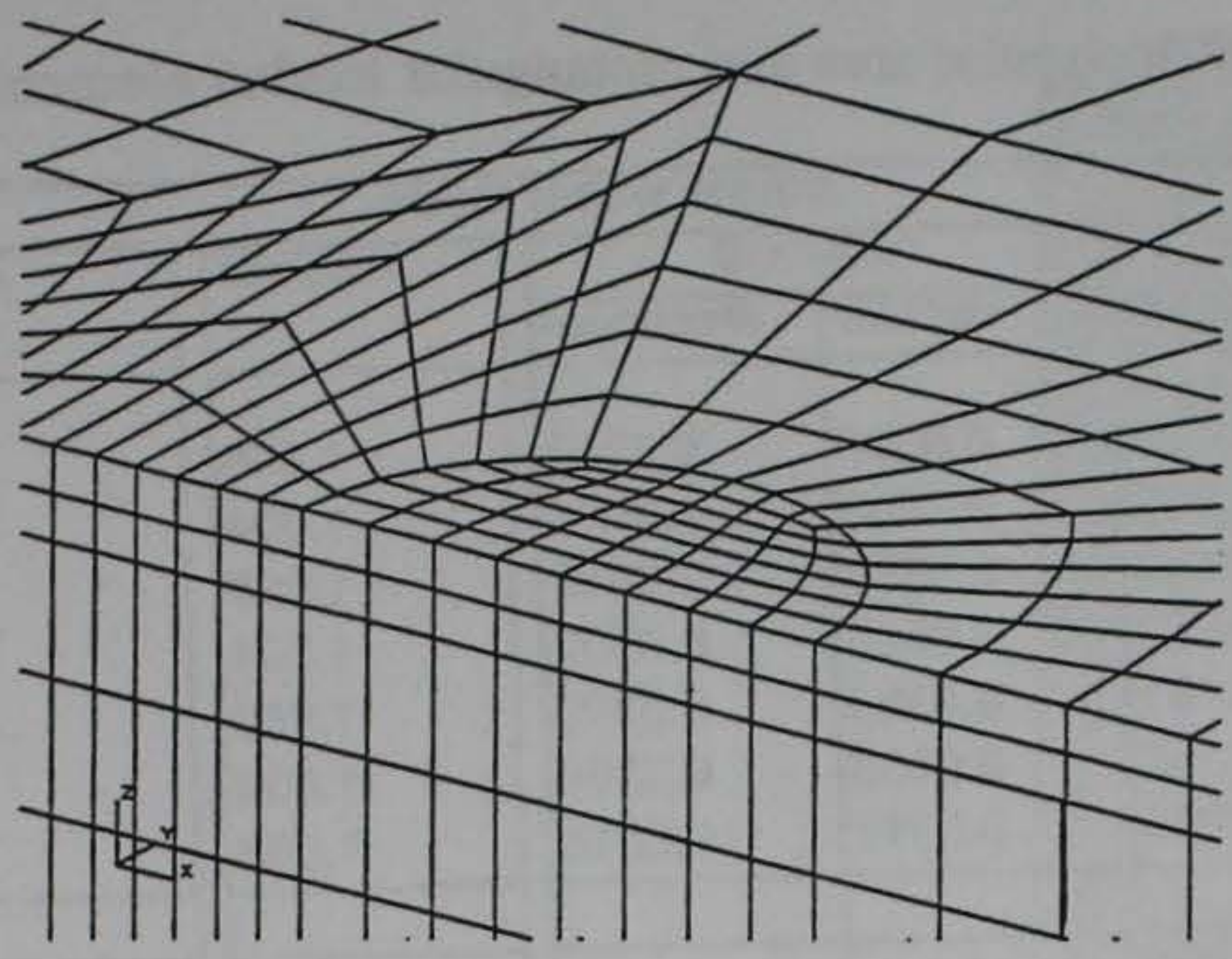

(a) Circular loaded area.

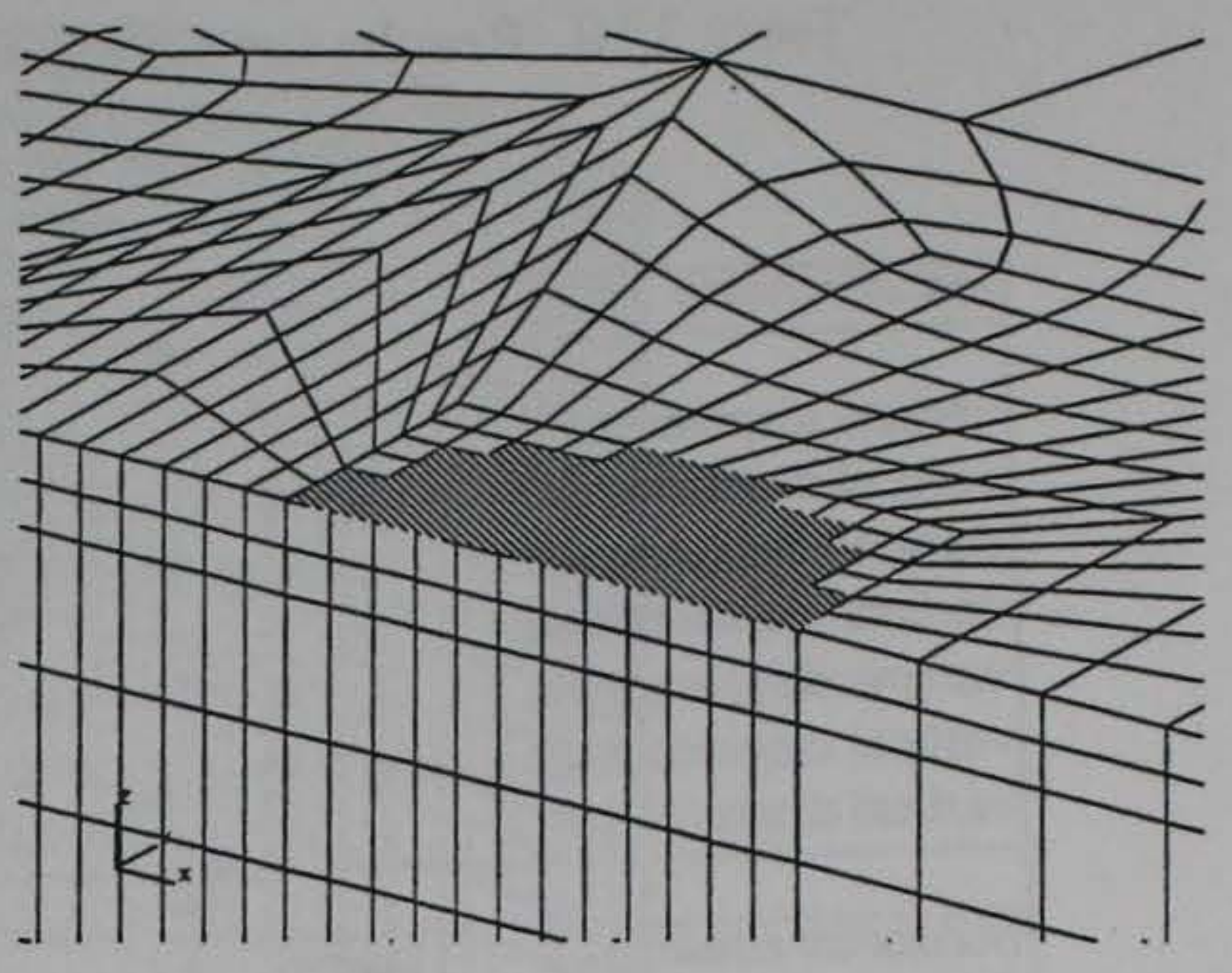

(b) Rectilinear loaded elements.

Figure 3.26. Box-type models with different meshes in loaded area.

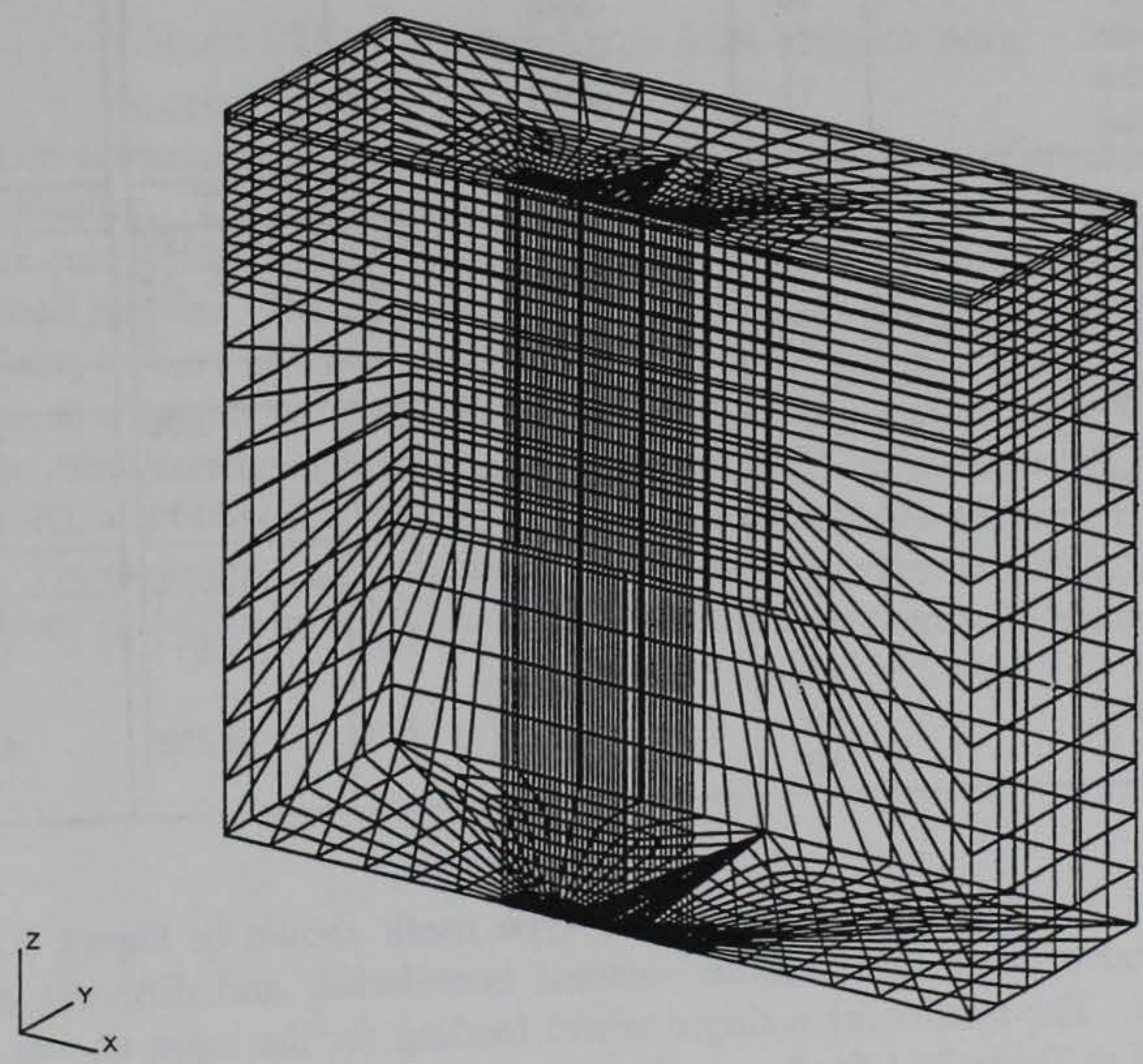

Figure 3.27. Box-type mesh with infinite and rectangular loaded elements. 
Table 3.10. Results for models with circular area and rectangular loaded elements.

\begin{tabular}{|c|c|c|c|c|c|c|}
\hline \multirow[b]{3}{*}{ result variable } & \multirow[b]{3}{*}{ point } & \multicolumn{5}{|c|}{ single wheel loads } \\
\hline & & \multirow[b]{2}{*}{ BISAR } & \multicolumn{2}{|c|}{ ABAQUS } & \multirow[t]{2}{*}{ rect/circ } & \multirow[t]{2}{*}{$\bar{\lambda}$} \\
\hline & & & circular & rectilinear & & \\
\hline vertical displacement & 1 & 0.0404 & 0.0390 & 0.0392 & 1.005 & $0.3 \%$ \\
\hline vertical displacement & 2 & 0.052 & 0.0503 & 0.0505 & 1.004 & $0.3 \%$ \\
\hline vertical displacement & 3 & 0.0628 & 0.0610 & 0.0615 & 1.008 & $0.8 \%$ \\
\hline vertical displacement & 4 & 0.052 & 0.0505 & 0.0507 & 1.004 & $0.3 \%$ \\
\hline vertical displacement & 5 & 0.0405 & 0.0393 & 0.0395 & 1.005 & $0.3 \%$ \\
\hline vertical displacement & 6 & 0.037 & 0.0358 & 0.0360 & 1.006 & $0.3 \%$ \\
\hline vertical displacement & 7 & 0.0329 & 0.0317 & 0.0318 & 1.003 & $0.2 \%$ \\
\hline horizontal strain & 8 & 148 & & & & \\
\hline horizontal strain & 8 & 148 & 143 & 144 & 1.007 & $0.7 \%$ \\
\hline horizontal strain & 8 & 148 & & & & \\
\hline horizontal strain & 9 & -146 & & & & \\
\hline horizontal strain & 9 & -146.5 & -145 & -145 & 1.000 & $0.0 \%$ \\
\hline horizontal strain & 9 & -147 & & & & \\
\hline vertical strain & 10 & -184 & & & & \\
\hline vertical strain & 10 & -286 & -264 & -265 & 1.004 & $-0.3 \%$ \\
\hline vertical strain & 10 & -388 & & & & \\
\hline vertical strain & 11 & -144 & & & & \\
\hline vertical strain & 11 & -226 & -209 & -210.2 & 1.006 & $-0.4 \%$ \\
\hline vertical strain & 11 & -308 & & & & \\
\hline vertical stress, z & 12 & -197 & -196 & -199 & 1.012 & $1.2 \%$ \\
\hline vertical stress, z & 13 & -25.9 & -25 & -26 & 1.007 & $0.1 \%$ \\
\hline vertical stress, $z$ & 10 & -2.6 & -3.15 & -3 & 1.006 & $0.0 \%$ \\
\hline vertical stress, z & 14 & -0.16 & 0.029 & 0.08 & 2.759 & $0.0 \%$ \\
\hline vertical stress, z & 15 & -10.3 & -10.15 & -10.17 & 1.002 & $0.0 \%$ \\
\hline vertical stress, z & 11 & -2.19 & -2.53 & -2.539 & 1.004 & $0.0 \%$ \\
\hline horiz. stress, $x$ & 12 & -150 & -148.6 & -151.1 & 1.017 & $1.3 \%$ \\
\hline horiz. stress, $x$ & 13 & 3.75 & 3.53 & 3.611 & 1.023 & $0.0 \%$ \\
\hline horiz. stress, $x$ & 10 & 21.2 & & & & \\
\hline horiz. stress, $x$ & 10 & 10.45 & 8.92 & 8.986 & 1.007 & $0.0 \%$ \\
\hline horiz. stress, $x$ & 10 & -0.3 & & & & \\
\hline
\end{tabular}

Several variations of the cylindrical-type mesh shown in Figure 3.28 were analyzed, which included fixed and infinite element boundaries, and different mesh fineness and orientations. The results for a single wheel loading for the mesh shown in Figure 3.28 are summarized in Table 3.11 for "coarse" and "refined" meshes with fixed boundary conditions. These comparisons are made at a number of the general locations previously depicted in Figure 3.22. 


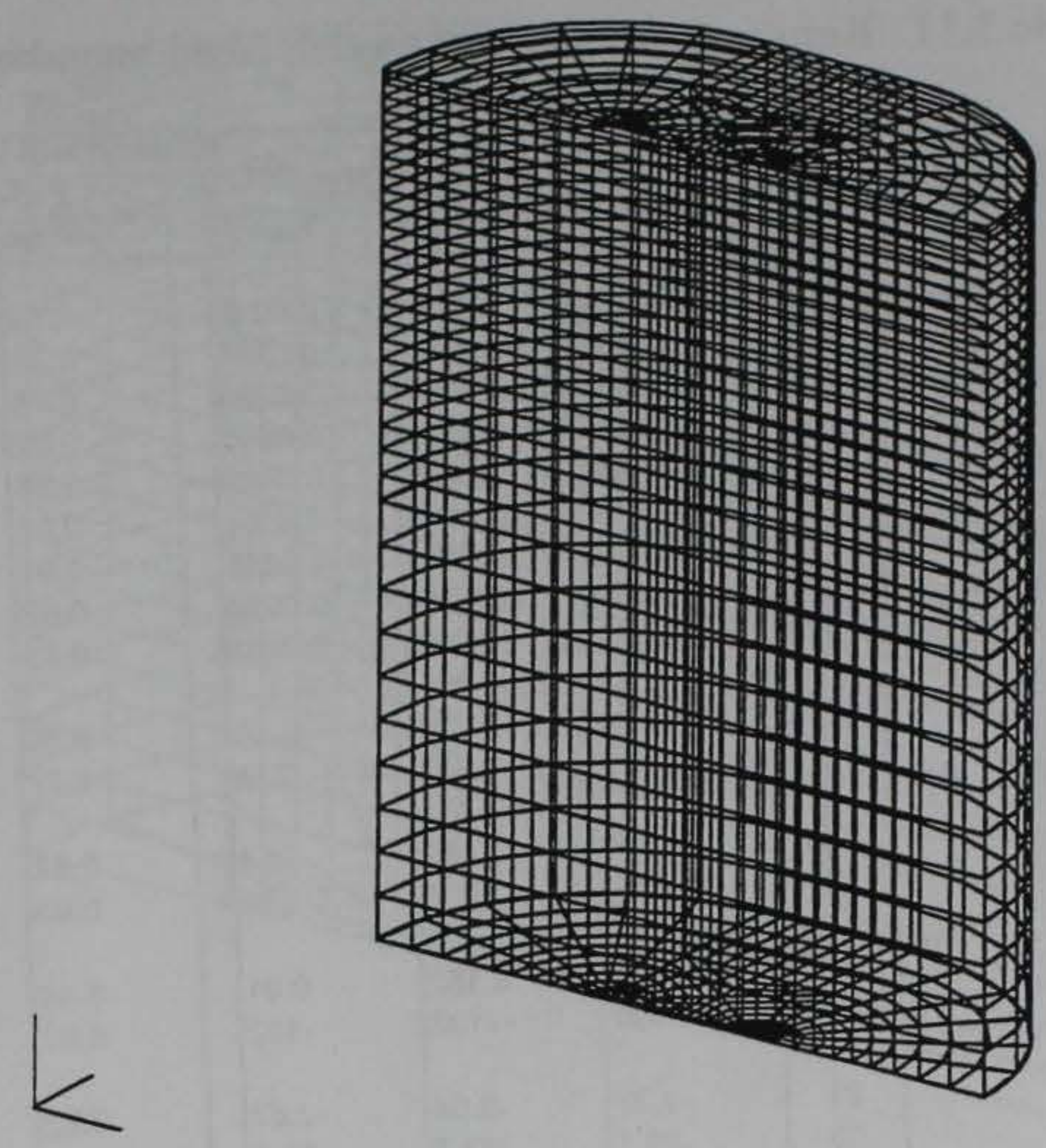

Figure 3.28. Cylindrical-type finite element mesh.

The first two columns in Table 3.11 describe the type of result (displacement, strain, or stress) and the location. The third column lists the LEM results from BISAR. Columns four and five list the comparable results determined from the FEM (ABAQUS) analyses for the coarse and refined meshes. The absolute ratios (FEM/LEM) and the normalized differences indicate the fidelity of the FEM results for the two meshes. The comparison of results for the two different mesh densities with the results from BISAR are quite consistent with previous results for other mesh configurations. Specifically, stresses are predicted fairly well, strains predicted less well, and vertical displacements under-predicted. In addition, the refined mesh shows a slight improvement in predictions (convergence). The boundary conditions and boundary locations appear to be the cause for most of the discrepancy in results. 
Table 3.11. Results for cylindrical model, fixed boundaries, single wheel load.

\begin{tabular}{|c|c|c|c|c|c|c|c|c|}
\hline \multirow[b]{3}{*}{ result variable } & \multirow[b]{3}{*}{ point } & \multicolumn{7}{|c|}{ single wheel load } \\
\hline & & \multirow[b]{2}{*}{ BISAR } & \multicolumn{2}{|c|}{ ABAQUS } & \multicolumn{2}{|c|}{ FEMULEM } & \multicolumn{2}{|c|}{$\lambda$} \\
\hline & & & coarse & refined & coarse & refined & coarse & refined \\
\hline vertical displacement & 16 & 0.0318 & 0.0234 & 0.0245 & 0.74 & 0.77 & $-13.4 \%$ & $-11.6 \%$ \\
\hline vertical displacement & 17 & 0.0339 & 0.0256 & 0.0268 & 0.76 & 0.79 & $-13.2 \%$ & $-11.3 \%$ \\
\hline vertical displacement & 18 & 0.0366 & 0.0286 & 0.0299 & 0.78 & 0.82 & $-12.7 \%$ & $-10.7 \%$ \\
\hline vertical displacement & 5 & 0.0405 & 0.0332 & 0.0345 & 0.82 & 0.85 & $-11: 6 \%$ & $-9.6 \%$ \\
\hline vertical displacement & 4 & 0.0520 & 0.0455 & 0.0469 & 0.88 & 0.90 & $-10.4 \%$ & $-8.1 \%$ \\
\hline vertical displacement & 3 & 0.0628 & 0.0569 & 0.0584 & 0.91 & 0.93 & $-9.4 \%$ & $-7.0 \%$ \\
\hline vertical displacement & 2 & 0.0520 & 0.0474 & 0.0488 & 0.91 & 0.94 & $-7.3 \%$ & $-5.1 \%$ \\
\hline vertical displacement & 6 & 0.0381 & 0.0311 & 0.0324 & 0.82 & 0.85 & $-11.1 \%$ & $-9.1 \%$ \\
\hline vertical displacement & 7 & 0.0347 & 0.0288 & 0.0301 & 0.83 & 0.87 & $-9.4 \%$ & $-7.3 \%$ \\
\hline horizontal strain & 20 & 30 & 21 & 19 & 0.70 & 0.63 & $-6.1 \%$ & $-7.4 \%$ \\
\hline horizontal strain & 8 & 148 & 217 & 214 & 1.47 & 1.45 & $46.6 \%$ & $44.6 \%$ \\
\hline vertical strain & 22 & -185 & -97 & -98.4 & 0.52 & 0.53 & $-22.7 \%$ & $-22.3 \%$ \\
\hline vertical strain & 10 & -388 & -251 & -258 & 0.65 & 0.66 & $-35.3 \%$ & $-33.5 \%$ \\
\hline vertical stress, z & 19 & 0.018 & 0.152 & 0.01 & 8.44 & 0.56 & $-0.1 \%$ & $0.0 \%$ \\
\hline vertical stress, z & 12 & -197 & -192 & -192 & 0.97 & 0.97 & $-2.5 \%$ & $-2.5 \%$ \\
\hline vertical stress, z & 21 & -1.37 & -3.04 & -2.67 & 2.22 & 1.95 & $0.8 \%$ & $0.7 \%$ \\
\hline vertical stress, z & 13 & -23.1 & -23.7 & -23.8 & 1.03 & 1.03 & $0.3 \%$ & $0.4 \%$ \\
\hline horiz. stress, $x$ & 19 & -11.8 & -8.81 & -7.49 & 0.75 & 0.63 & $-1.5 \%$ & $-2.2 \%$ \\
\hline horiz. stress, $x$ & 12 & -150 & -134 & -135 & 0.89 & 0.90 & $-8.0 \%$ & $-7.5 \%$ \\
\hline horiz. stress, $x$ & 21 & -1.3 & -1.98 & -2.15 & 1.52 & 1.65 & $0.3 \%$ & $0.4 \%$ \\
\hline horiz. stress, X & 13 & 4.33 & 4.27 & 3.82 & 0.99 & 0.88 & $0.0 \%$ & $0.3 \%$ \\
\hline
\end{tabular}

Three variations of this model were analyzed considering different arrangements of infinite elements along the boundaries. First, the basic model was augmented with horizontal infinite elements along the vertical boundaries as shown in Figure 3.29, with the vertical displacements along the bottom remaining fixed. Second, a model with fixed horizontal displacements along the sides and vertical infinite elements only along the bottom was considered. Finally, a model with horizontal and vertical elements along the sides and bottom, respectively, was analyzed. These three variations on the application of infinite elements provide some indication as to the use of infinite elements only on some of the boundaries. 


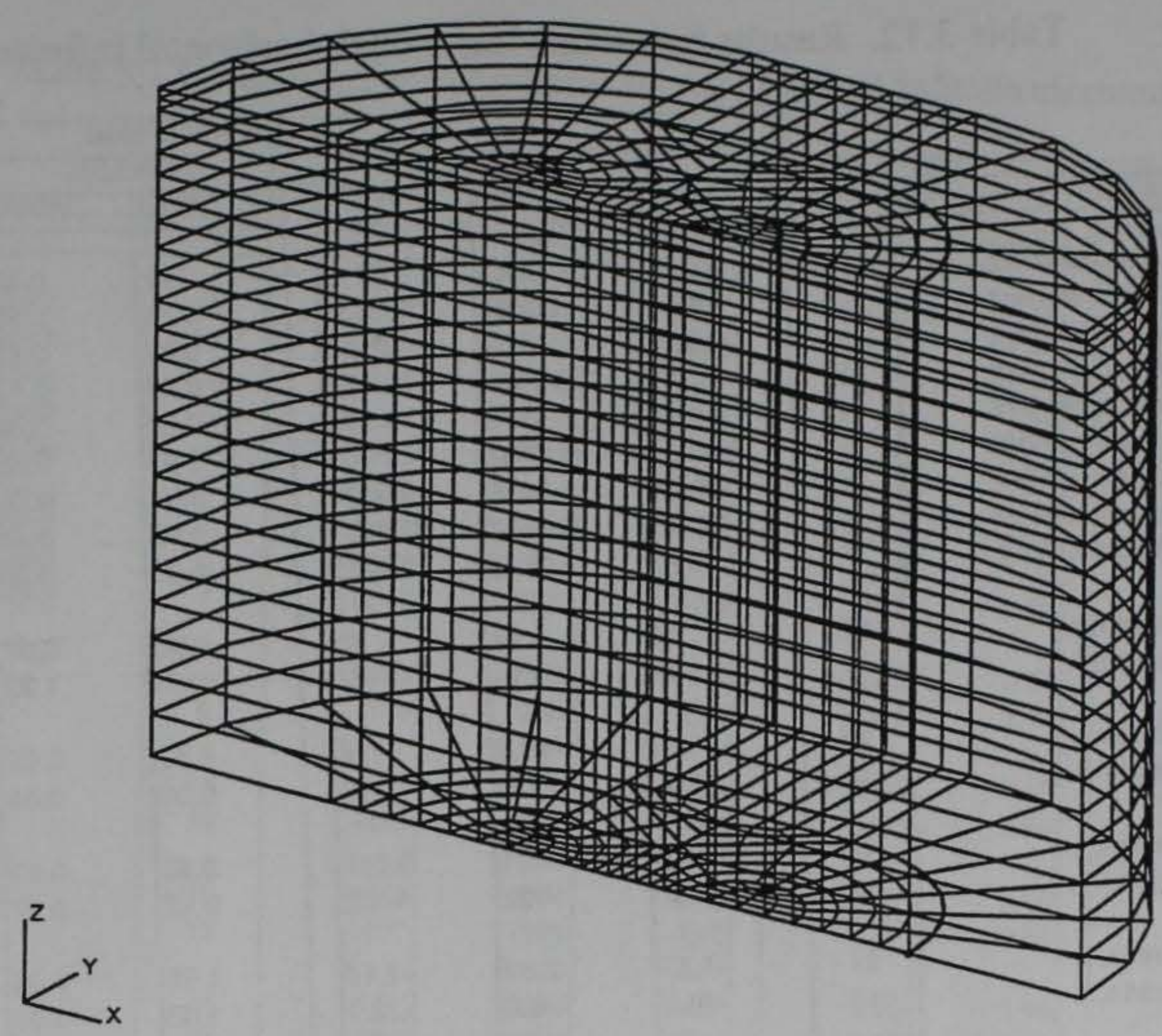

Figure 3.29. Cylindrical-type mesh with horizontal infinite elements.

The results for the model with horizontal infinite elements (Figure 3.29) only are compared with the LEM results in Table 3.12. As shown in these results, the addition of infinite elements along the sides actually makes little difference in the stress and strain results. Some predictions are slightly improved but most are little changed. The largest difference in results is the considerable under-prediction of vertical displacements in the model with horizontal infinite elements, as compared to the fixed boundary model. Actually, this result is not too surprising if one considers the actual boundary conditions modeled in each case. In the "fixed" boundary model, whereas the horizontal displacement along the side boundary is fixed, the vertical displacement is unrestrained. Although the horizontal infinite elements relax the restraint in the horizontal direction, they add a measure of restraint in the vertical direction. Thus, for prediction of vertical displacements, the bottom boundary remains fixed and the side boundaries offer more vertical restraint than the "fixed" model. The effectiveness of the infinite elements in this model is also reduced by the totally horizontal orientation of the elements. Although this orientation is reasonable in the upper portion, the element lengths and orientation in the lower portion of the model violate the requirements that infinite elements generally radiate away from the "pole" with a length equal to their distance from the pole. 
Table 3.12. Results for cylindrical model, horizontal infinite elements.

\begin{tabular}{|c|c|c|c|c|c|c|c|c|}
\hline \multirow[b]{3}{*}{ result variable } & \multirow[b]{3}{*}{ point } & \multicolumn{7}{|c|}{ single wheel load } \\
\hline & & \multirow[b]{2}{*}{ BISAR } & \multicolumn{2}{|c|}{ ABAQUS } & \multicolumn{2}{|c|}{ FEM/LEM } & \multicolumn{2}{|c|}{$\pi$} \\
\hline & & & fixed & infinite & fixed & infinite & fixed & infinite \\
\hline vertical displacement & 16 & 0.0318 & 0.0245 & 0.0110 & 0.77 & 0.35 & $-11.6 \%$ & $-33.1 \%$ \\
\hline vertical displacement & 17 & 0.0339 & 0.0268 & 0.0129 & 0.79 & 0.38 & $-11.3 \%$ & $-33.4 \%$ \\
\hline vertical displacement & 18 & 0.0366 & 0.0299 & 0.0153 & 0.82 & 0.42 & $-10.7 \%$ & $-33.9 \%$ \\
\hline vertical displacement & 5 & 0.0405 & 0.0345 & 0.0192 & 0.85 & 0.47 & $-9.6 \%$ & $-33.9 \%$ \\
\hline vertical displacement & 4 & 0.0520 & 0.0469 & 0.0305 & 0.90 & 0.59 & $-8.1 \%$ & $-34.2 \%$ \\
\hline vertical displacement & 3 & 0.0628 & 0.0584 & 0.0408 & 0.93 & 0.65 & $-7.0 \%$ & $-35.0 \%$ \\
\hline vertical displacement & 2 & 0.0520 & 0.0488 & 0.0300 & 0.94 & 0.58 & $-5.1 \%$ & $-35.0 \%$ \\
\hline vertical displacement & 6 & 0.0381 & 0.0324 & 0.0167 & 0.85 & 0.44 & $-9.1 \%$ & $-34.1 \%$ \\
\hline vertical displacement & 7 & 0.0347 & 0.0301 & 0.0135 & 0.87 & 0.39 & $-7.3 \%$ & $-33.8 \%$ \\
\hline horizontal strain & 20 & 30 & 19 & 20 & 0.63 & 0.67 & $-7.4 \%$ & $-6.8 \%$ \\
\hline horizontal strain & 8 & 148 & 214 & 197 & 1.45 & 1.33 & $44.6 \%$ & $33.1 \%$ \\
\hline vertical strain & 22 & -185 & -98.4 & -114 & 0.53 & 0.62 & $-22.3 \%$ & $-18.3 \%$ \\
\hline vertical strain & 10 & -388 & -258 & -252 & 0.66 & 0.65 & $-33.5 \%$ & $-35.1 \%$ \\
\hline vertical stress, z & 19 & 0.018 & 0.01 & 0.015 & 0.56 & 0.83 & $0.0 \%$ & $0.0 \%$ \\
\hline vertical stress, z & 12 & -197 & -192 & -192 & 0.97 & 0.97 & $-2.5 \%$ & $-2.5 \%$ \\
\hline vertical stress, z & 21 & -1.37 & -2.67 & -1.15 & 1.95 & 0.84 & $0.7 \%$ & $-0.1 \%$ \\
\hline vertical stress, z & 13 & -23.1 & -23.8 & -22.1 & 1.03 & 0.96 & $0.4 \%$ & $-0.5 \%$ \\
\hline horiz. stress, x & 19 & -11.8 & -7.49 & -8.21 & 0.63 & 0.70 & $-2.2 \%$ & $-1.8 \%$ \\
\hline horiz. stress, $x$ & 12 & -150 & -135 & -145 & 0.90 & 0.97 & $-7.5 \%$ & $-2.5 \%$ \\
\hline horiz. stress, $x$ & 21 & -1.3 & -2.15 & -1.08 & 1.65 & 0.83 & $0.4 \%$ & $-0.1 \%$ \\
\hline horiz. stress, $x$ & 13 & 4.33 & 3.82 & 4.41 & 0.88 & 1.02 & $0.3 \%$ & $0.0 \%$ \\
\hline
\end{tabular}

The results for the model with vertical infinite elements only are compared with the LEM results in Table 3.13. As shown in these results, the addition of infinite elements at the base makes little difference in the stress and strain results. The prediction of vertical displacements in the model with vertical-only infinite elements is quite poor and is quite a bit higher than the LEM results. The model with infinite elements at the base is more flexible than the "fixed" boundary model at the base and adds no vertical restraint along the vertical sides. Thus, for prediction of vertical displacements, the free side boundary combined with the vertical infinite elements leads to higher displacements than the LEM model which has some vertical restraint along the sides. Note that the vertical infinite elements also do not meet the requirements regarding length and orientation as described previously. 
Table 3.13. Results for cylindrical model, vertical infinite elements.

\begin{tabular}{|c|c|c|c|c|c|c|c|c|}
\hline \multirow[b]{3}{*}{ result variable } & \multirow[b]{3}{*}{ point } & \multicolumn{7}{|c|}{ single wheel load } \\
\hline & & \multirow[b]{2}{*}{ BISAR } & \multicolumn{2}{|c|}{ ABAQUS } & \multicolumn{2}{|c|}{ FEM/LEM } & \multicolumn{2}{|c|}{$\lambda$} \\
\hline & & & fixed & infinite & fixed & infinite & fixed & infinite \\
\hline vertical displacement & 16 & 0.0318 & 0.0245 & 0.0497 & 0.77 & 1.56 & $-11.6 \%$ & $28.5 \%$ \\
\hline vertical displacement & 17 & 0.0339 & 0.0268 & 0.0520 & 0.79 & 1.53 & $-11.3 \%$ & $28.8 \%$ \\
\hline vertical displacement & 18 & 0.0366 & 0.0299 & 0.0551 & 0.82 & 1.51 & $-10.7 \%$ & $29.5 \%$ \\
\hline vertical displacement & 5 & 0.0405 & 0.0345 & 0.0597 & 0.85 & 1.47 & $-9.6 \%$ & $30.6 \%$ \\
\hline vertical displacement & 4 & 0.0520 & 0.0469 & 0.0721 & 0.90 & 1.39 & $-8.1 \%$ & $32.0 \%$ \\
\hline vertical displacement & 3 & 0.0628 & 0.0584 & 0.0836 & 0.93 & 1.33 & $-7.0 \%$ & $33.1 \%$ \\
\hline vertical displacement & 2 & 0.0520 & 0.0488 & 0.0740 & 0.94 & 1.42 & $-5.1 \%$ & $35.0 \%$ \\
\hline vertical displacement & 6 & 0.0381 & 0.0324 & 0.0576 & 0.85 & 1.51 & $-9.1 \%$ & $31.1 \%$ \\
\hline vertical displacement & 7 & 0.0347 & 0.0301 & 0.0553 & 0.87 & 1.59 & $-7.3 \%$ & $32.8 \%$ \\
\hline horizontal strain & 20 & 30 & 19 & 19 & 0.63 & 0.63 & $-7.4 \%$ & $-7.4 \%$ \\
\hline horizontal strain & 8 & 148 & 214 & 214 & 1.45 & 1.45 & $44.6 \%$ & $44.6 \%$ \\
\hline vertical strain & 22 & -185 & -98.4 & -98 & 0.53 & 0.53 & $-22.3 \%$ & $-22.4 \%$ \\
\hline vertical strain & 10 & -388 & -258 & -258 & 0.66 & 0.66 & $-33.5 \%$ & $-33.5 \%$ \\
\hline vertical stress, z & 19 & 0.018 & 0.01 & 0.01 & 0.56 & 0.56 & $0.0 \%$ & $0.0 \%$ \\
\hline vertical stress, z & 12 & -197 & -192 & -192 & 0.97 & 0.97 & $-2.5 \%$ & $-2.5 \%$ \\
\hline vertical stress, z & 21 & -1.37 & -2.67 & -2.67 & 1.95 & 1.95 & $0.7 \%$ & $0.7 \%$ \\
\hline vertical stress, $\mathbf{z}$ & 13 & -23.1 & -23.8 & -23.8 & 1.03 & 1.03 & $0.4 \%$ & $0.4 \%$ \\
\hline horiz. stress, x & 19 & -11.8 & -7.49 & -7.49 & 0.63 & 0.63 & $-2.2 \%$ & $-2.2 \%$ \\
\hline horiz. stress, $x$ & 12 & -150 & -135 & -135.4 & 0.90 & 0.90 & $-7.5 \%$ & $-7.3 \%$ \\
\hline horiz. stress, $x$ & 21 & -1.3 & -2.15 & -3.82 & 1.65 & 2.94 & $0.4 \%$ & $1.3 \%$ \\
\hline horiz. stress, $x$ & 13 & 4.33. & 3.82 & 2.15 & 0.88 & 0.50 & $0.3 \%$ & $1.1 \%$ \\
\hline
\end{tabular}

Finally, a cylindrical model that incorporated horizontal infinite elements along the sides and vertical infinite elements along the base, as depicted in Figure 3.30, was analyzed. Note that this model contained only horizontal and vertical infinite elements and thus does not satisfy the requirement that infinite elements be generally oriented radially away from the "pole" (point of load application). While this model is generally simpler to generate than model with radial infinite elements, the effect of the "improper" modeling on results was not known a priori. 


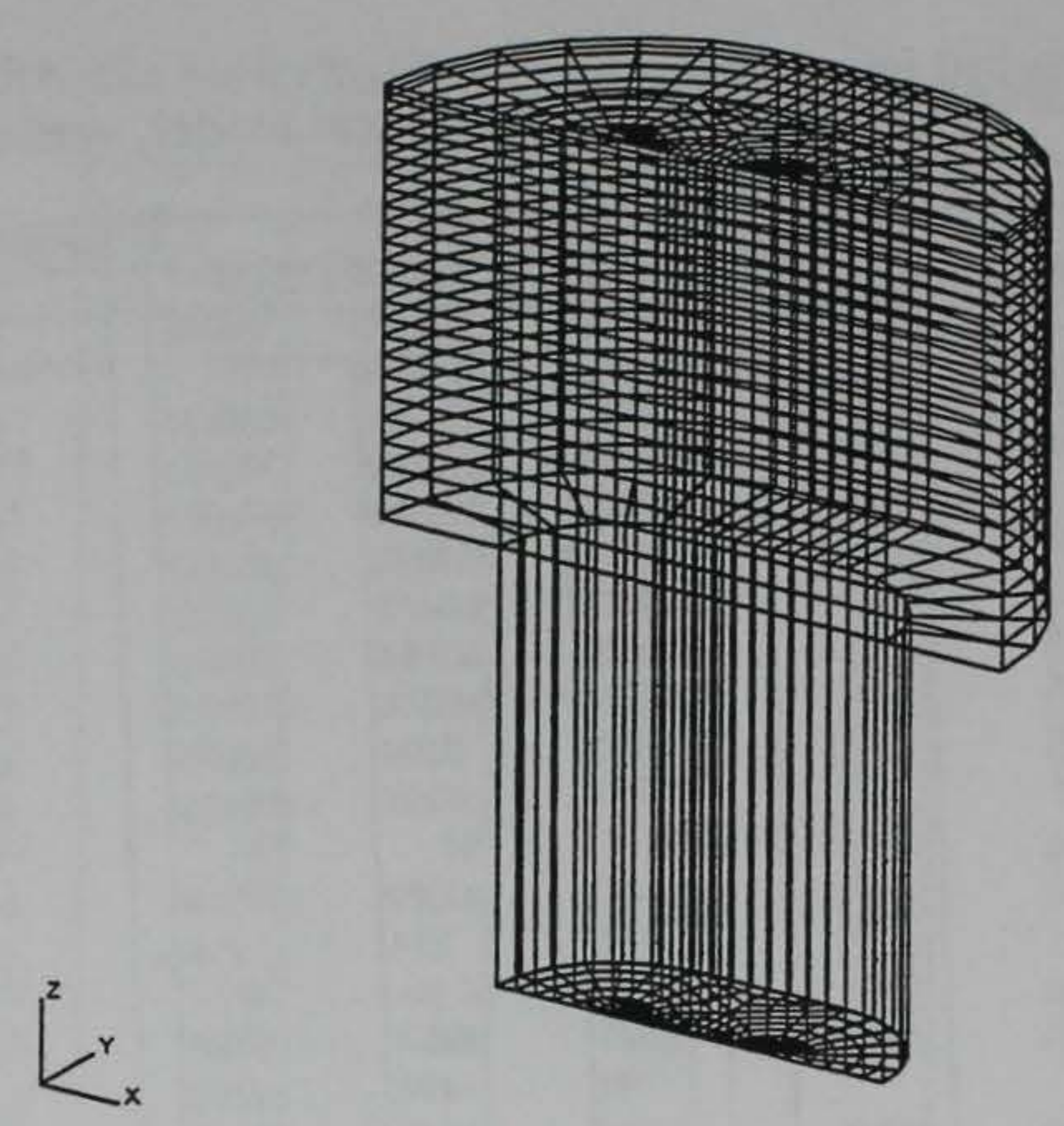

Figure 3.30. Cylindrical-type mesh with vertical and horizontal infinite elements.

The results of this analysis for a single wheel loading are compared with the LEM results and the results of the "fixed" boundary model in Table 3.14. In general, the fidelity of the results for stress and strain are fairly comparable to the fixed boundary model. The major exception is the considerable over-prediction of vertical displacement in the model with infinite elements. It is unclear at this time what is the source of this discrepancy. A review of the displacement basin indicates that the over-prediction is essentially constant, i.e., the FEM prediction is 0.023 inch greater than the LEM prediction at all points. This constant, almost rigid-body vertical motion, may indicate that the displacements may be very sensitive to the orientation of the vertical infinite elements, and/or to the lack of radial infinite elements other than near the surface and directly below the load.

In general, this cylindrical-type model is not recommended for further application to the problem at hand due to the relative difficulties in modeling and the poor results obtained from the models investigated. The general fixed-boundary model is somewhat more difficult to generate than the previous box-type model due to the curved sides. More importantly, the model is not amenable to proper modeling with infinite elements due to a basic geometry that inhibits use of radially-oriented elements of proper length. Finally, the previously described attempts at using infinite element models that do not meet the requirements for infinite elements lead to inconsistent, unsatisfactory results that are difficult to understand or explain. For the additional difficulty in modeling incurred by this mesh type, it is more beneficial to carry the curved shapes to the vertical plane as well as the horizontal plane and produce the "spherical-type" model described in the following paragraphs. 
Table 3.14. Results for cylindrical model, horizontal and vertical infinite elements.

\begin{tabular}{|c|c|c|c|c|c|c|c|c|}
\hline \multirow[b]{3}{*}{ result variable } & \multirow[b]{3}{*}{ point } & \multicolumn{7}{|c|}{ single wheel load } \\
\hline & & \multirow[b]{2}{*}{ BISAR } & \multicolumn{2}{|c|}{ ABAQUS } & \multicolumn{2}{|c|}{ FEMREM } & \multicolumn{2}{|c|}{$\lambda$} \\
\hline & & & fixed & infinite & fixed & infinite & fixed & infinite \\
\hline vertical displacement & 16 & 0.0318 & 0.0245 & 0.0547 & 0.77 & 1.72 & $-11.6 \%$ & $36.5 \%$ \\
\hline vertical displacement & 17 & 0.0339 & 0.0268 & 0.0572 & 0.79 & 1.69 & $-11.3 \%$ & $37.1 \%$ \\
\hline vertical displacement & 18 & 0.0366 & 0.0299 & 0.0601 & 0.82 & 1.64 & $-10.7 \%$ & $37.4 \%$ \\
\hline vertical displacement & 5 & 0.0405 & 0.0345 & 0.0642 & 0.85 & 1.59 & $-9.6 \%$ & $37.7 \%$ \\
\hline vertical displacement & 4 & 0.0520 & 0.0469 & 0.0758 & 0.90 & 1.46 & $-8.1 \%$ & $37.9 \%$ \\
\hline vertical displacement & 3 & 0.0628 & 0.0584 & 0.0861 & 0.93 & 1.37 & $-7.0 \%$ & $37.1 \%$ \\
\hline vertical displacement & 2 & 0.0520 & 0.0488 & 0.0751 & 0.94 & 1.44 & $-5.1 \%$ & $36.8 \%$ \\
\hline vertical displacement & 6 & 0.0381 & 0.0324 & 0.0616 & 0.85 & 1.62 & $-9.1 \%$ & $37.4 \%$ \\
\hline vertical displacement & 7 & 0.0347 & 0.0301 & 0.0574 & 0.87 & 1.65 & $-7.3 \%$ & $36.1 \%$ \\
\hline horizontal strain & 20 & 30 & 19 & -63 & 0.63 & -2.10 & $-7.4 \%$ & $-62.8 \%$ \\
\hline horizontal strain & 8 & 148 & 214 & 151 & 1.45 & 1.02 & $44.6 \%$ & $2.0 \%$ \\
\hline vertical strain & 22 & -185 & -98.4 & -238 & 0.53 & 1.29 & $-22.3 \%$ & $13.7 \%$ \\
\hline vertical strain & 10 & -388 & -258 & -382 & 0.66 & 0.98 & $-33.5 \%$ & $-1.5 \%$ \\
\hline vertical stress, z & 19 & 0.018 & 0.01 & 0.003 & 0.56 & 0.17 & $0.0 \%$ & $0.0 \%$ \\
\hline vertical stress, z & 12 & -197 & -192 & -192 & 0.97 & 0.97 & $-2.5 \%$ & $-2.5 \%$ \\
\hline vertical stress, z & 21 & -1.37 & -2.67 & -1.59 & 1.95 & 1.16 & $0.7 \%$ & $0.1 \%$ \\
\hline vertical stress, z & 13 & -23.1 & -23.8 & -22.4 & 1.03 & 0.97 & $0.4 \%$ & $-0.4 \%$ \\
\hline horiz. stress, $x$ & 19 & -11.8 & -7.49 & -26 & 0.63 & 2.20 & $-2.2 \%$ & $7.1 \%$ \\
\hline horiz. stress, $x$ & 12 & -150 & -135 & -164 & 0.90 & 1.09 & $-7.5 \%$ & $7.0 \%$ \\
\hline horiz. stress, x & 21 & -1.3 & -2.15 & -0.31 & 1.65 & 0.24 & $0.4 \%$ & $-0.5 \%$ \\
\hline horiz. stress, $x$ & 13 & 4.33 & 3.82 & 5.23 & 0.88 & 1.21 & $0.3 \%$ & $-0.5 \%$ \\
\hline
\end{tabular}

A very simple spherical-type model was investigated to evaluate the possibility of using this shape and to compare the simplest 3-D application to the LEM results. This model, shown in Figure 3.31, consists of one-fourth of a half-sphere of a single material (one layer) and includes infinite elements at the boundaries. The two vertical surfaces are planes of symmetry. The central area of the mesh is the "finite" portion of the model, with the outer area being infinite elements representing the elastic boundaries. A single wheel loading is applied over the central circular area and the solid elements generally radiate out from this area. The infinite elements thus meet the specified requirements as closely as can be accomplished for a three-dimensional model. 


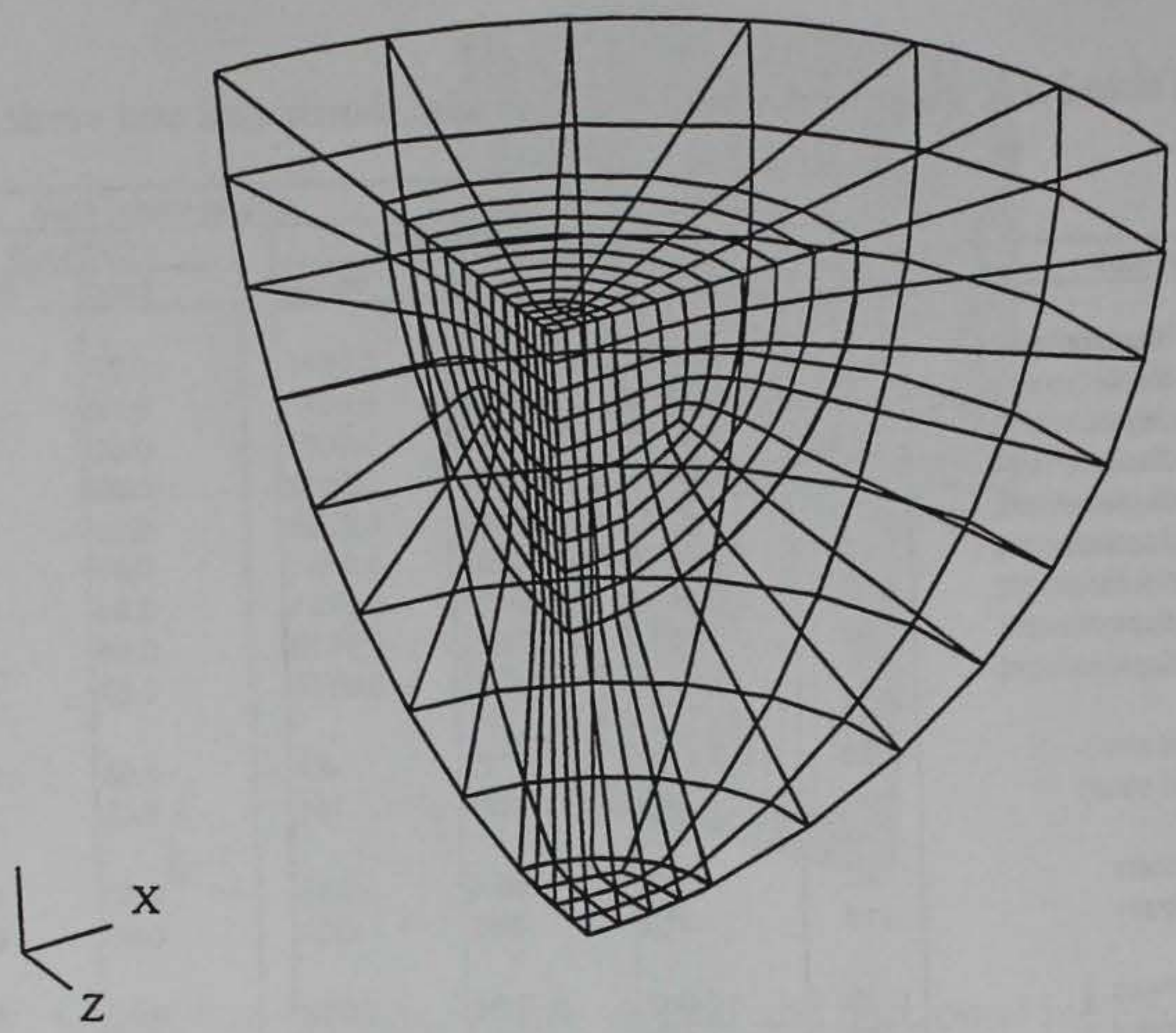

Figure 3.31. Single-layer spherical-type finite element mesh.

Results of this analysis were compared with a comparable BISAR analysis at three depths and at two radial distances, specifically under the center of the load and at the edge of the load. The results are compared in Table 3.15, which is a different layout than the previous tables in this report. At each of the six comparison locations, which are defined by the depth and radial distance on the second and third rows of the table, the results are compared for seven components of displacement, strain, and stress as indicated in the leftmost column. Each comparison includes the LEM (BISAR) prediction, the FEM prediction, the direct ratio of the FEM and LEM result, and the normalized percent difference.

The results indicate excellent agreement between the FEM and LEM except for stresses and strains at the surface (depth=0). This apparent difference is actually a by-product of the method of strain and stress reporting at a free surface in the finite element model. In the finite element model, the stresses and strains are actually calculated and stored at the element integration points and averaged at the element nodes. At interior nodes, the average of the element quantities at integration points in adjacent elements is a good measure of the nodal quantity. However, at free surface nodes there are no adjacent element integration points with which to average and the nodal quantity more generally reflects the integration point value, in this case usually under-predicting the nodal quantities which tend to be maximum at the free surface. Note that native nodal quantities, such as displacement are directly computed at the nodes and do not suffer from this nodal averaging discrepancy. 
Table 3.15. Results for simple, single layer spherical-shaped model.

\begin{tabular}{|c|rrr|rrr|}
\hline node & 1 & 26 & 51 & 5 & 30 & 55 \\
\hline $\mathrm{X}$ & 0 & 0 & 0 & 8.69 & 8.69 & 8.69 \\
\hline $\mathrm{Y}$ (depth) & 0 & 21.725 & 43.45 & 0 & 21.286 & 42.572 \\
\hline
\end{tabular}

vertical $\mathbf{y}$ displacement

\begin{tabular}{|c|rrr|rrr|}
\hline LEM & 0.0607 & 0.0201 & 0.0106 & 0.0387 & 0.0182 & 0.0104 \\
\hline FEM & 0.0598 & 0.0196 & 0.01051 & 0.0377 & 0.0179 & 0.0103 \\
\hline FEM/LEM & 0.99 & 0.98 & 0.99 & 0.97 & 0.98 & 0.99 \\
\hline$\lambda$ & $-1.5 \%$ & $-0.8 \%$ & $-0.1 \%$ & $-1.6 \%$ & $-0.5 \%$ & $-0.2 \%$ \\
\hline
\end{tabular}

vertical y stress

\begin{tabular}{|c|r|}
\hline LEM & 199 \\
\hline FEM & 174 \\
\hline FEM/LEM & 0.87 \\
\hline$\lambda$ & $-12.6 \%$ \\
\hline
\end{tabular}

\begin{tabular}{|c|r|}
\hline LEM & 16 \\
\hline FEM & 12 \\
\hline FEM/LEM & 0.7 \\
\hline$\lambda$ & $-29.0 \%$ \\
\hline
\end{tabular}

horizontal z stress

\begin{tabular}{|c|rrr|rrr|}
\hline LEM & 169 & -0.645 & -0.468 & 99.6 & -0.48 & -0.44 \\
\hline FEM & 120 & -0.23 & -0.65 & 65 & -0.42 & -0.5 \\
\hline FEM/LEM & 0.71 & 0.36 & 1.39 & 0.65 & 0.88 & 1.14 \\
\hline$\lambda$ & $-29.0 \%$ & $0.2 \%$ & $-0.1 \%$ & $-20.5 \%$ & $0.0 \%$ & $0.0 \%$ \\
\hline
\end{tabular}

vertical y strain

\begin{tabular}{|c|rrr|rrr|}
\hline LEM & 1610 & 804 & 234 & 807 & 601 & 219 \\
\hline FEM & 1797 & 780 & 241 & 820 & 589 & 226 \\
\hline FEM/LEM & 1.12 & 0.97 & 1.03 & 1.02 & 0.98 & 1.03 \\
\hline$\lambda$ & $11.6 \%$ & $-1.5 \%$ & $0.4 \%$ & $0.8 \%$ & $-0.7 \%$ & $0.4 \%$ \\
\hline
\end{tabular}

horizontal $x$ strain

\begin{tabular}{|c|rrr|rrr|}
\hline LEM & 807 & -287 & -86 & 0 & -156 & -74 \\
\hline FEM & 342 & -279 & -90 & -96 & -153 & -74 \\
\hline FEM/LEM & 0.42 & 0.97 & 1.05 & & 0.98 & 1.00 \\
\hline$\lambda$ & $-57.6 \%$ & $1.0 \%$ & $-0.5 \%$ & $-11.9 \%$ & $0.4 \%$ & $0.0 \%$ \\
\hline
\end{tabular}

horizontal z strain

\begin{tabular}{|c|rrr|rrr|}
\hline LEM & 807 & -287 & -86 & 807 & -245 & -84 \\
\hline FEM & 342 & -279 & -90 & 420 & -240 & -88 \\
\hline FEMM/LEM & 0.42 & 0.97 & 1.05 & 0.52 & 0.98 & 1.05 \\
\hline$\lambda$ & $-57.6 \%$ & $1.0 \%$ & $-0.5 \%$ & $-48.0 \%$ & $0.6 \%$ & $-0.5 \%$ \\
\hline
\end{tabular}

The effect of nodal averaging of element quantities is simply illustrated in Figure 3.32, which plots the FEM predictions of vertical and horizontal nodal stress quantities versus depth. Perhaps the most obvious discrepancy in this method of nodal averaging prediction is evident in the vertical stress at the center of the loaded area, which, by statics, must approach the applied tire pressure of 199.4 psi at the surface. We can see in the plot of Figure 3.32 that the stress gradient with depth would more appropriately fit the surface pressure of $199.4 \mathrm{psi}$ than the nodal averaged prediction of 174 psi. This same anomaly is present, though less conspicuous in the other predicted stresses. This anomaly in element quantities predicted by typical finite element procedures should be kept in mind in interpretation of any present and future results predicted using this method. 


\section{Stress Variation with Depth (FEM)}

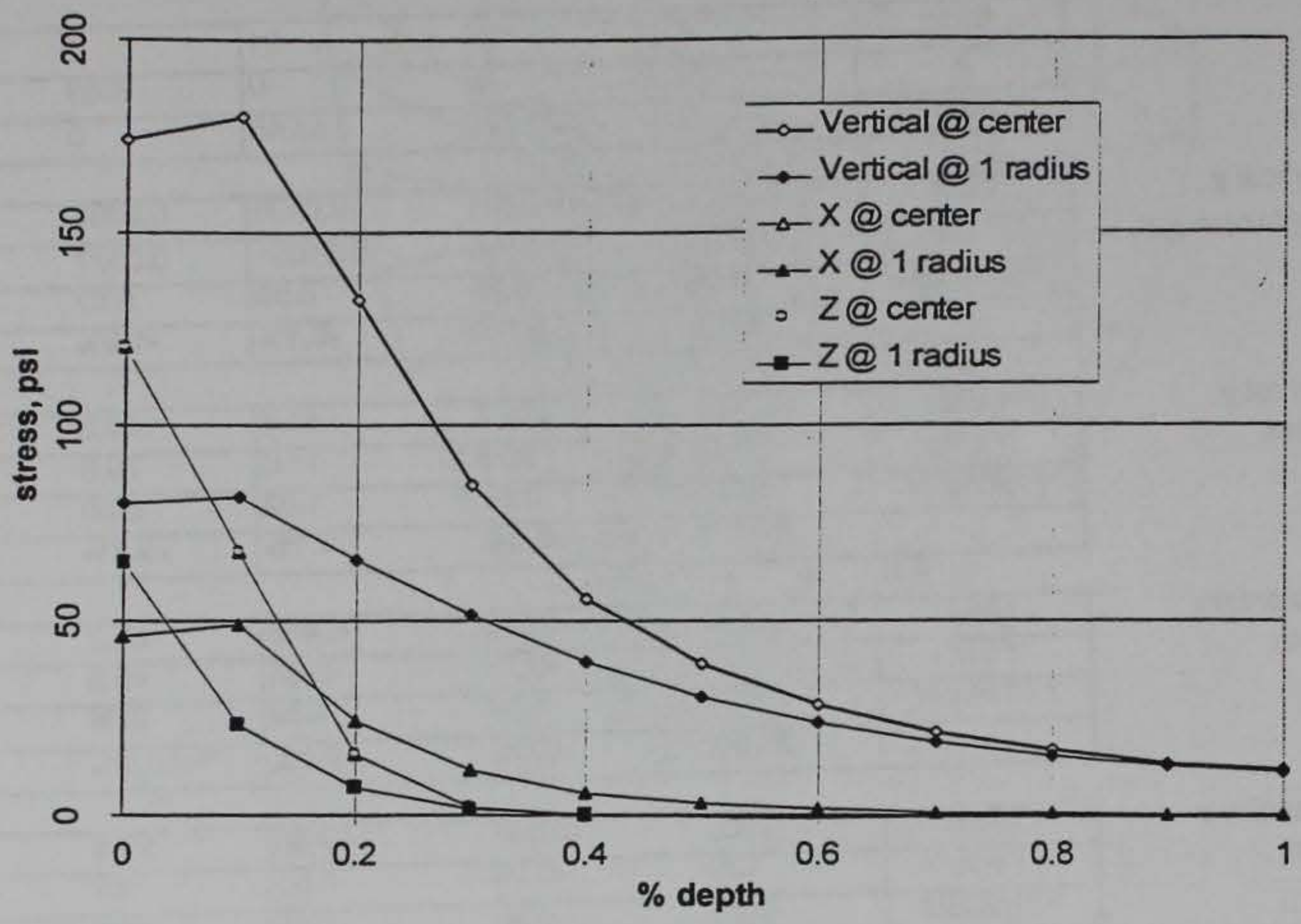

Figure 3.32. Predicted nodal stress versus depth (spherical model).

A refined mesh was also analyzed for the simple, single-layer spherical model to verify the previously described assertion regarding the anomaly in stresses and strains at the free surface. Though not included here, the results of this analysis indeed confirmed that the element quantities (stress, strain) did converge toward the expected values predicted by the Layered Elastic Method.

The spherical-type model was applied in three additional different configurations to the problem at hand, i.e., the baseline pavement layer thicknesses, materials, and wheel loading for the B-727. Each of these models was for a single wheel loading and had the overall shape of the previous simple one-layer model, but consisted of the three layers of asphaltic concrete, base course, and subgrade utilized in the baseline cases. The three models included variations in modeling of the infinite element orientations and the mesh density.

The first of these models, shown in Figure 3.33, consists of an inner "core" of the pavement system with the three layers modeled similarly to that of previous 3-D models. The quarter-hemispherical core includes all three layers with a radial mesh in a plan view. The boundaries are modeled with infinite elements that radiate from the "pole" (loaded area) to produce the raiher unusual configuration shown. This boundary configuration obviously does not reflect the reality of the horizontal pavement layers extending from the inner model but was analyzed to determine what effect this modeling "error" would have on the predicted results. 


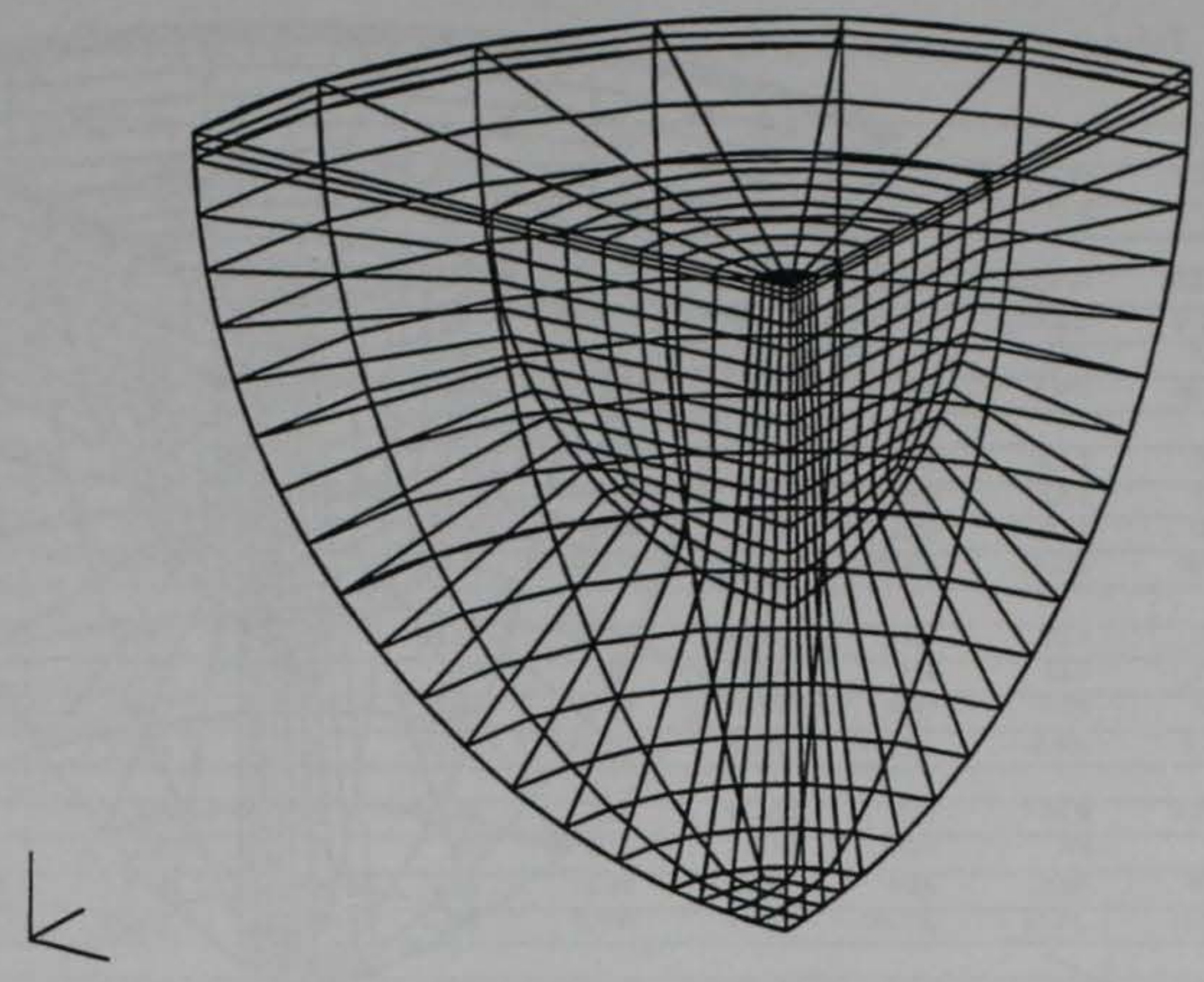

Figure 3.33. Three-layer spherical-type mesh with radial infinite elements.

Though not presented here for brevity, the results of the above model indicated an overly stiff system, with predicted vertical displacements well below that predicted by the LEM and previous 2-D and 3-D finite element models. This result was certainly expected since the boundary infinite elements extend radially outward, creating an unrealistically stiff boundary, especially for the base course. The predicted stresses underneath the load were less affected by this unrealistic boundary, yielding results comparable to previous FEM analyses.

The second spherical-type model analyzed with three layers utilized more realistic boundary modeling, with the mesh shown in Figure 3.34. The infinite elements properly maintain the layer thicknesses to provide a plausible boundary stiffness. This configuration does, however, partially violate the preferred orientation of infinite elements in the top two layers that are presumed to radiate from the pole. The results of the analysis permit an examination of the effect of this minor variance in the application of infinite elements. 


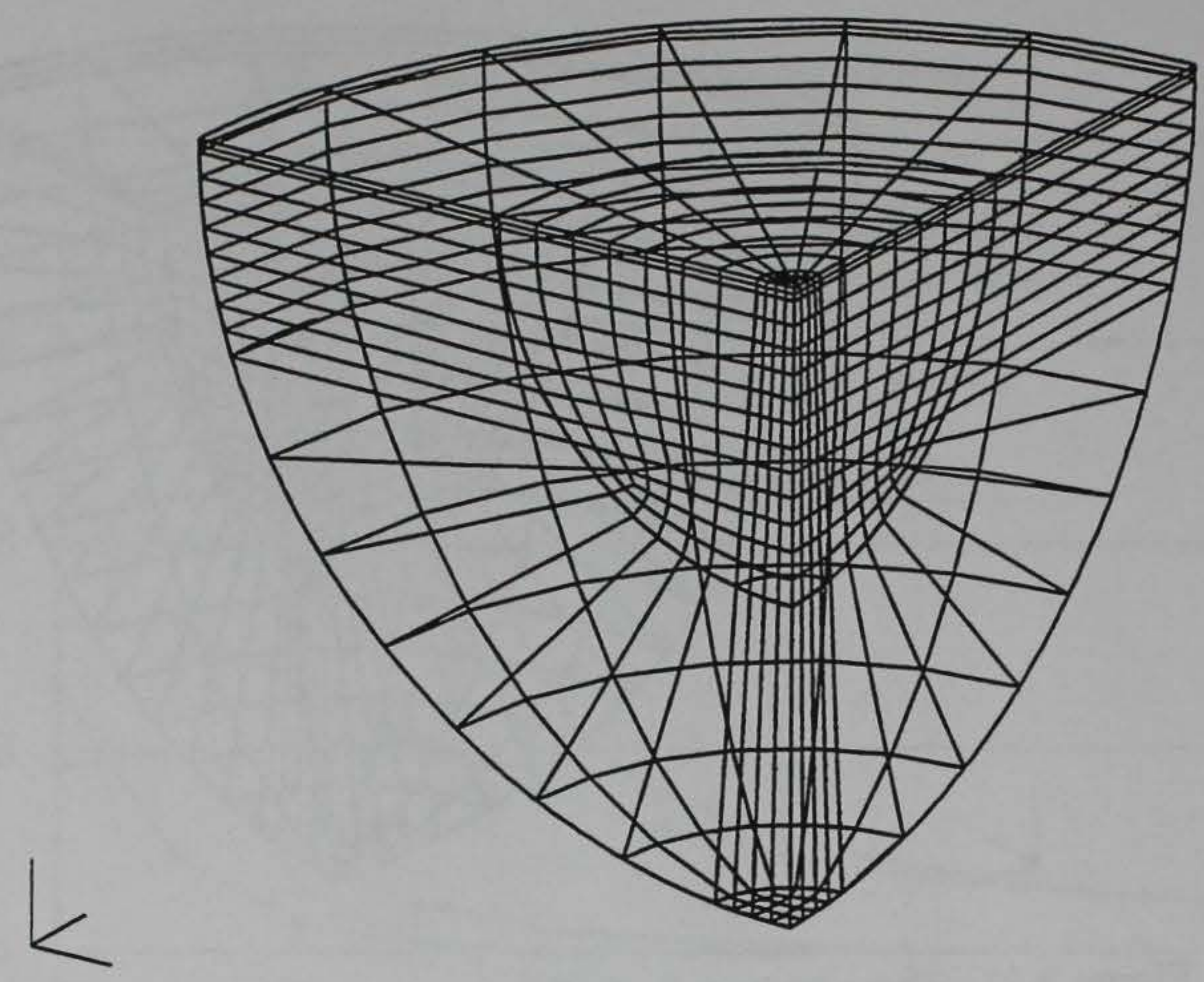

Figure 3.34. Three-layer spherical-type mesh with layered infinite elements.

Selected results from this analysis are presented in Table 3.16 for five depths under the center of the load, and five depths along element boundaries radiating downward from the edge of the load. The finite element results are compared with BISAR results computed at the same coordinate locations. The results indicate good agreement with the LEM results, with the expected exception of surface stresses and strains. This exception was described and explained in the previous, single layer spherical-type model and appears reasonable in this case. Basin displacements are about 7-9 percent lower than the LEM prediction and most stress and strain predictions not at the free surface are within a few percent of the LEM prediction. Overall, this model predicts interior stresses and strains very well. 
Table 3.16. Results for three-layer spherical-type model.

\begin{tabular}{|c|c|c|c|c|c|c|c|c|c|c|}
\hline node & 1 & 6 & 11 & 90 & 110 & 5 & 10 & 15 & 94 & 114 \\
\hline x & 0 & 0 & 0 & 0 & 0 & 8.69 & 8.788 & 8.886 & 10.292 & 71.697 \\
\hline$Y$ (depth) & 0 & 1.5 & 3 & 24.5 & 46) & 0 & 1.5 & $\overline{3}$ & 24.5 & 46 \\
\hline
\end{tabular}

vertical y

\begin{tabular}{|c|rrrrr|rrrrr|}
\hline LEM & 0.0628 & 0.0623 & 0.0615 & 0.0428 & 0.0387 & 0.052 & 0.0516 & 0.0511 & 0.0414 & 0.0378 \\
\hline FEM & 0.0572 & 0.0569 & 0.056 & 0.0385 & 0.0344 & 0.0465 & 0.04625 & 0.046 & 0.0372 & 0.0337 \\
\hline FEMMLLEM & 0.91 & 0.91 & 0.91 & 0.90 & 0.89 & 0.89 & 0.90 & 0.90 & 0.90 & 0.89 \\
\hline$\lambda$ & $-8.9 \%$ & $-8.6 \%$ & $-8.8 \%$ & $-6.8 \%$ & $-6.8 \%$ & $-8.8 \%$ & $-8.5 \%$ & $-8.1 \%$ & $-6.7 \%$ & $-6.5 \%$ \\
\hline
\end{tabular}

vertical y

\begin{tabular}{|c|rrrrrrrrrr|}
\hline LEM & 199 & 197 & 189 & 25.9 & 2.6 & 99.6 & 84.9 & 79.1 & 18.2 & 2.4 \\
\hline FEM & 177 & 194 & 178 & 24.9 & 3.5 & 59.2 & 62.7 & 59.7 & 17.4 & 3.2 \\
\hline FEMULEM & 0.86 & 0.98 & 0.94 & 0.96 & 1.35 & 0.59 & 0.74 & 0.75 & 0.96 & 1.33 \\
\hline$\lambda$ & $-14.1 \%$ & $-1.5 \%$ & $-5.5 \%$ & $-0.5 \%$ & $0.5 \%$ & $-20.3 \%$ & $-17.2 \%$ & $-9.7 \%$ & $-0.4 \%$ & $0.4 \%$ \\
\hline
\end{tabular}

horiz. $x$

\begin{tabular}{|c|rrrrr|rrrr|r|}
\hline LEM & 282 & 150 & 50.65 & -3.75 & -10.45 & 182 & 83.1 & 23.6 & -3.38 & -9.5 \\
\hline FEM & 230 & 149 & 55 & -3.5 & -8.4 & 126 & 75.7 & 27.3 & -3.56 & -7.74 \\
\hline FEMMLILEM & 0.82 & 0.99 & 1.09 & 0.93 & 0.80 & 0.69 & 0.91 & 1.16 & 1.05 & 0.87 \\
\hline$\lambda$ & $-18.4 \%$ & $-0.4 \%$ & $1.5 \%$ & $0.1 \%$ & $0.7 \%$ & $-19.9 \%$ & $-2.6 \%$ & $1.3 \%$ & $-0.1 \%$ & $0.6 \%$ \\
\hline
\end{tabular}

horiz. $z$

\begin{tabular}{|c|rrrrr|rrrrr|}
\hline LEMM & 282 & 150 & 50.65 & -3.75 & -10.45 & 101 & 84.9 & 62.05 & -0.83 & -8.81 \\
\hline FEIM & 230 & 149 & 55 & -3.5 & -8.4 & 55.7 & 73 & 57 & -0.89 & -6.96 \\
\hline FEMMLEM & 0.82 & 0.99 & 1.09 & 0.93 & 0.80 & 0.55 & 0.86 & 0.92 & 1.07 & 0.79 \\
\hline$\lambda$ & $-18.4 \%$ & $-0.4 \%$ & $1.5 \%$ & $0.1 \%$ & $0.7 \%$ & $-16.1 \%$ & $-4.2 \%$ & $-1.8 \%$ & $0.0 \%$ & $0.7 \%$ \\
\hline
\end{tabular}

vertical y

\begin{tabular}{|c|rrrrr|rrrrr|}
\hline LEM & 120 & 429 & 1123 & 315 & 285.5 & 58.9 & 138 & 390.5 & 217 & 254.5 \\
\hline FEM & 132 & 420 & 991 & 303 & 262 & 19 & 72 & 260 & 210 & 239 \\
\hline FEMULEM & 1.10 & 0.98 & 0.88 & 0.96 & 0.92 & 0.32 & 0.52 & 0.67 & 0.97 & 0.94 \\
\hline$\lambda$ & $1.1 \%$ & $-0.8 \%$ & $-11.8 \%$ & $-1.1 \%$ & $-2.1 \%$ & $-3.6 \%$ & $-5.9 \%$ & $-11.6 \%$ & $-0.6 \%$ & $-1.4 \%$ \\
\hline
\end{tabular}

horiz. $x$

\begin{tabular}{|c|rr|}
\hline LEM & 551 & 1 \\
\hline FEEM & 438 & 1 \\
\hline FEMMLEM & 0.79 & 1.00 \\
\hline$\lambda$ & $-20.5 \%$ & $0.0 \%$ \\
\hline
\end{tabular}

\begin{tabular}{rrr}
183 & -147.5 & -1 \\
\hline 183 & -144 & -11 \\
1.00 & 0.98 & 0.9 \\
$0.0 \%$ & $0.6 \%$ & $0.9 \%$
\end{tabular}

\begin{tabular}{rr|rrrrr}
-123 & -167 & 487 & 128 & -122.5 & -101 & -157 \\
\hline-118 & -145 & 366 & 140 & -71.3 & -100 & -140 \\
\hline 0.96 & 0.87 & 0.75 & 1.09 & 0.58 & 0.99 & 0.89 \\
\hline $0.9 \%$ & $4.0 \%$ & $-22.0 \%$ & $2.2 \%$ & $9.3 \%$ & $0.2 \%$ & $3.1 \%$
\end{tabular}

horiz, $z$

\begin{tabular}{|c|rrrrr|rrrrr|}
\hline LEM & 551 & 183 & -147.5 & -123 & -167 & 66 & 138 & 174 & -5.4 & -138 \\
\hline FEEM & 438 & 183 & -144 & -118 & -145 & 0.8 & 126 & 157 & -61 & -119 \\
\hline FEMMLEMM & 0.79 & 1.00 & 0.98 & 0.96 & 0.87 & 0.01 & 0.91 & 0.90 & 0.96 & 0.86 \\
\hline$\lambda$ & $-20.5 \%$ & $0.0 \%$ & $0.6 \%$ & $0.9 \%$ & $4.0 \%$ & $-11.8 \%$ & $-2.2 \%$ & $-3.1 \%$ & $0.4 \%$ & $3.4 \%$ \\
\hline
\end{tabular}

Based on the favorable results of the previous FEM model, a refined model, shown in Figure 3.35 , was analyzed for the same conditions. Results were similarly compared with an equivalent BISAR analysis, resulting in the comparisons shown in Table 3.17. As expected, the result comparison improved somewhat for practically all quantities. The refined mesh produces a very acceptable level of prediction, compared to the LEM (BISAR) prediction. 


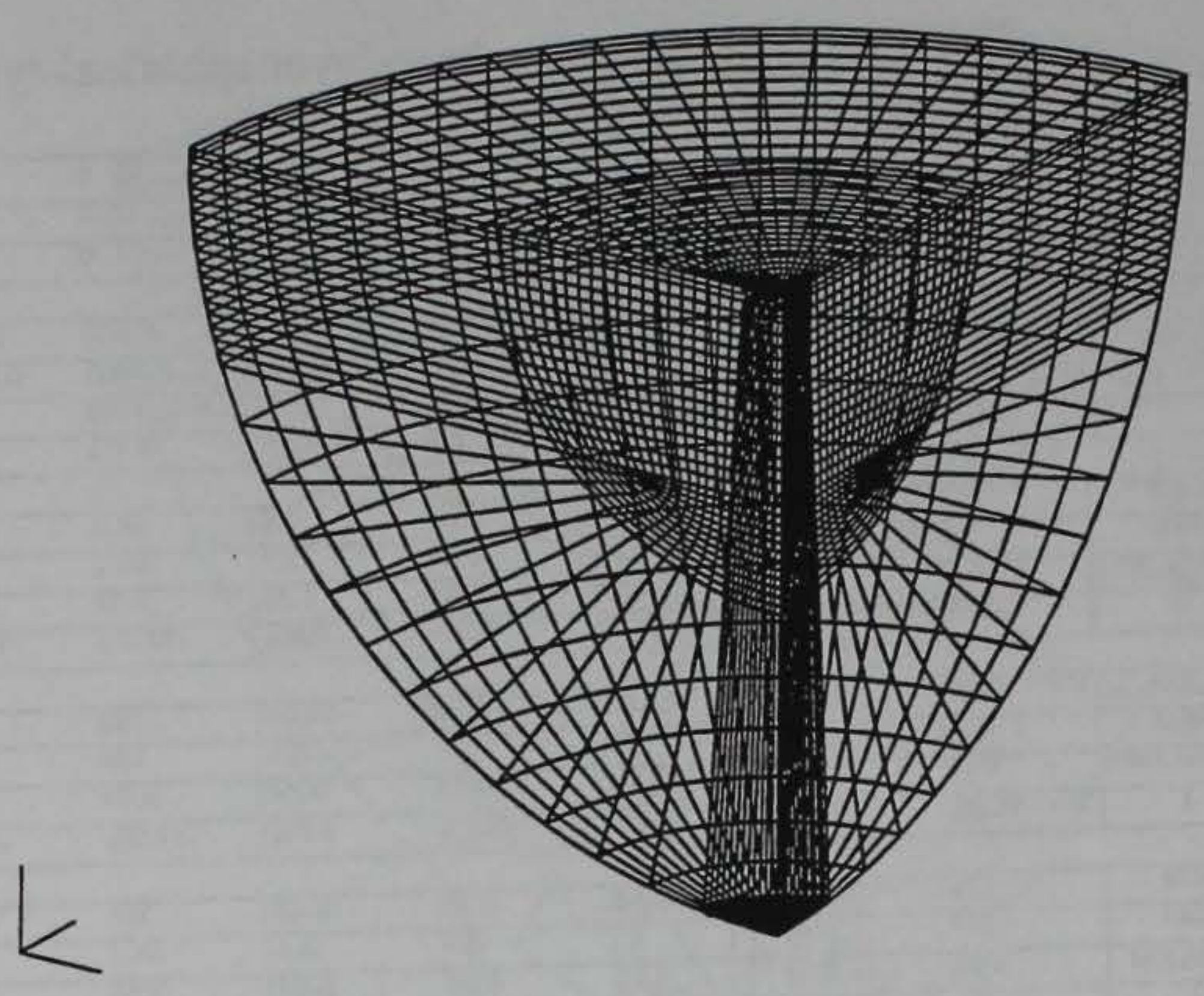

Figure 3.35. Refined three-layer spherical-type mesh with layered infinite elements.

Table 3.17. Results for refined three-layer spherical-type model.

\begin{tabular}{|c|c|c|c|c|c|c|c|c|c|c|}
\hline node & 2909 & 2916 & 2923 & 3407 & 3050 & 635 & 646 & 657 & 1864 & 1 \\
\hline X & 0 & 0 & 0 & 0 & 0 & 8.69 & 8.788 & 8.886 & 10.292 & 11.67 \\
\hline $\bar{Y}$ (depth) & 0 & 1.5 & $\overline{3}$ & 24.5 & 46 & $\overline{0}$ & 1.5 & $\overline{3}$ & 24.5 & 46 \\
\hline
\end{tabular}

vertical y

\begin{tabular}{|c|rrrrr|rrrrr|}
\hline LEM & 0.0628 & 0.0623 & 0.0615 & 0.0428 & 0.0387 & 0.052 & 0.0516 & 0.0517 & 0.0414 & 0.0378 \\
\hline FEM & 0.0583 & 0.0579 & 0.0571 & 0.0391 & 0.03495 & 0.0475 & 0.0473 & 0.04695 & 0.0377 & 0.0342 \\
\hline FEM/LEM & 0.93 & 0.93 & 0.93 & 0.91 & 0.90 & 0.91 & 0.92 & 0.92 & 0.91 & 0.90 \\
\hline$\lambda$ & $-7.2 \%$ & $-7.0 \%$ & $-7.0 \%$ & $-5.9 \%$ & $-6.0 \%$ & $-7.2 \%$ & $-6.8 \%$ & $-6.6 \%$ & $5.9 \%$ & $5.7 \%$ \\
\hline
\end{tabular}

vertical y

\begin{tabular}{|c|rrrrr|rrrrr|}
\hline LEM & 199 & 197 & 189 & 25.9 & 2.6 & 99.6 & 84.9 & 79.1 & 18.2 & 2.4 \\
\hline FEM & 174 & 196 & 180 & 25.7 & 3.58 & 60.2 & 65.7 & 63.6 & 17.9 & 3.28 \\
\hline FEMM/LEM & 0.87 & 0.99 & 0.95 & 0.99 & 1.38 & 0.60 & 0.77 & 0.80 & 0.98 & 1.37 \\
\hline$\lambda$ & $-12.6 \%$ & $-0.5 \%$ & $-4.5 \%$ & $-0.1 \%$ & $0.5 \%$ & $-19.8 \%$ & $-9.6 \%$ & $-7.8 \%$ & $-0.2 \%$ & $0.4 \%$ \\
\hline
\end{tabular}

horiz. $x$

\begin{tabular}{|c|rrrrr|rrrrr|}
\hline LEM & 282 & 150 & 50.65 & -3.75 & -10.45 & 182 & 83.1 & 23.6 & -3.38 & -9.5 \\
\hline FEM & 228 & 150 & 58.3 & -3.63 & -8.59 & 133 & 75.6 & 24.7 & -3.56 & -7.89 \\
\hline FEIMLEM & 0.81 & 1.00 & 1.15 & 0.97 & 0.82 & 0.73 & 0.91 & 1.05 & 1.05 & 0.83 \\
\hline$\lambda$ & $-19.1 \%$ & $0.0 \%$ & $2.7 \%$ & $0.0 \%$ & $0.7 \%$ & $-17.4 \%$ & $-2.7 \%$ & $0.4 \%$ & $-0.1 \%$ & $0.6 \%$ \\
\hline
\end{tabular}

horiz. $z$

stress

\begin{tabular}{|c|rrrrr|rrrrr|}
\hline LEMM & 282 & 150 & 50.65 & -3.75 & -10.45 & 101 & 84.9 & 62.05 & -0.83 & -8.81 \\
\hline FEEM & 228 & 150 & 58.3 & -3.63 & -8.59 & 53.89 & 74.9 & 59.3 & -0.83 & -7.12 \\
\hline FEMM/LEM & 0.81 & 1.00 & 1.15 & 0.97 & 0.82 & 0.53 & 0.88 & 0.96 & 1.00 & 0.81 \\
\hline$\lambda$ & $-19.1 \%$ & $0.0 \%$ & $2.7 \%$ & $0.0 \%$ & $0.7 \%$ & $-16.7 \%$ & $-3.5 \%$ & $-1.0 \%$ & $0.0 \%$ & $0.6 \%$ \\
\hline
\end{tabular}

vertical y

\begin{tabular}{|c|rrrrr|rrrrr|}
\hline LEM & 120 & 429 & 1123 & 315 & 285.5 & 58.9 & 138 & 390.5 & 217 & 254.5 \\
\hline FEM & 147 & 422 & 998 & 312 & 271 & 16.6 & 82.3 & 286 & 215 & 246 \\
\hline FEMMLLEM & 1.23 & 0.98 & 0.89 & 0.99 & 0.95 & 0.28 & 0.60 & 0.73 & 0.99 & 0.97 \\
\hline$\lambda$ & $2.4 \%$ & $-0.6 \%$ & $-11.1 \%$ & $-0.3 \%$ & $-1.3 \%$ & $-3.8 \%$ & $-5.0 \%$ & $-9.3 \%$ & $-0.2 \%$ & $-0.8 \%$ \\
\hline
\end{tabular}

horiz. $x$

\begin{tabular}{|c|rrrrr|rrrrr|}
\hline LEM & 551 & 183 & -147.5 & -123 & -167 & 487 & 128 & -122.5 & -101 & -157 \\
\hline FEM & 430 & 186 & -136 & -121 & -150 & 395 & 134 & -98.3 & -102 & -144 \\
\hline FEMM/LEM & 0.78 & 1.02 & 0.92 & 0.98 & 0.90 & 0.81 & 1.05 & 0.80 & 1.01 & 0.92 \\
\hline$\lambda$ & $-22.0 \%$ & $0.5 \%$ & $2.1 \%$ & $0.4 \%$ & $3.1 \%$ & $-16.7 \%$ & $1.1 \%$ & $4.4 \%$ & $-0.2 \%$ & $2.4 \%$ \\
\hline
\end{tabular}

horiz. z

\begin{tabular}{|c|rrrrr|rrrrr|}
\hline LEM & 551 & 183 & -147.5 & -123 & -167 & 66 & 138 & 174 & -63.4 & -138 \\
\hline FEMM & 431 & 186 & -137 & -121 & -150 & 16.3 & 130 & 168 & -61.9 & -123 \\
\hline FEMM/LEM & 0.78 & 1.02 & 0.93 & 0.98 & 0.90 & 0.25 & 0.94 & 0.97 & 0.98 & 0.89 \\
\hline$\lambda$ & $-21.8 \%$ & $0.5 \%$ & $1.9 \%$ & $0.4 \%$ & $3.1 \%$ & $-9.0 \%$ & $-1.5 \%$ & $-1.1 \%$ & $0.3 \%$ & $2.7 \%$ \\
\hline
\end{tabular}




\subsubsection{Summary of three-dimensional results comparison.}

The results of interest for several three-dimensional finite element models have been presented in the preceding sections. The box-type finite element models are reasonably simple to generate and predicted stresses and strains very well in each configuration. Vertical displacements were predicted well only in the models with infinite elements at the boundaries.

The cylindrical-type model predicted stresses quite well, vertical displacements fairly well, and was inconsistent in strain predictions. The cylindrical-type models with infinite elements predicted some results better than the fixed boundary model but surprisingly overpredicted vertical displacements. This model type is not recommended for further development due to difficulty in generating acceptable configurations of infinite elements at the boundaries.

A simple application of the spherical-type mesh for a single layer system provided excellent agreement with the Layered Elastic Method. This analysis also provided a straightforward example to demonstrate the effect of nodal-averaged element quantities such as stress and strain at a free surface. In this case, the predicted nodal-averaged values were less than the actual values.

The spherical-type mesh was applied to the baseline three-layer pavement system using three mesh and boundary configurations. The mesh with perfectly radial infinite elements produced an overly stiff system, as expected. The two meshes with consistent infinite element configurations (horizontal layers) produced very acceptable predictions, considering the caveat regarding free-surface stress and strain predictions.

Overall, the three-dimensional finite element models predicted displacement, stress, and strain in the pavement system with a fidelity comparable to the two-dimensional models and generally acceptable when compared to the Layered Elastic Method. The box-type model and spherical-type models are reasonable candidates for further investigation and application. 


\section{Chapter 4 CONCLUSIONS AND RECOMMENDATIONS}

\subsection{CONCLUSIONS}

Although the analytical models considered in this study were rather simple, several conclusions may be drawn from the effort. Firstly, the primary conclusion must be that the finite element method, properly applied, can model the flexible pavement system to produce excellent agreement with the more prevalent modeling technique of the Layered Elastic Method. In addition, several considerations as to proper modeling were illustrated via the parameter studies conducted using the two- and three-dimensional models. For example, the importance of the boundary locations and conditions was demonstrated by evaluating the convergence of the key results as the boundary conditions were changed. This investigation indicated that the boundaries should be modeled with infinite elements to produce the best agreement with the LEM results. The effect of mesh refinement and mesh type was generally shown to be small, thus reasonable meshes can be utilized. A brief investigation of the "no tension" option for the linear elastic material model indicated that this was not a useful option for this type of analysis.

The three-dimensional finite element models predicted results to a similar level of accuracy as the two-dimensional models. Several mesh and boundary configurations were investigated and also indicated that infinite element boundaries, properly applied, can improve the predictions.

\subsection{RECOMMENDATIONS}

At this stage, it is recommended that the development of the analytical model proceed methodically toward inclusion of nonlinear interface behavior, nonlinear material properties, and more general three-dimensional loading. It is further recommended that these enhancements be implemented and investigated in relatively small steps, i.e., not changing more than one parameter at any particular stage. For example, non-bonded interface behavior or complex nonlinear material models can be investigated separately using two-dimensional models before proceeding to inclusion in three-dimensional models.

It is also recommended that finite element modeling be applied to one or more typical pavement material laboratory tests to calibrate the material model.

Finally, it is recommended that a detailed long-range plan for investigation and model development be determined with a goal of developing a detailed analytical model for flexible pavement design and analysis. 


\section{Chapter 5 REFERENCES}

ABAQUS User's Manual, Version 5.2, Vols. I \& II, Hibbitt, Karlsson and Sorenson, 1992.

Bryant, Larry M., "Improved Analytical Model for Pavement Design", final report submitted to U. S. Army Engineer Waterways Experiment Station, Vicksburg, MS 39180, under Contract No. DACA39-96-C-0004, July 1996.

FAD Computer Program, Computer Aided Design for Flexible Airfields. Version 1.0, references TM 5-825-2, AFM 32-8008 Vol. 2. U.S Army Engineer Division, Missouri River. Omaha, NE. Updated September 1994.

Huang, Yang H., Pavement Analysis and Design, 1993. Prentice-Hall, Englewood Cliffs, NJ.

NEWFILE Computer Program, Aircraft Specifications Data File Maintenance Program, Military Rigid and Flexible Pavement Design. US Army Engineer Waterways Experiment Station, Vicksburg, MS. Updated January 1994.

P3/PATRAN User Manual, Vols. 1 - 4, PDA Engineering, Costa Mesa CA. 1993.

Yoder, E. J., and M. W. Witczak, 1975. Principles of Pavement Design, Wiley, New York. 


\section{REPORT DOCUMENTATION PAGE}

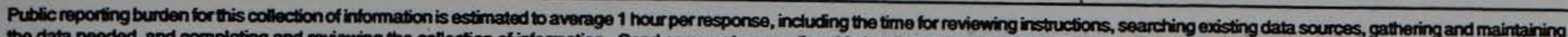

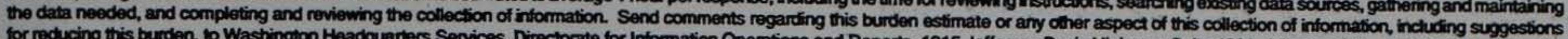

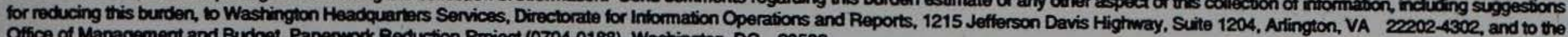
Office of Management and Budget, Paperwork Reduction Project (0704-0188), Wastington, DC 20503.
1. AGENCY USE ONLY (Leave blank)
2. REPORT DATE July 1998
3. REPORT TYPE AND DATES COVERED
Final report

\section{TITLE AND SUBTITLE}

Preliminary Analytical Model for Flexible Pavement

5. FUNDING NUMBERS

Contract No.

DNA001-93-C-0147

6. AUTHOR(S)

Larry M. Bryant

\section{PERFORMING ORGANIZATION NAME(S) AND ADDRESS(ES)}

Applied Research Associates, Inc.

8. PERFORMING ORGANIZATION REPORT NUMBER

112 Monument Place

Vicksburg, MS 39180

9. SPONSORINGMONITORING AGENCY NAME(S) AND ADDRESS(ES)

U.S. Army Corps of Engineers, Washington, DC 20314-1000;

U.S. Army Engineer Waterways Experiment Station

3909 Halls Ferry Road, Vicksburg, MS 39180-6199
10. SPONSORINGMONITORING AGENCY REPORT NUMBER

Contract Report GL-98-4

\section{SUPPLEMENTARY NOTES}

Available from National Technical Information Service, 5285 Port Royal Road, Springfield, VA 22161.

12a. DISTRIBUTIONAVAILABILITY STATEMENT

Approved for public release; distribution is unlimited.

12b. DISTRIBUTION CODE

\section{ABSTRACT (Maximum 200 words)}

This report documents the first step in development of a preliminary analytical model for flexible pavement analysis for the Airfields and Pavements Division (APD), Geotechnical Laboratory, U.S. Army Engineer Waterways Experiment Station. This first step may be generally described as development of a linear elastic finite element model that reasonably compares with the empirical and/or layered elastic solutions in current use. This report does not attempt to document a literature survey related to pavement analysis nor does it discuss the background of previous pavement analysis methods or finite element methods beyond that necessary for understanding of the problem at hand. Further, this study attempts to determine the optimal usage of the specific tools at hand, i.e., PATRAN (1993) and ABAQUS (1992), in development of the improved analytical model. It does not attempt to generalize to other finite element modeling tools or the broad finite element method. This report includes and builds upon previous work done by the author in this area.

14. SUBJECT TERMS

Finite elements
Pavement analysis
Pavement design

\section{NUMBER OF PAGES}

\section{3}

16. PRICE CODE

17.

17. SECURITY CLASSIFICATION OF REPORT

UNCLASSIFIED
18. SECURTY CLASSIFICATION OF THIS PAGE

UNCLASSIFIED

NSN 7540-01-280-5500

Standard Form 298 (Rev. 2-89) Prescribed by ANSI Sto. Z39-18

298-102 